\title{
U.S. Geological Survey Climate and Land Use Change Science Strategy-A Framework for Understanding and Responding to Global Change
}

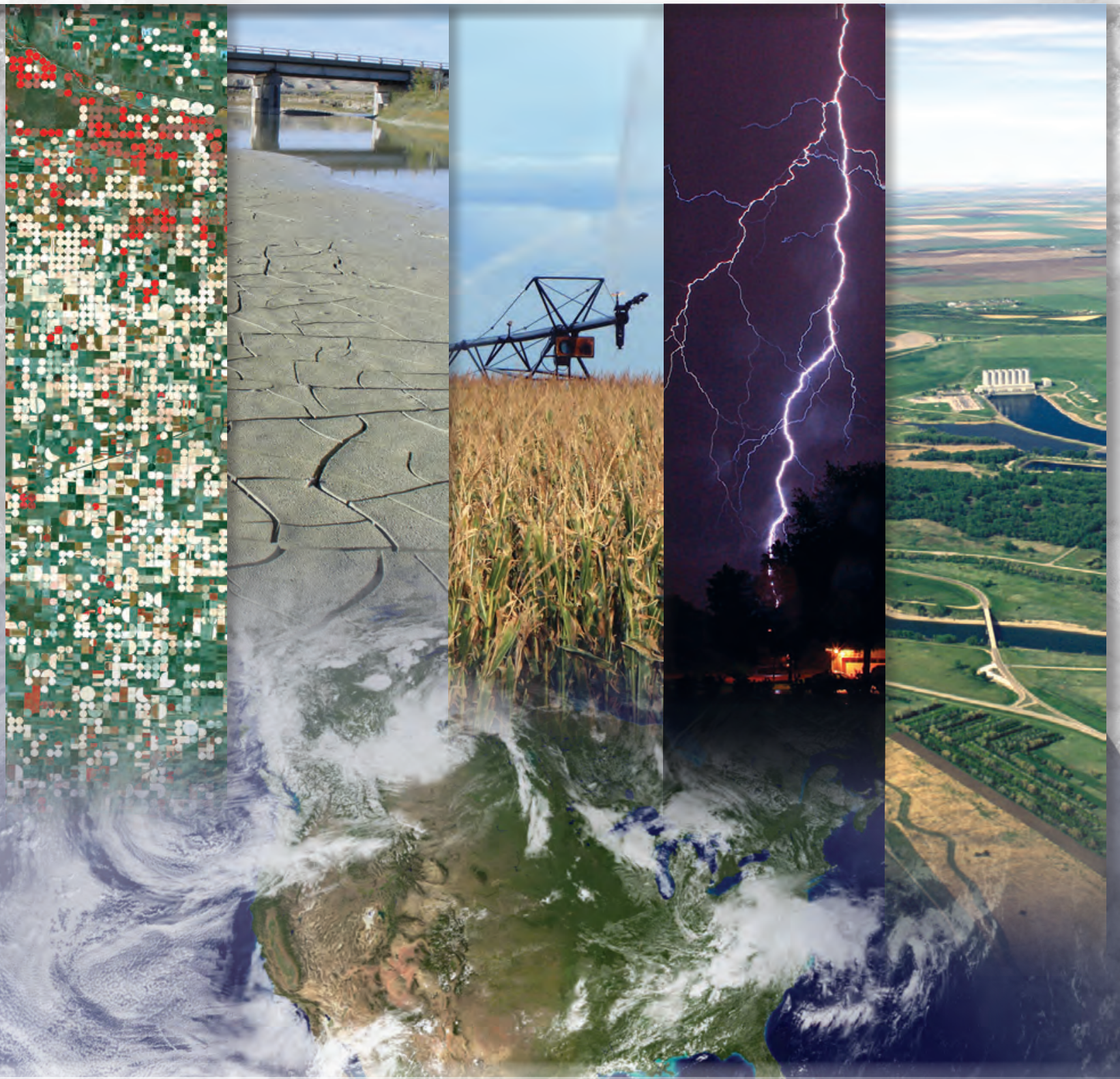

Circular 1383-A

U.S. Department of the Interior U.S. Geological Survey 



\section{U.S. Geological Survey Climate and Land Use Change Science Strategy- A Framework for Understanding and Responding to Global Change}

By Virginia R. Burkett, David A. Kirtland, Ione L. Taylor, Jayne Belnap, Thomas M. Cronin, Michael D. Dettinger, Eldrich L. Frazier, John W. Haines, Thomas R. Loveland, Paul C.D. Milly, Robin O'Malley, Robert S. Thompson, Alec G. Maule, Gerard McMahon, and Robert G. Striegl

Circular 1383-A 


\title{
U.S. Department of the Interior \\ KEN SALAZAR, Secretary \\ U.S. Geological Survey \\ Marcia K. McNutt, Director
}

\author{
U.S. Geological Survey, Reston, Virginia: 2013
}

For more information on the USGS - the Federal source for science about the Earth, its natural and living resources, natural hazards, and the environment, visit http://www.usgs.gov or call 1-888-ASK-USGS.

For an overview of USGS information products, including maps, imagery, and publications, visit http://www.usgs.gov/pubprod

To order this and other USGS information products, visit http://store.usgs.gov

Any use of trade, firm, or product names is for descriptive purposes only and does not imply endorsement by the U.S. Government.

Although this information product, for the most part, is in the public domain, it also may contain copyrighted materials as noted in the text. Permission to reproduce copyrighted items must be secured from the copyright owner.

Suggested citation:

Burkett, V.R., Kirtland, D.A., Taylor, I.L., Belnap, Jayne, Cronin, T.M., Dettinger, M.D., Frazier, E.L., Haines, J.W., Loveland, T.R., Milly, P.C.D., O'Malley, Robin, Thompson, R.S., Maule, A.G., McMahon, Gerard, and Striegl, R.G., 2013, U.S. Geological Survey climate and land use change science strategy —A framework for understanding and responding to global change: U.S. Geological Survey Circular 1383-A, 43 p. 


\section{Foreword}

In 2007, the U.S. Geological Survey (USGS) published a Bureau Science Strategy Facing Tomorrow's Challenges - U.S. Geological Survey Science in the Decade 2007-2017. It provided a view of the future, establishing science goals that reflected the USGS's fundamental mission in areas of societal impact such as energy and minerals, climate and land use change, ecosystems, natural hazards, environmental health, and water. Intended to inform long-term program planning, the strategy emphasizes how USGS science can make substantial contributions to the well-being of the Nation and the world.

In 2010, I realigned the USGS management and budget structure, changing it from a structure associated with scientific disciplines — Geography, Geology, Biology and Hydrology — to an issue-based organization along the lines of the Science Strategy. My aim was to align our management structure with our mission, our science priorities, our metrics for success, and our budget. An added benefit was that the USGS immediately appeared relevant to more Americans, and it became easier for those outside the agency to navigate our organizational structure to find where within the USGS they would find the solution to their problem. External partners rarely approached us with a problem in "geology," but they might need help with an issue in climate change or energy research.

The new organization is focused on seven science mission areas:

- Climate and Land Use Change

- Core Science Systems

- Ecosystems

- Energy and Minerals

- Environmental Health

- Natural Hazards

- Water

The scope of each of these new mission areas is broader than the science directions outlined in the USGS Science Strategy and together cover the scope of USGS science activities.

In 2010, I also commissioned seven Science Strategy Planning Teams (SSPTs) to draft science strategies for each USGS mission area. Although the existing Bureau Science Strategy could be a starting point for this exercise, the SSPTs had to go well beyond the scope of the existing document. What is of value and enduring from the work of the programs that existed under the former science disciplines needed to be reframed and reinterpreted under the new organization of the science mission areas. In addition, new opportunities for research directions have emerged in the five years since the Bureau Science Strategy was drafted, and exciting possibilities for cooperating and collaborating in new ways are enabled by the new mission focus of the organization.

Scientists from across the Bureau were selected for these SSPTs for their experience in strategic planning, broad range of experience and expertise, and knowledge of stakeholder needs and relationships. Each SSPT was charged with developing a long-term (10-year) science strategy that encompasses the portfolio of USGS science in the respective mission area. Each science strategy will reinforce others because scientific knowledge inherently has significance to multiple issues. Leadership of the USGS and the Department of the Interior will use the science vision and priorities developed in these strategies for program guidance, implementation planning, accountability reporting, and resource allocation. These strategies will guide science and technology investment and workforce and human capital strategies. They will inform our partners regarding opportunities for communication, collaboration, and coordination.

The USGS has taken a significant step toward demonstrating that we are ready to collaborate on the most pressing natural science issues of our day and the future. I believe a leadership aligned to support these issue-based science directions and equipped with the guidance provided in these new science strategies in the capable hands of our scientists will create a new era for USGS of which we can all be proud.

Marcia McNutt

Director 


\section{Contents}

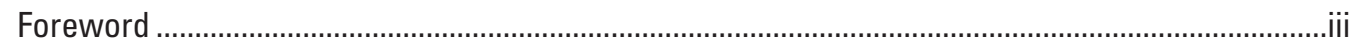

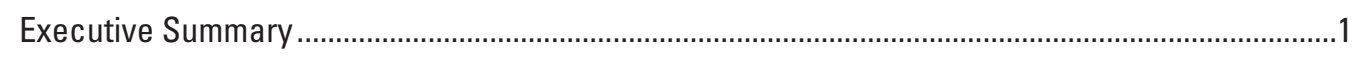

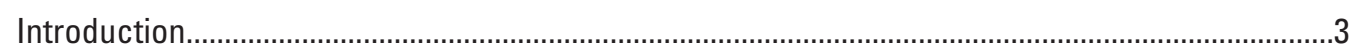

Science for a Changing World...............................................................................................

A Scientific Basis for Resource Management and Decisionmaking ..........................................

Core Strengths, Partnerships, and Science Integration ..........................................................

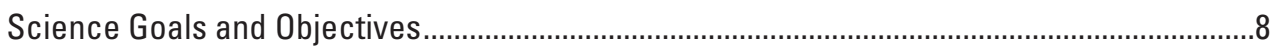

Overview........................................................................................................

Goal 1: Improve Understanding of Past Global Changes in Support of Policy and Management Decisions ...................................................................................

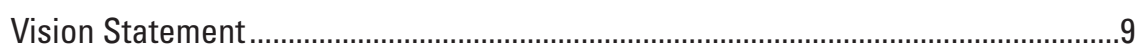

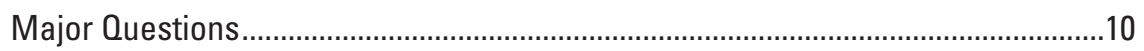

Strategic Actions and Products ........................................................................10

Short Term (1-5 Years) ..................................................................................

Longer Term (5-10 Years) ........................................................................10

Goal 2: Improve Understanding and Prediction of the Global Carbon Cycle ..................12

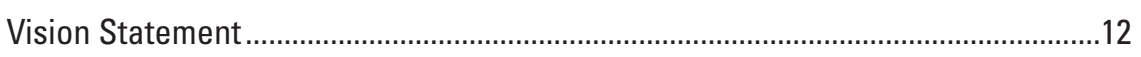

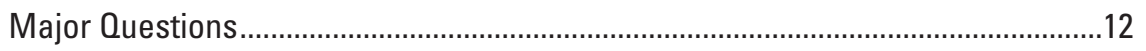

Strategic Actions and Products ...........................................................................13

Short Term (1-5 Years) ..........................................................................13

Longer Term (5-10 Years) ...........................................................................13

Goal 3: Improve Understanding of Biogeochemical Cycles and Their Coupled

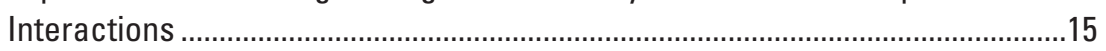

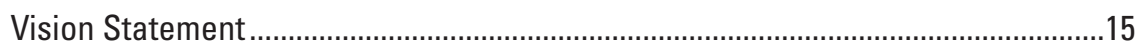

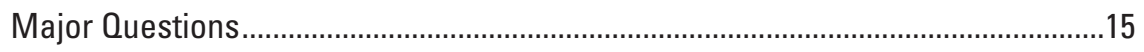

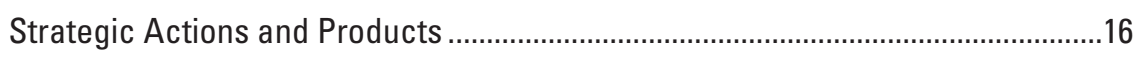

Short Term (1-5 Years) .............................................................................. 16

Longer Term (5-10 Years) ..........................................................................16

Goal 4: Improve Understanding of Land-Use and Land-Cover Change: Rates,

Causes, and Consequences .............................................................................18

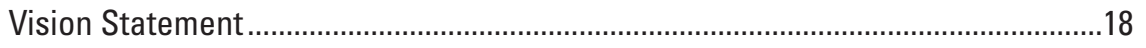

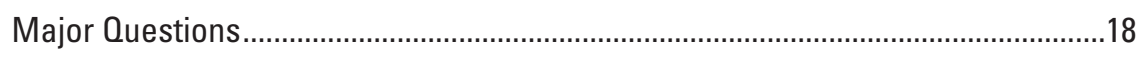

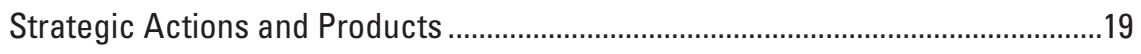

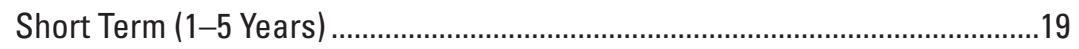

Longer Term (5-10 Years) ....................................................................19 
Goal 5: Improve Understanding and Predictions of Changes in Hydrologic Processes, Droughts, Floods, and Water Availability Under Changing Land Use and Climate

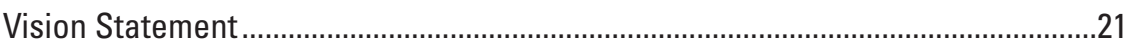

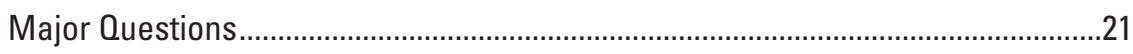

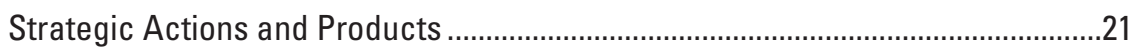

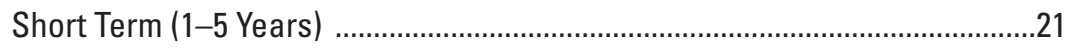

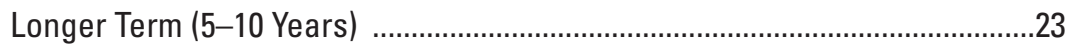

Goal 6: Improve Understanding and Prediction of Coastal Response to Sea-Level Rise, Climatic Change, and Human Development................................24

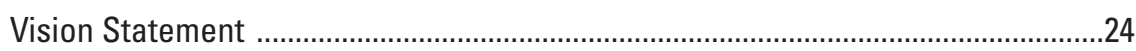

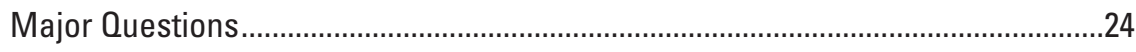

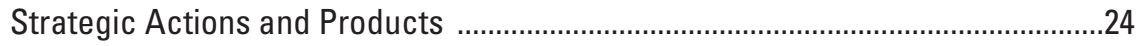

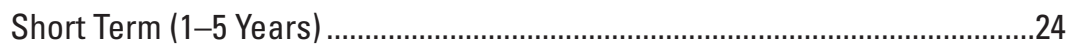

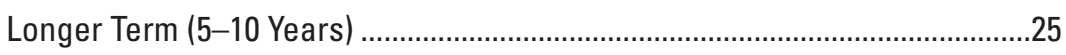

Goal 7: Improve Understanding and Prediction of Biological Responses to
Global Change

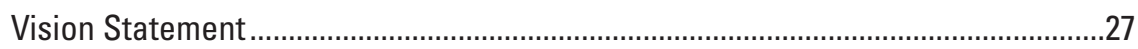

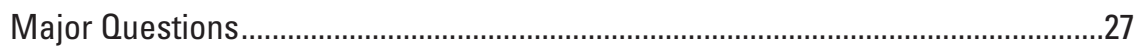

Strategic Actions and Products ............................................................................27

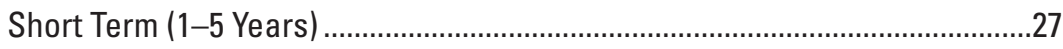

Longer Term (5-10 Years) ............................................................................27

Monitoring: A Critical Component of Global Change Science and Adaptive Resource

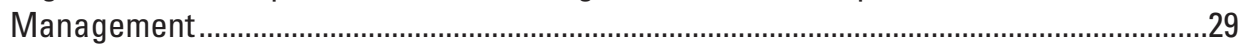

Interrelations of Climate and Land Use Change and Other Mission Areas ....................................33

Communicating Science to Society—Services, Products, and Delivery............................................35

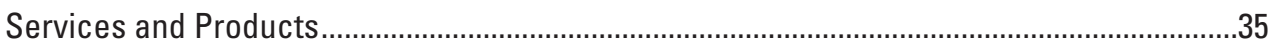

Research Results—From Fundamental to Applied .....................................................35

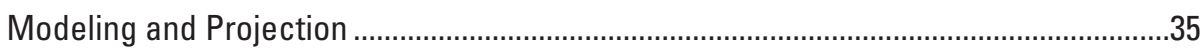

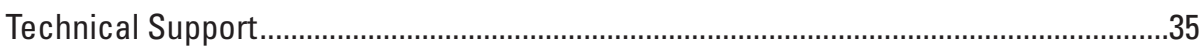

Enabling Efficient Transformation of Data to Knowledge ................................................36

Delivering Science-USGS Framework for Collaboration and Communication ......................36

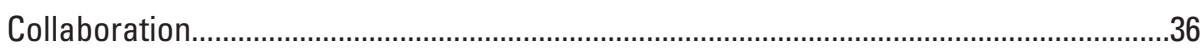

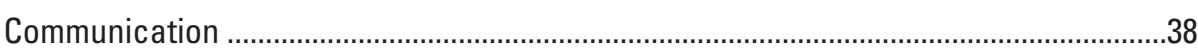

Summary —Understanding and Responding to Climate and Land-Use Change..............................39

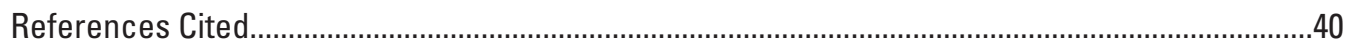

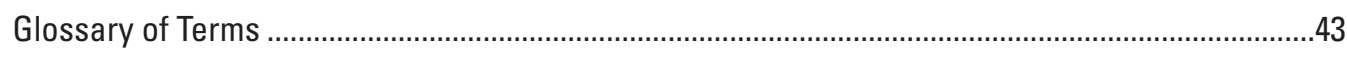




\section{Figures}

1. Diagram showing a simplified, land- and human-centered view of the complex Earth system.

2. Integrated science for global change.

3. Diagram showing connectivity among the seven fundamental science goals for the U.S. Geological Survey Climate and Land Use Change Mission Area.

4. Diagram showing Climate and Land Use Change interaction with the other mission areas to understand global change.
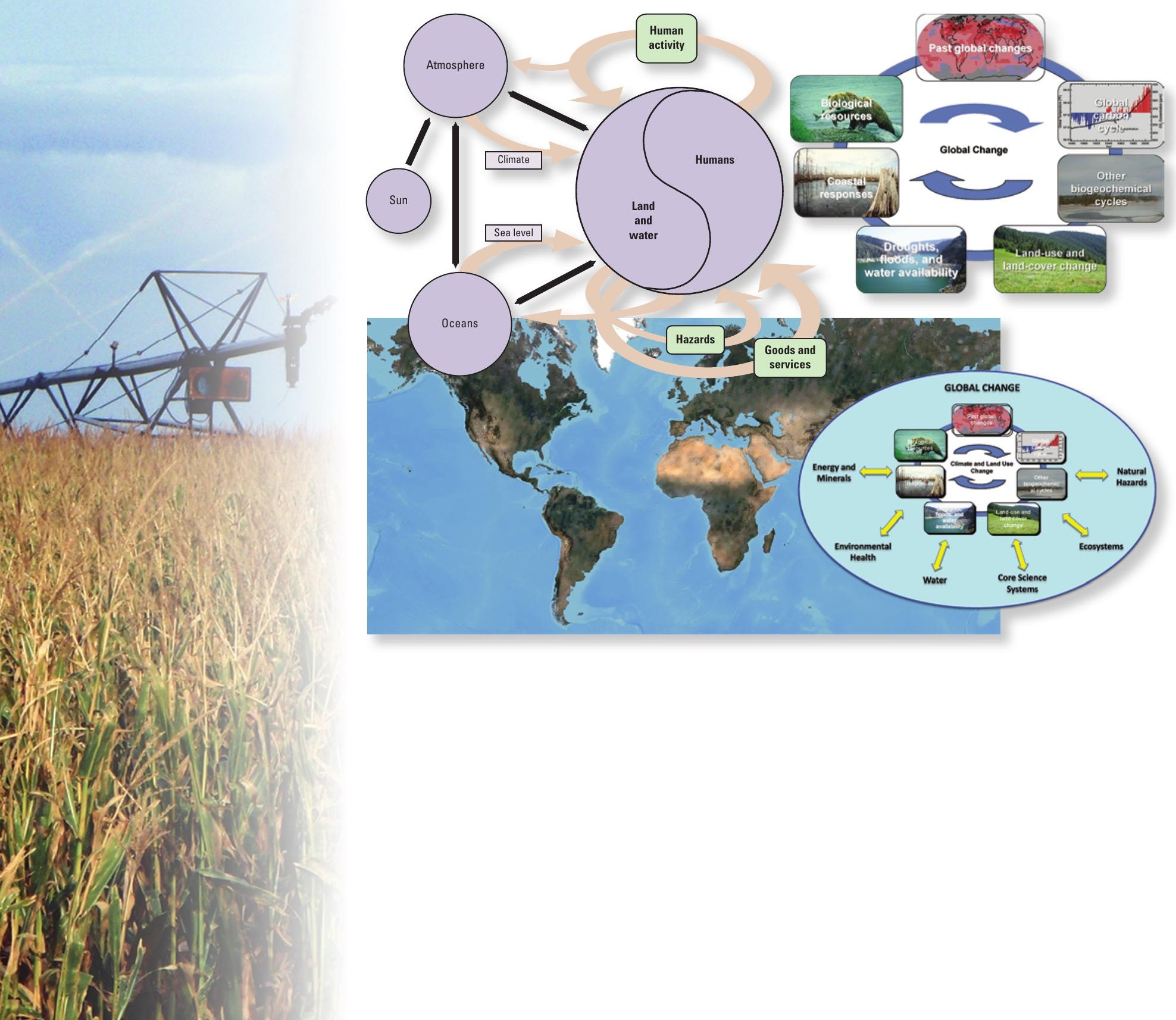


\section{Abbreviations}

$\begin{array}{ll}\mathrm{C} & \text { carbon } \\ \mathrm{CH}_{4} & \text { methane } \\ \text { CLU } & \text { Climate and Land Use Change } \\ \mathrm{CO}_{2} & \text { carbon dioxide } \\ \text { CSC } & \text { Climate Science Center } \\ \text { CSS } & \text { Core Science Systems } \\ \text { DOI } & \text { Department of the Interior } \\ \text { ECV } & \text { essential climate variable } \\ \text { ENSO } & \text { El Niño-Southern Oscillation } \\ \text { EPA } & \text { Environmental Protection Agency } \\ \text { FY } & \text { fiscal year } \\ \text { IAG } & \text { interagency working group } \\ \text { IPCC } & \text { Intergovernmental Panel on Climate Change } \\ \text { LCC } & \text { Landscape Conservation Cooperatives } \\ \text { LULC } & \text { land use/land cover } \\ \text { LULCC } & \text { land-use/land-cover change } \\ \text { NASA } & \text { National Aeronautics and Space Administration } \\ \text { NAWOA } & \text { National Water Quality Assessment } \\ \text { NCA } & \text { National Climate Assessments } \\ \text { NCCWSC } & \text { National Climate Change and Wildlife Science Center } \\ \text { NGO } & \text { nongovernmental organization } \\ \text { NO } & \text { nitrate } \\ \text { NOAA } & \text { National Oceanic and Atmospheric Administration } \\ \text { NRC } & \text { National Research Council } \\ \text { NSF } & \text { National Science Foundation } \\ \text { SSPT } & \text { Science Strategy Planning Team } \\ \text { USDA } & \text { U.S. Department of Agriculture } \\ \text { USGCRP } & \text { U.S. Global Change Research Program } \\ \text { USGS } & \text { U.S. Geological Survey } \\ & \end{array}$




\title{
U.S. Geological Survey Climate and Land Use Change Science Strategy-A Framework for Understanding and Responding to Global Change
}

\author{
By Virginia R. Burkett, David A. Kirtland, Ione L. Taylor, Jayne Belnap, Thomas M. Cronin,Michael D. Dettinger,
} Eldrich L. Frazier, John W. Haines, Thomas R. Loveland, Paul C.D. Milly, Robin O’Malley, Robert S. Thompson, Alec G. Maule, Gerard McMahon, and Robert G. Streigl

\section{Executive Summary}

The U.S. Geological Survey (USGS), a nonregulatory Federal science agency with national scope and responsibilities, is uniquely positioned to serve the Nation's needs in understanding and responding to global change, including changes in climate, water availability, sea level, land use and land cover, ecosystems, and global biogeochemical cycles. Global change is among the most challenging and formidable issues confronting our Nation and society. Scientists agree that global environmental changes during this century will have far-reaching societal implications (Intergovernmental Panel on Climate Change, 2007; U.S. Global Change Research Program, 2009). In the face of these challenges, the Nation can benefit greatly by using natural science information in decisionmaking.

Since the passage of the U.S. Global Change Research Act of 1990, the USGS has made substantial scientific contributions to understanding the interactive living and nonliving components of the Earth system. USGS natural science activities have led to fundamental advances in observing and understanding climate and land-cover change and the effects these changes have on ecosystems, natural-resource availability, and societal sustainability. Most of these major advances were pursued in partnership with other organizations within and outside the Department of the Interior. The inherent value of partnerships with other U.S. Global Change Research Program agencies and natural-resource managers is emphasized in all aspects of the planning and implementation of this Science Strategy for the coming decade.

Over the next 10 years, the USGS will make substantial contributions to understanding how Earth systems interact, respond to, and cause global change. The USGS will work with science partners, decisionmakers, and resource managers at local to international levels (including Native American tribes) to improve understanding of past and present change; develop relevant forecasts; and identify those lands, resources, and communities most vulnerable to global change processes. Science will play an essential role in helping communities and land and resource managers understand local to global implications, anticipate effects, prepare for changes, and reduce the risks associated with decisionmaking in a changing environment. USGS partners and stakeholders will benefit from the data, predictive models, and decision-support products and services resulting from the implementation of this strategy.

This Science Strategy recognizes core USGS strengths that are applied to key societal problems. It establishes seven goals for USGS global change science and strategic actions that may be implemented in the short term ( $1-5$ years) and the longer term (5-10 years) to improve our understanding of the following areas of inquiry:

1. Rates, causes, and impacts of past global changes;

2. The global carbon cycle;

3. Biogeochemical cycles and their coupled interactions;

4. Land-use and land-cover change rates, causes, and consequences;

5. Droughts, floods, and water availability under changing land-use and climatic conditions;

6. Coastal response to sea-level rise, climatic change, and human development; and

7. Biological responses to global change. 
In addition to the seven thematic goals, we address the central role of monitoring in accordance with the USGS Science Strategy recommendation that global change research should rely on existing "...decades of observational data and long-term records to interpret consequences of climate variability and change to the Nation's biological populations, ecosystems, and land and water resources" (U.S. Geological Survey, 2007, p. 19). We also briefly describe specific needs and opportunities for coordinating USGS global change science among USGS Mission Areas and address the need for a comprehensive and sustained communications strategy.
Late afternoon thunderstorms building up over the land mass to the north of Everglades National Park, Florida, August 2012. Photograph by G. Lynn Wingard, USGS. 


\section{Introduction}

\section{Science for a Changing World}

Since the USGS was created by Congress with the Organic Act of March 3, 1879 (43 U.S.C. 31), it has evolved from an organization charged with inventorying the Nation's public lands and natural resources to an accomplished research institution with broad scientific objectives. Its central mission in the 21st Century is "Science for a Changing World" in recognition of the role that science and scientists can play in monitoring, understanding, and forecasting global environmental change and in informing mitigation and adaptation strategies. This document presents a focused vision and strategy to guide global change science within the USGS in the short ( $1-5$ years) and the longer ( $5-10$ years) terms. The vision and strategy consider anticipated national and Department of the Interior needs and the capabilities and core strengths of the USGS.

Global change refers to large-scale changes in the environment that may alter the Earth's capacity to sustain life and human endeavor (U.S. Global Change Research Act of 1990). This includes alterations in climate, atmospheric chemistry, oceans and other water resources, the land surface and its biological productivity, and ecological systems, including the goods and services they provide. Key physical drivers of global change and their interaction with human populations and ecosystems are depicted in figure 1. Collectively, global change and its effects are among the most challenging and formidable issues confronting our Nation and society, and solutions call for a deep appreciation of the complex relations among Earth systems and human activities.

The USGS has the multidisciplinary scientific expertise needed to investigate the Earth as a system in which the biosphere, hydrosphere, lithosphere, and atmosphere are interrelated. While the USGS does not have regulatory or land-management responsibility, it does have a worldwide reputation for objective, unbiased science. Its 133-year history of producing scientific knowledge and tools that support natural-resource decisionmaking is unique among Federal agencies. This science strategy draws on this unique expertise, and its specific goals and objectives are unified under the following vision statement for USGS global change science:

USGS scientists will collect, analyze, disseminate, and interpret observational records and perform process-oriented research to determine causes and consequences of global change; USGS science will help society anticipate and adapt to global change.

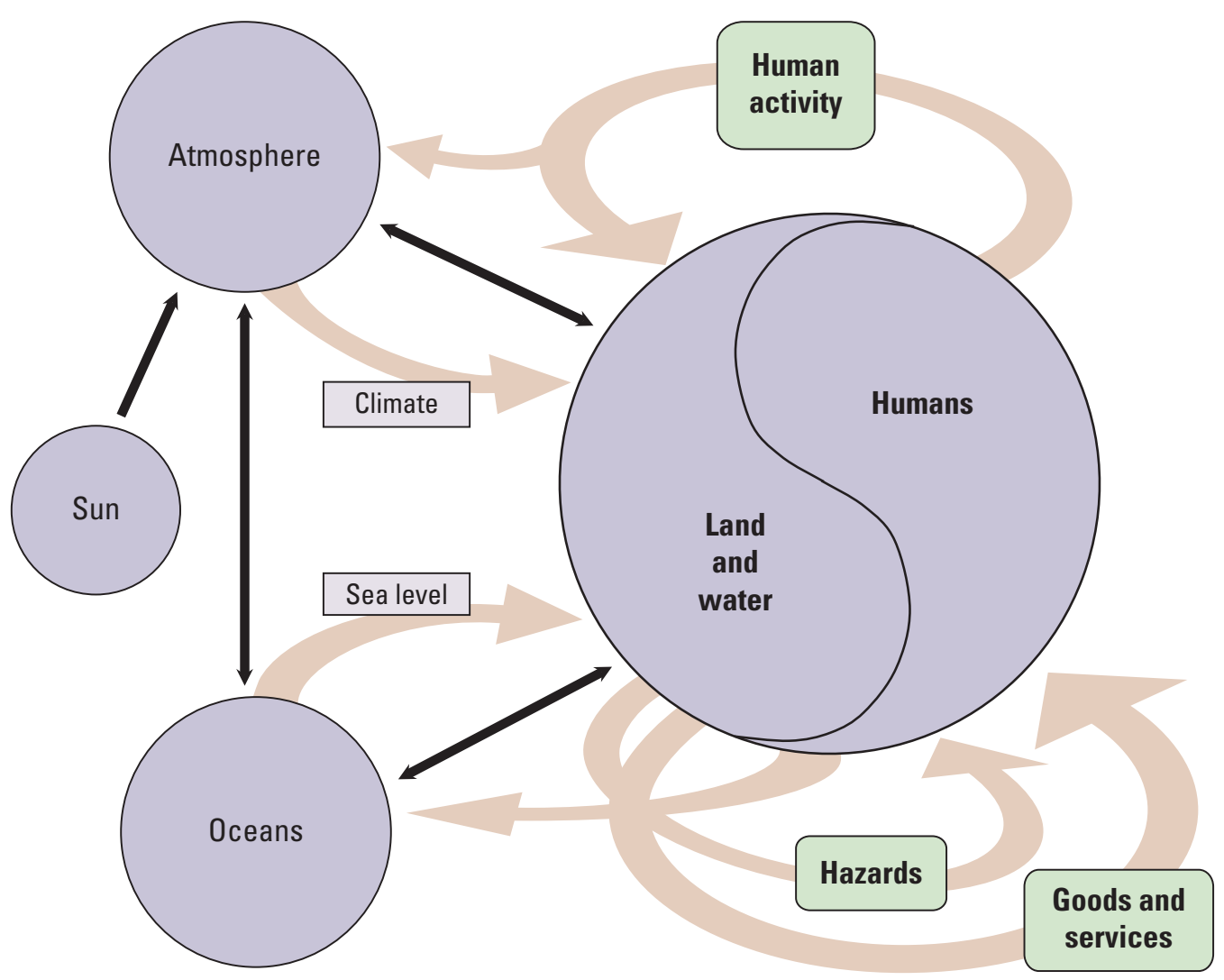

Figure 1. A simplified, land- and human-centered view of the complex Earth system. People affect the Earth system largely through activities on the land surface. In turn, through natural processes, people are affected by Earth-system changes through the impacts of those changes on land and water resources. 


\section{A Scientific Basis for Resource Management and Decisionmaking}

The Department of the Interior (DOI) manages approximately 20 percent of the land in the United States and adjacent coastal waters. DOI management and stewardship responsibilities include migratory, threatened, and endangered species; national parks, wildlife refuges, monuments, and other public lands; water resources; Native American trust resources; and the U.S. freely associated States and insular territories. Consequently, many sections of this document refer to the needs of decisionmakers in agencies and bureaus under the stewardship authority of DOI.
In addition to responding to science needs of the DOI bureaus, this science strategy addresses needs of naturalresource managers at local, regional, State, and Federal levels. The USGS also contributes to national and international scientific activities that inform societies about the nature and effects of global change, including participation in climate-change assessments by the U.S. Global Change Research Program (USGCRP) and the Intergovernmental Panel on Climate Change (IPCC). This science strategy report presents science goals, monitoring objectives, and communication strategies the USGS can implement to achieve the vision as stated on the previous page. The goals are integrative and crosscutting, and their success depends on the ability of the USGS to recruit, retain, and nurture a workforce with the appropriate mix of skills and expertise.
The Department of the Interior (DOI) is the primary Federal custodian of America's natural resources and America's heritage. DOI's Strategic Plan for Fiscal Years 2011-2016 establishes goals, strategies, and measures that will guide the Department's activities for the next 5 years. One of the five broad mission statements contained within DOI's Strategic Plan is to provide a scientific foundation for decisionmaking (U.S. Department of the Interior, 2011). The USGS is responsible for achieving the priority goals associated with the science mission of the plan:

1. Ensure the quality and relevance of science products to partners and customers

2. Provide science for sustainable resource use, protection, and adaptive management

3. Assess and forecast climate change and its effects

4. Develop a comprehensive science framework for understanding the Earth

Most of the specific actions recommended under these four DOI goals relate directly to global change. In addition, the reforms set forth in the strategic plan by the Secretary of Interior place particular emphasis on achieving results in the near-term, including renewable energy, sustainable water management and conservation, and climate-change adaptation.

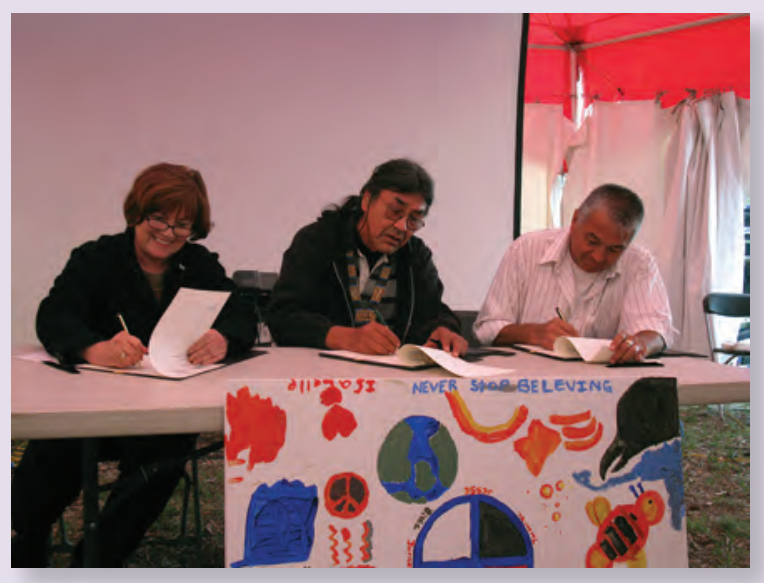

From left to right, Suzette Kimball, USGS Acting Director; Clarence Alexander, Alaska Board Chairman (Yukon Flats); and Carl Sidney, Yukon Board Chairman, Dahka Tlingit Nation; signing a Memorandum of Understanding between the USGS and the Yukon River Inter-Tribal Watershed Council (YRITWC) during closing ceremonies of the 7th Biennial Summit, Whitehorse, Yukon Territories, August 2009.

Ice breakup on the Yukon River at Pilot Station, Alaska.

Photograph by Mark Dornblaser, USGS. 


\section{Core Strengths, Partnerships, and Science Integration}

The USGS occupies a unique position in the global change science community with its long-term, process-based research; observational networks; and extensive databases encompassing the fields of geology, hydrology, climate history, land-use and land-cover change, ecosystem science, and carbon and nutrient cycles. Documenting, understanding, and predicting environmental and natural-resource change at a national scale have formed the core of USGS research since it was first established.

In recent years, USGS scientists have addressed questions about the causes and effects of these changes from local to global scales. With long-term observational networks and extensive databases, analysis and modeling capabilities, and diverse scientific expertise, the USGS provides broad perspectives needed to expand understanding of past, current, and future global changes and their effects on the Nation's resources and economy. The USGS works with local, State, Federal, nongovernmental, private, and tribal partners to understand past climate variability and deliver credible future scenarios of global-change effects on land, water, and ecological and biological resources. Integrative systems modeling enables USGS scientists to examine how systems respond to global changes. Examples of core USGS strengths that are central to the way the USGS conducts global change science are highlighted in figure 2 .

USGS contributions to understanding global change include the following specific examples:

- Landsat satellite imagery

- Management and delivery of the world's longest continuously acquired collection of space-based land remote sensing data

- National assessment of 30 years of trends in U.S. land-use and land-cover change

- Authorship on reports critical to informing public policy

- The U.S. National Climate Assessments (NCA)

- IPCC Assessment Reports and Technical Papers

- USGCRP Synthesis and Assessment Products on the following topics:

- Abrupt climate change

- Past climate variability and change in the Arctic and at high latitudes

- Thresholds of change in ecosystems

- State of the carbon cycle

- Coastal sensitivity to sea-level rise: focus on midAtlantic region
- Scenarios of greenhouse gas emissions and integrated scenario development

- Carbon budget for North America

- Adaptation for ecosystems/resources

- Impacts of climate variability and change on transportation systems and infrastructure in the central Gulf Coast region

- Decision-support experiments and evaluations using seasonal to interannual forecasts and observational data

- Global and regional future projections of river runoff

- National land-cover databases

- Methodologies for assessing carbon sequestration and storage in geologic formations and terrestrial ecosystems

- Detection of ongoing climatic trends and impacts, such as

- Seasonally earlier peak streamflow in the U.S. northeast and west

- Seasonally earlier arrival of spring migratory birds

- Retreating glaciers in Alaska and the Cascade and Rocky Mountains

- Declining permafrost in Alaska

- Global reconstruction and model simulations of past global warmth and impacts

- Effects of warming on plant and animal species, such as Arctic-wide assessment of polar bear and sea-ice habitat, and shifts in migratory bird range

- Sea-level rise vulnerability maps for U.S. coastal regions and coastal national parks

- Regional assessment of the effects of climate and landuse change on terrestrial habitat connectivity for faunal species with different dispersal patterns, home range size, and habitat usage.

The Climate and Land Use Change Mission Area through its Land Remote Sensing Program operates the Landsat satellites and provides the Nation's portal to the largest archive of remotely sensed land data in the world, supplying access to current and historical images. These images serve many purposes from assessing the impact of natural disasters to monitoring global agricultural production. 


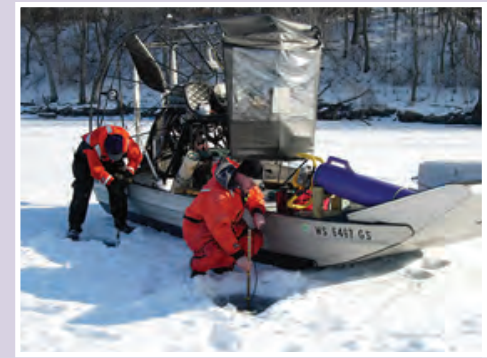

Focused science capacity in fundamental and applied aspects of geology, geography, hydrology, and biology.

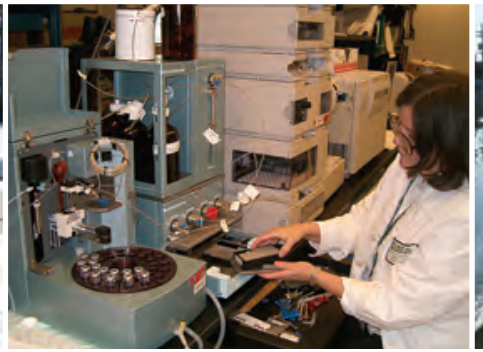

Long-term research and monitoring to describe trends in land use, water, energy, minerals, species and ecosystems, and the consequences of global change.

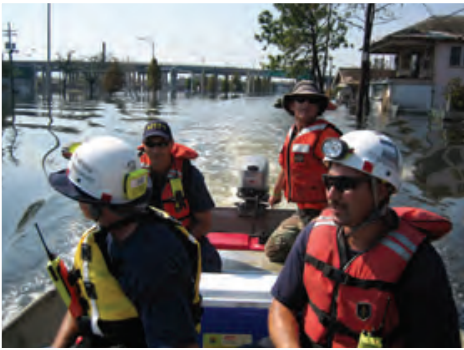

Application and translation that integrates environmental and climate-change data to predict impacts on natural resources and human populations.

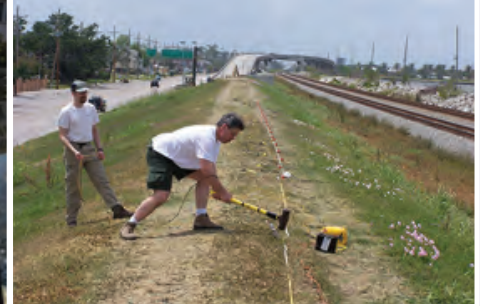

Consistent data collection and continuous synthesis for vulnerability and impact assessments to meet the needs of decisionmakers.

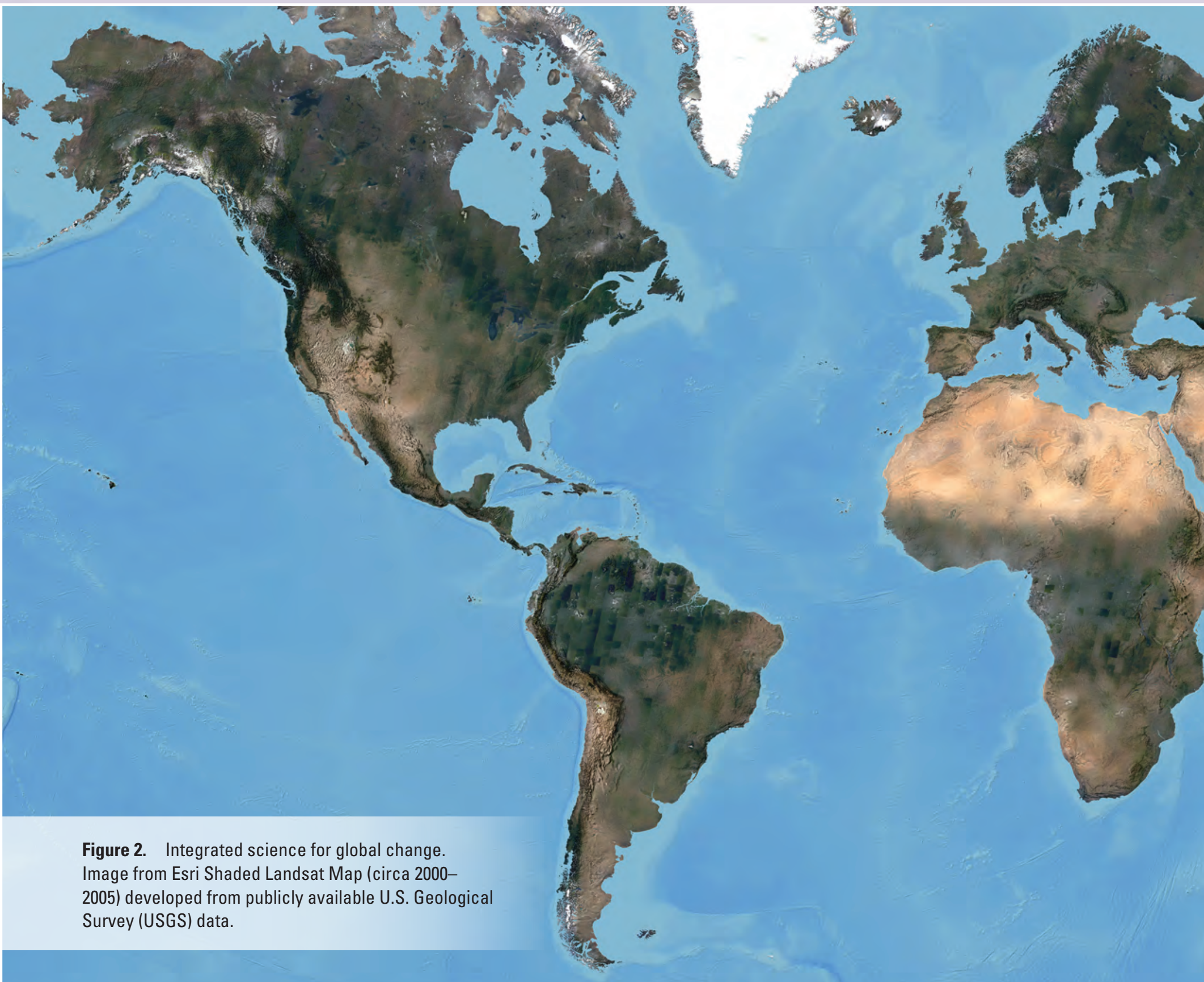




\section{Science Goals and Objectives}

\section{Overview}

This global change science strategy recognizes core USGS strengths and applies them to key problems in the context of seven programmatic goals focused on past global change, carbon, biogeochemical cycles, land use/land cover, droughts and floods, sea level, and biological changes. Each goal was selected based on the following criteria:

- Employs integrated scientific research and assessment to fill knowledge gaps about national climate, land use, ecosystem, and energy priorities.

- Addresses topics critical for managing natural resources and the environment, with tangible effects on environmental goods, services, and risks.

- Uses USGS core capacity, disciplinary strengths, integrative capacities, and long-term databases.

- Invests in comprehensive, integrated observation and monitoring to understand local to global change processes and conditions.

- Leverages or expands partnerships that advance the science goal.

- Builds on the leadership role of the USGS in the USGCRP.

- Addresses topics critical to DOI for managing natural resources, wildlife habitat, and the environment with special concern or attention to those resources critical to Native American subsistence tribal cultures.

The seven goals are interconnected programmatically and scientifically. The carbon cycle, for example, interacts directly with changes in climate and land use, which in turn affect and are affected by species response and hydrology. Monitoring, modeling, research, and decisionmaking relating to any of these goals will need to be coordinated with all the others; therefore, the science goals are scientific concentrations in a broader continuum of efforts rather than strictly separate activities. Similarly, the global change theme cannot be fully separated from the other science Mission Areas within the USGS. Global change is expected to alter the conditions associated with natural hazards, stress ecosystems and natural resources, such as water resources, and influence carbon sequestration and energy strategies. Consequently, this science strategy and the seven goals described in this section, will be coordinated with other USGS Mission Areas.

These seven goals are not intended to be distinct, nonoverlapping categories for USGS global change projects, nor do they include all areas of USGS global change science. Rather, they highlight priority areas where resources should be directed over the next 5 to 10 years. The science activities described in this document are not intended to be policy prescriptive, but all seven science goals contain elements that will help inform societal responses to global change. Many topical research needs, which may not be explicitly stated as strategic actions, are nonetheless essential for the successful achievement of the seven goals for USGS global change science. Actions recommended to achieve an individual goal may either depend on or influence products and outcomes from the other goals - a process consistent with interactions and feedbacks among global change drivers and impacts shown in figure 3 .

The seven high-priority goals for USGS global change science are developed in more detail in this section, starting with a statement summarizing the specific societal issues and challenges faced or anticipated. A vision statement and a series of the key scientific research questions pertinent to the goal follow. Finally, a set of short-term and longer-term strategic actions are described that, if implemented, will advance USGS science from its current state toward the desired future state articulated in the vision statement.

\section{Goal 1: Improve Understanding of Past Global Changes in Support of Policy and Management Decisions}

USGS conducts research on past global changes through investigations of changes in Earth's climate, surface, hydrologic and geologic processes, and other aspects of the Earth system. USGS scientists study past changes in diverse environments throughout the United States and across the globe that provide a baseline against which ongoing changes can be assessed. Paleoclimate investigations began long before the current focus on greenhouse effects because climatic change is a natural, inherent, and critical component of Earth's environmental history. Changes in Earth's climate occur over all timescales due to external causes, such as cycles of Earth's orbit and solar output, and internal processes like sea-floor spreading, ocean-atmosphere interactions, glacier and icesheet growth and decay, and carbon cycling, among others.

Past climate changes have been both gradual and abrupt; some climate changes were periodic. Often, climate changes had large amplitudes or rates of change reflecting climatic thresholds, nonlinear climate behavior and partially understood feedbacks involving biogeochemical cycles, changes in Earth's albedo, and others. Nonlinear responses and abrupt changes are particularly important phenomena for understanding future climate changes. Because instrumental records of temperature, rainfall, sea level, and other climate parameters are too short to reveal the full range of climatic variability or to identify dangerous thresholds, it is of vital importance that we understand better how the Earth system functions and how it responds to forcings and perturbations beyond those of the past few decades. Because Earth's climate has fluctuated in the past partly due to changing atmospheric carbon dioxide 


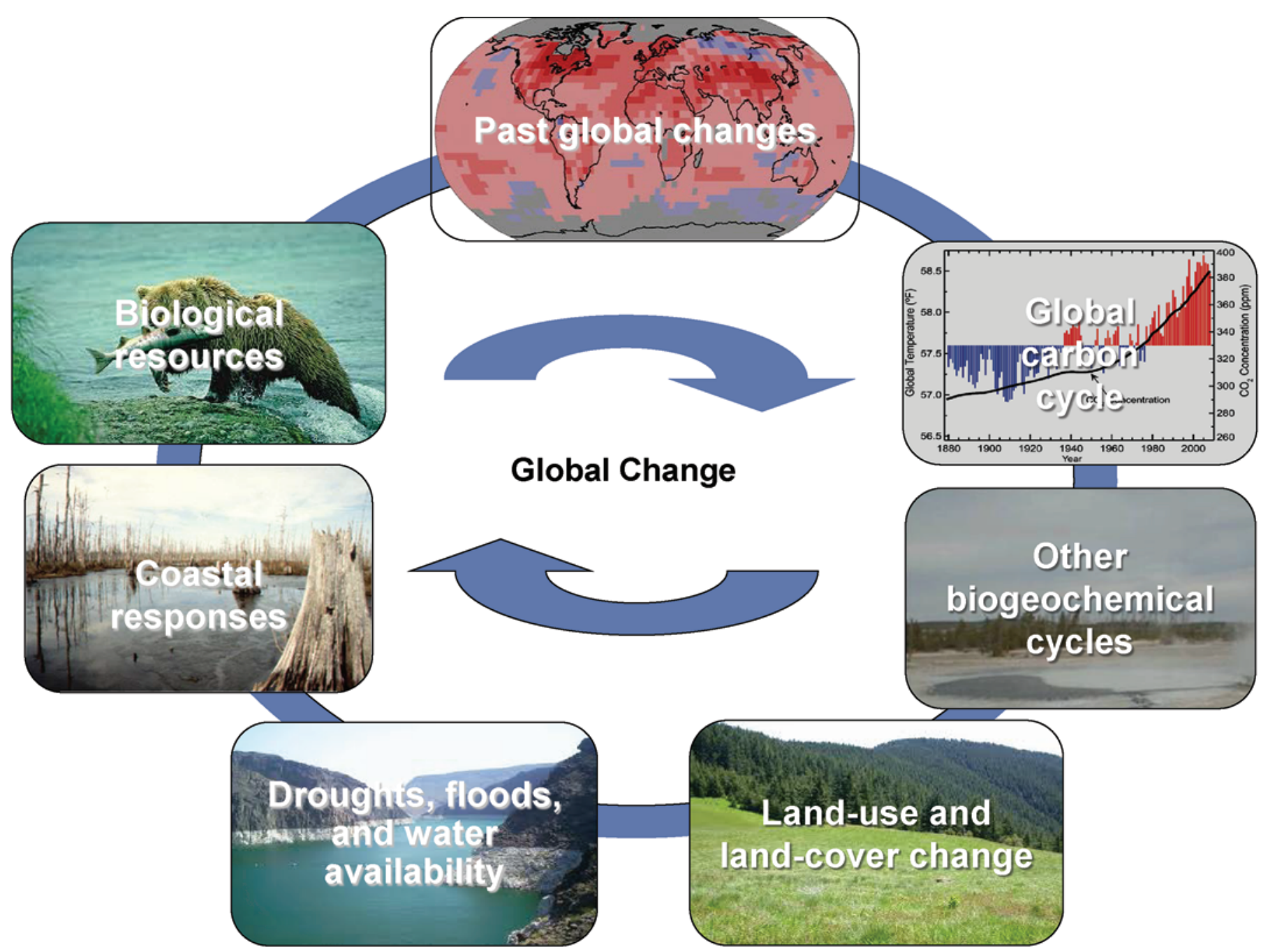

Figure 3. Connectivity among the seven fundamental science goals for the U.S. Geological Survey Climate and Land Use Change Mission Area.

concentrations, studies of past conditions and changes provide a basis for properly assessing potential ranges and uncertainties of impacts from various levels of human-induced climate change. Reconstructing past climates also provides the basis for developing and validating conceptual and computer models designed to simulate interactions among key components of the Earth system, thereby allowing us to assess and predict vulnerabilities of specific landscapes, ecosystems, and natural resources to global changes.

Today the USGS has strong capabilities in many fields required to document and understand past global changes, including geology, paleontology, paleohydrology, geochemistry, numerical analysis, and modeling. The Bureau's breadth of scientific expertise will be applied to characterize and understand past global changes from the last century back through millions of years of Earth history. Insights from historical, paleoenvironmental, and paleoclimatic studies increasingly will be used to support decisions in the management of water and other natural resources and in national and international planning for the potential consequences of future global changes. USGS research on past global change also involves meaningful linkages with other USGS Mission Areas and outside collaborators, including the National Oceanic and Atmospheric Administration (NOAA), the National Science Foundation (NSF), DOI bureaus and other Federal agencies, academic researchers, and international scientific organizations.

\section{Vision Statement}

The USGS will investigate past global changes, including past climate states and variability; rates of climate change; and interactions among climatic, hydrologic, biologic, geologic, and human-induced processes. This information provides a framework for understanding ongoing and projected climatic and environmental changes and contributes to the scientific basis for societal decisions. 


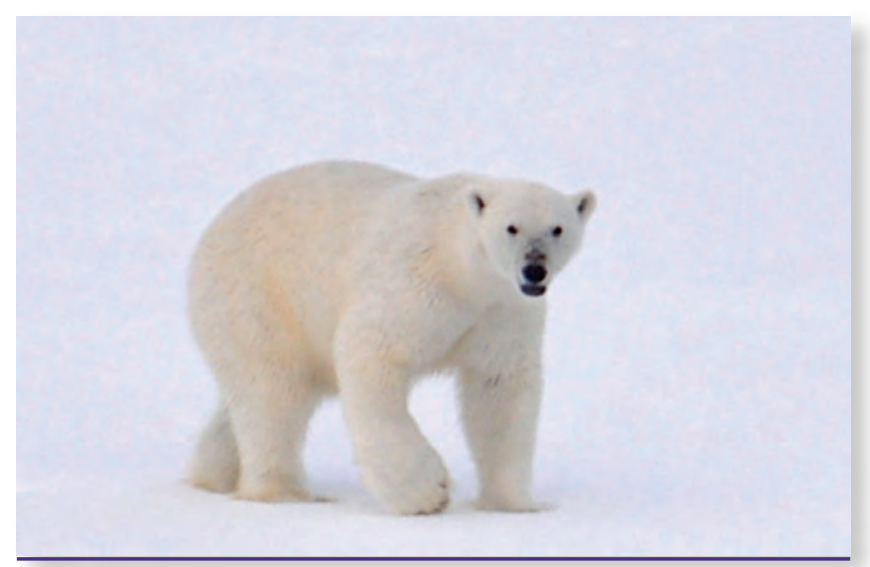

A polar bear walks on Arctic Ocean ice, August 23, 2009. Photograph by Patrick Kelley, U.S. Coast Guard.

\section{Major Questions}

- What were the patterns of change and variability in climate, greenhouse gases, and Earth-surface environments over timescales ranging from the past few decades to millions of years?

- What were the causes, durations, levels of greenhouse gases and ocean acidification, and environmental characteristics of past warm climate episodes?

- How do ongoing and projected changes in climate, water resources, ecosystems, and the surficial environment compare with past climatic shifts and degrees of variability reconstructed for the past hundreds to thousands of years?

- How rapid and widespread have past global changes been, and were there thresholds that, when crossed, led to unexpected or nonlinear responses in climate, hydrology, ecosystems, or other aspects of the Earth system?

- What can global changes of the past reveal about the vulnerabilities of specific ecosystems, natural resources, or landscapes to particular changes in climate, atmospheric chemistry, or other components of the Earth system? How can this information be used in support of management?

- How did humans influence the environment and climate before and since the industrial revolution? How have forest clearances, water storage and irrigation systems, and other economic activities affected ecosystems, landscapes, and natural resources?

- How can the acquisition, synthesis, and analysis of historical records and paleodata contribute to the scientific basis of management and policy decisions? How can communication with users be improved?

\section{Strategic Actions and Products}

Short Term (1-5 Years)

- Establish or improve methods for reconstructing and dating changes in mean conditions (and variability around these means) of climatic parameters, landsurface conditions, hydrology, marine environments, and other important facets of past global change.

- Create a national synthesis of currently available data on past climatic and environmental changes and variability, particularly for vulnerable natural resources, lands, and marine environments managed by the Federal Government.

- Improve understanding of past interactions among key components of the Earth system, such as climate, hydrology, and Earth-surface processes.

- Investigate the amplitudes, spatial extents, and causes of past abrupt global changes and nonlinear responses to external forcing in climate, land surface, hydrology, and ecosystems.

- Expand participation of USGS in national efforts, such as NOAA's National Geophysical Data Center, and international activities, such as IPCC assessments, to use paleodata and modern Earth-surface records to evaluate the potential consequences of future global change and to assess the abilities of models to simulate past changes and their effects.

\section{Longer Term (5-10 Years)}

- Conduct focused studies on the climatic and environmental characteristics of past periods of warmer global climates and of higher-than-present levels of greenhouse gases and identify the causes of these episodes and their terminations.

- Contribute insights from the past in the construction and validation of Earth system models in collaboration with other research groups.

- Assess patterns of climatic and environmental variability from the recent past to the past few millions of years to provide a framework for understanding potential future global change.

- With natural resource managers and other decisionmakers, determine information needs and enhance communication of paleo perspectives of ongoing and potential future global change.

- Document how species and ecosystems have adapted to past global change, and use this information to evaluate the vulnerability of these natural resources to potential future changes. 
Abrupt changes in global and regional climate have been frequent and well documented. Although the exact causes of such abrupt changes are not yet well understood, geologic evidence and climate modeling strongly suggest that they are triggered by crossing thresholds that are internal to the climate system. During the last deglaciation, several abrupt temperature shifts occurred over about a century, resulting in hemispheric-scale climate changes. Abrupt cooling episodes also occurred, reflecting the impacts of abrupt drainage of vast ice-dammed glacial lakes that developed along the Laurentide Ice Sheet margin. The release of freshwater from glacial lakes may have suppressed ocean circulation in the North Atlantic, thereby interrupting global heat transport that moves excess heat from the equator toward the poles. Other abrupt changes involved rapid disintegration of ice sheets, which raised global sea level at rates as much as 5 meters in a century. On shorter timescales, large regional droughts can begin and end abruptly due to changes in atmospheric circulation and precipitation patterns that are linked to changes in oceanic circulation and temperature distributions such as those that accompany the El Niño-Southern Oscillation.
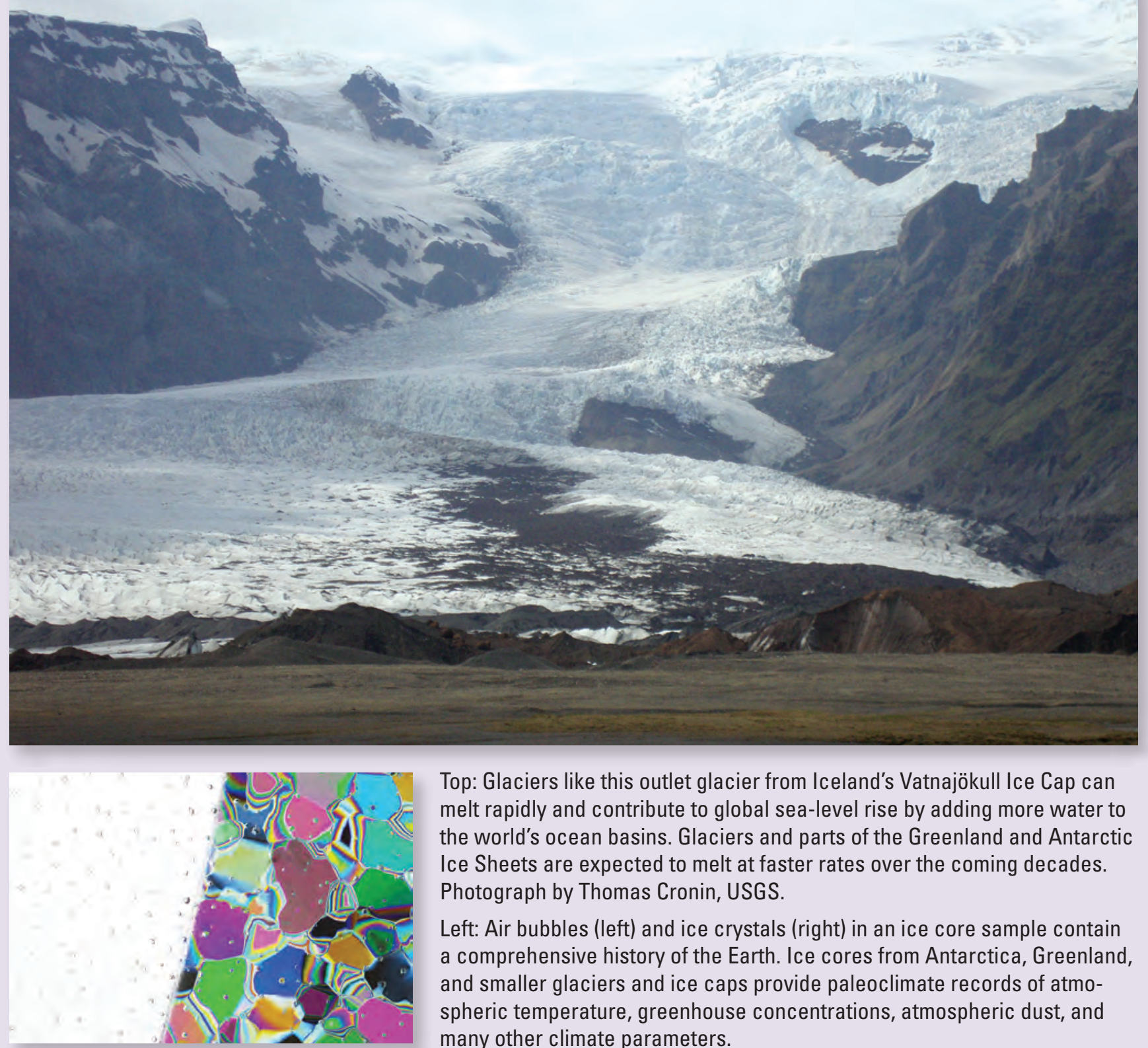

Top: Glaciers like this outlet glacier from Iceland's Vatnajökull Ice Cap can melt rapidly and contribute to global sea-level rise by adding more water to the world's ocean basins. Glaciers and parts of the Greenland and Antarctic Ice Sheets are expected to melt at faster rates over the coming decades. Photograph by Thomas Cronin, USGS.

Left: Air bubbles (left) and ice crystals (right) in an ice core sample contain a comprehensive history of the Earth. Ice cores from Antarctica, Greenland, and smaller glaciers and ice caps provide paleoclimate records of atmospheric temperature, greenhouse concentrations, atmospheric dust, and many other climate parameters. 


\section{Goal 2: Improve Understanding and Prediction of the Global Carbon Cycle}

Natural biogeochemical processes, including biological organic matter production and decomposition, ecosystem respiration, inorganic and organic carbon sequestration, and mineral weathering are inextricably linked to the global carbon cycle and to atmospheric carbon dioxide levels $\left(\mathrm{CO}_{2}\right)$. Changes in the transfer of inorganic and organic carbon into and out of the Earth's carbon stores by burning of fossil fuels, change in land use/land cover (LULC), warming or cooling, and alteration of the hydrologic cycle consequently affect $\mathrm{CO}_{2}$ in the atmosphere. Studies of the global carbon cycle are, therefore, critical to understanding the potential effects of these changes on climate. These studies also will inform potential mitigation options for carbon sequestration and storage in Earth systems. The future course of atmospheric $\mathrm{CO}_{2}$ and global climate change will be determined by complex interactions among human activities and carbon-cycle processes that exchange $\mathrm{CO}_{2}$ with the oceans and terrestrial systems. Policy decisions require information about potential effectiveness of emission reductions and other mitigation activities, as well as the extent to which these measures might be offset by response of the global carbon cycle to climate and land-use change. The USGS will provide scientific information essential for these decisions in support of sound national policies. Today's atmospheric $\mathrm{CO}_{2}$ concentrations are unprecedented in at least the last 800,000 years and probably the last approximately 3 million years (Luthi and others, 2008; Hoenisch and others, 2009; and Pagani and others, 2009).

Policy and legislative decisions about energy policy, resource management, and carbon accounting must be based on many factors, including scientific and nonscientific considerations. Scientific information about the global carbon cycle is essential to anticipate potential impacts of changes in atmospheric $\mathrm{CO}_{2}$ on society, species, and ecosystems. USGS research on the carbon cycle will focus on the interactions among climate, land use, biogeochemical cycling of carbon at plot to global scales, and atmospheric $\mathrm{CO}_{2}$ and methane $\left(\mathrm{CH}_{4}\right)$. The most important topics will include improved process understanding of carbon cycling and fluxes at all scales, including the effects of changes in LULC and water, permafrost, and methane hydrate distributions on $\mathrm{CO}_{2}$ and $\mathrm{CH}_{4}$ production, consumption and exchange with the atmosphere; the transfer of particulate and dissolved carbon from terrestrial ecosystems to freshwater and marine environments; and ocean acidification/carbonation impacts on marine ecosystems. Coupling these studies with the continued development of ecosystem carbon cycle models will result in improved understanding of carbon exchange between land and water surfaces and the atmosphere; carbon transfer from terrestrial to freshwater and marine ecosystems; methane emissions from permafrost, wetlands, freshwater bodies and marine gas hydrates; and relations between LULC and carbon cycling.

In addition to these key research activities, USGS carbon cycle experts are conducting a national comprehensive assessment of carbon sequestration resources as mandated by the Energy Independence and Security Act of 2007 (Zhu and others, 2010). The USGS assessment will quantify ecological carbon stocks, carbon sequestration, and greenhouse gas fluxes across the land and water surface and the export of carbon by rivers to coastal areas of the United States. This methodology includes mapping and modeling of LULC changes, ecosystem disturbances, carbon stocks and potential sequestration, $\mathrm{CO}_{2}$ and $\mathrm{CH}_{4}$ fluxes, cost benefit analyses, and improved statistical verification methods. The USGS also developed a probabilistic methodology for evaluating geologic carbon dioxide storage (Brennan and others, 2010). This methodology estimates pore volume of potential storage formations across a range of uncertainty levels based on information about geologic, geochemical, and hydrologic processes. Following these nearterm, national-scale assessments of sequestration capacities, new observational capabilities and research efforts will be needed to more precisely characterize geochemical, hydrologic, and rock mechanical issues raised at specific sequestration sites.

The National Research Council report, "Global Environmental Change: Research Pathways for the Next Decade," specifically emphasized the need for a comprehensive carbon cycle research strategy (National Research Council, 1999). In response, the Carbon and Climate Working Group of USGCRP wrote, "A U.S. Carbon Cycle Science Plan" (Sarmiento and Wofsy, 1999) to establish the U.S. Carbon Cycle Science Program. The USGS collaborates with nine other agencies through this program to clarify the changes, magnitudes, and distributions of carbon sources and sinks; the fluxes between the major terrestrial, oceanic, and atmospheric carbon reservoirs; and the underlying mechanisms involved, including humans, fossil fuel emissions, land use, and climate.

\section{Vision Statement}

The USGS will provide scientific information that may be used for national climate, energy, and land-management policy decisions affecting atmospheric $\mathrm{CO}_{2}$ concentrations.

\section{Major Questions}

- What are the rates, amounts, and chemical forms of carbon transferred among terrestrial and aquatic ecosystems and the atmosphere?

- What are the effects of past, present, and potential future human activities on carbon cycling and atmospheric concentrations of $\mathrm{CO}_{2}$, methane, and other greenhouse gases?

- What is the potential for increasing and sustaining storage of carbon in U.S. geological and ecological systems? 
- What are the biological, hydrological, geophysical, and geochemical processes that determine impacts of climate and land-use change on the carbon cycle?

- What do past interactions among the global carbon cycle, atmospheric $\mathrm{CO}_{2}$, atmospheric methane, and climate tell us about potential future interactions?

-What are the most important amplifying and dampening carbon-cycle feedbacks that will result from rising greenhouse gas concentrations?

- How is the carbon cycle affected by changes in biogeochemical cycling of water, energy, sediments, and nutrients?

- What underlying geologic and hydrologic conditions most significantly impact the magnitude, capacity, and storage time of $\mathrm{CO}_{2}$ sequestration?

\section{Strategic Actions and Products}

\section{Short Term (1-5 Years)}

- Improve quantitative understanding of the processes controlling the biogeochemical cycling of carbon, including carbon storage, flux, and biogeochemical transformation, in terrestrial (soil, sediment, vegetation, and agriculture), aquatic (lacustrine, fluvial, and wetland), and nearshore marine environments.

- Develop methodologies for estimating potential carbon sequestration (volume capacity and distribution) and carbon storage vulnerability in geological and ecological systems.

- Improve existing and develop new and more accurate integrated ecosystem, hydrologic, and biogeochemical models of terrestrial and aquatic carbon cycling and exchange with the atmosphere.
- Conduct fundamental research that complements the work performed by the Department of Energy and others on the geologic, hydrologic, and geochemical processes in the subsurface that control and result from the injection of liquid carbon dioxide into oil and gas reservoirs and other permeable geologic units.

- Initiate periodic national comprehensive carbon resource assessments of potential carbon sequestration, carbon storage vulnerability, and carbon gas exchange by terrestrial and aquatic ecosystems and geologic formations.

- Integrate multidisciplinary methods and tools for carbon sequestration assessment and monitoring.

- Improve estimates of historical and present-day carbon fluxes associated with water and sediment transport.

- Improve understanding of effects of elevated $\mathrm{CO}_{2}$ concentrations on ocean acidification/carbonation.

Longer Term (5-10 Years)

- Periodically update and refine assessments of carbon sequestration and loss from terrestrial and aquatic ecosystems and geologic formations.

- Publish national maps of carbon stocks and fluxes based on integrated, multidisciplinary, multiagency studies of carbon cycling and storage.

- Contribute to international efforts to model future changes in the global carbon cycle and atmospheric $\mathrm{CO}_{2}$ concentrations.

- Synthesize studies of ocean acidification/carbonation and its impacts.

Agricultural fields and an abandoned farmstead in eastern Montana in the Great Plains region. The Great Plains region of the United States has experienced significant land-use change since European settlement, with vast swaths of grasslands converted to agricultural lands. Access to water, technological changes, a growing biofuels industry, fluctuating demands for agricultural products, and government policies have resulted in periodic historical shifts in land use in the region and may drive major land-use changes in the next several decades. Land use and land management in the region have significant implications for carbon storage and greenhouse-gas fluxes. Photograph by Terry Sohl, USGS. 
The Global Carbon Cycle incorporates the biogeochemical transformation, storage, and movement of inorganic and organic carbon among terrestrial and aquatic ecosystems, oceans, and the atmosphere. This includes plant production by natural forests, grasslands and agriculture; mineralization and volatilization of living and dead biomass by fires, respiration and decomposition; delivery of dissolved and eroded carbon to oceans by rivers; sequestration of carbon by soils, inland waters and oceans; and the exchange of carbon dioxide, methane and hydrocarbons between terrestrial and aquatic ecosystems and the atmosphere. USGS scientists study the carbon cycle in field, laboratory, and modeling investigations and seek solutions to abate global increases in atmospheric carbon dioxide concentrations.

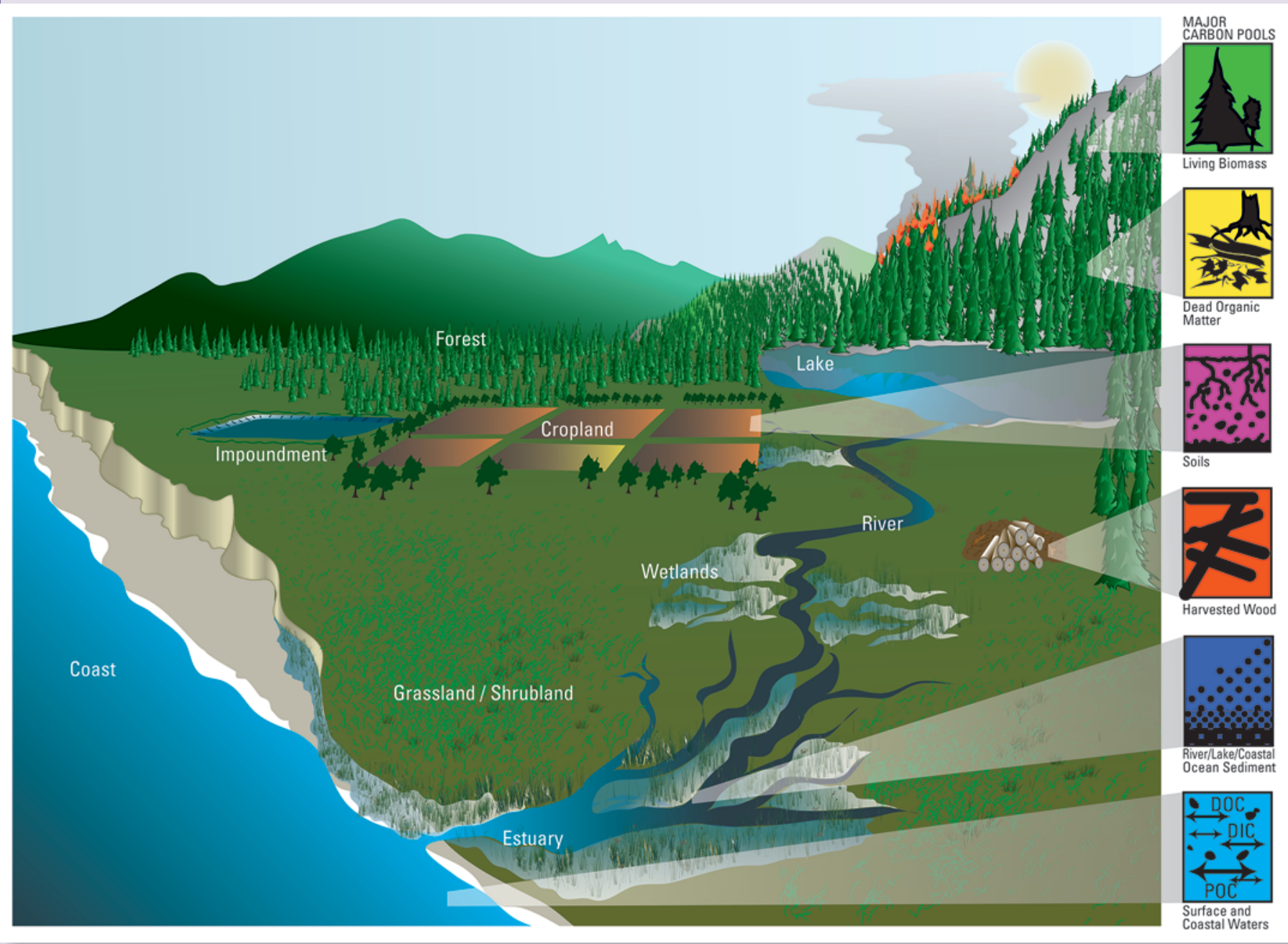

A section of the Upper Green River Valley in western Wyoming, just south of Yellowstone and Grand Teton National Parks, showing different ecosystems (such as forests, wetlands, and aquatic habitats) whose capacities for carbon storage and reduction of greenhouse gas emissions will be assessed by the USGS. Scientists with the USGS are assessing the potential to store carbon in vegetation, soils, and sediments, which is known as biological carbon sequestration. Photograph by Donald Ohlen, USGS.

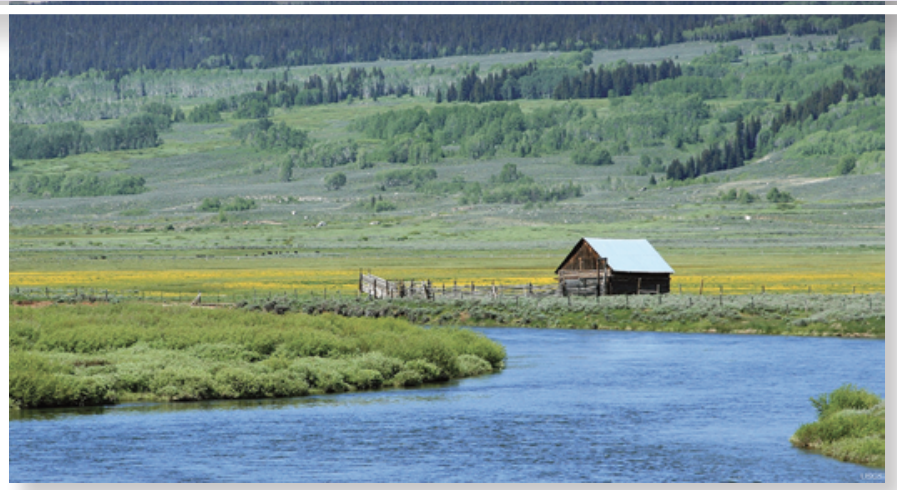




\section{Goal 3: Improve Understanding of Biogeochem- ical Cycles and Their Coupled Interactions}

Human activities have become a major global geophysical force in the past century and the global impacts of our effects on biogeochemical cycling are very poorly understood. Six nutrient elements - carbon (addressed in Goal 2), oxygen, hydrogen, nitrogen, phosphorus, and sulfur - make up 95 percent of the biospheric mass on Earth and constitute the major biogeochemical cycles of the Earth's land-ocean-atmosphere system, establishing the biochemical foundations for life. Imbalances in the availability and use of these elements, as well as interactions with carbon, the major cations (potassium, calcium, sodium, and magnesium) and metals such as mercury, zinc, and iron, have both direct and indirect effects on the distribution and viability of organisms and on climate and landscapes globally. The full impacts of human alterations to these cycles and their coupled interactions are unknown; thus, this goal is an attempt to establish, rather than maintain and expand, the basis for early warnings of potential impacts.

Anthropogenic effects on nitrogen and phosphorus cycles have greatly increased in the past 150 years, especially the last 50 years (Vitousek and others, 2009). Fossil-fuel burning, an increase in leguminous crops, and the production of fertilizers have more than doubled the input of nitrogen into ecosystems relative to preindustrial times. This has negatively affected terrestrial and aquatic ecosystems in many ways (Pardo and others, 2011; Baron and others, 2011; Baron and others, in press). For example, agricultural runoff and atmospheric nitrogen deposition have caused widespread hypoxia in most coastal areas worldwide, causing ecological and economic damage. Hypoxia increases ocean acidity such that nutrient runoff creates regions where global $\mathrm{CO}_{2}$-induced ocean acidification is exacerbated. On land, the cover and extent of invasive annual grasses increase with increased nitrogen deposition, resulting in accelerated fire cycles and subsequent losses of habitat, forage, and soils. Increased nitrogen has been strongly linked to a decline in ecosystem biodiversity and to alterations in plant community composition. Many Americans drink water from wells with nitrate concentrations close to or exceeding the U.S. Environmental Protection Agency (USEPA) safe drinking water standards, and new research links ingestion of nitrate to cancer and birth defects.

The key nutrient element phosphorus is limiting to plant productivity and is often combined with nitrogen in fertilizers (Vitousek and others, 2009). As soil nutrients become exhausted and more marginal areas are brought into agricultural cultivation, increasing amounts of fertilizer are applied by farmers. Current human use of phosphorus is unsustainable, and unlike nitrogen, it cannot be synthetically produced. Thus, emerging scarcity may induce widespread crop failures, while overuse contaminates rivers, lakes and oceans.

Much less attention has been paid to the coupling among different major biogeochemical cycles and their interactions with the carbon cycle. In addition, little work has addressed how cation, anion, and mineral cycles interact with the major elements.

Modification of plant communities due to disturbance regimes also can affect biogeochemical cycles. For example, soil erosion can reduce nutrient availability to ecosystems over the long term. The biological, economic, and societal impacts of the changing biogeochemical cycles may, in turn, affect ecosystem services such as climate regulation, water availability, plant health, and agricultural productivity at local to global scales. A better basic understanding of how altered biogeochemical cycles function, how human activities change them, and what impacts these changes will have on biologic, climatic, hydrologic, and land conditions will allow us to better meet future challenges associated with such cycles. Without such understanding, our ability to manage and predict many global challenges society will face is limited, especially as even more alterations of these cycles can be expected in the future.

The interdisciplinary field of biogeochemistry requires the engagement of many scientific specialties to answer even simple questions. This goal builds on long-standing USGS work. Given its wide range of expertise in all the fields needed for the study of biogeochemical cycles, the USGS is uniquely poised to make significant contributions in collaboration with agriculturally and environmentally oriented partners like the USEPA, the National Aeronautics and Space Administration (NASA), the U.S. Department of Agriculture (USDA), NOAA and other DOI bureaus.

\section{Vision Statement}

The USGS will provide scientific knowledge and tools for tracking and understanding changes in the Earth's major biogeochemical cycles; their internal interactions and their interactions with the cycles of carbon, major cations and micronutrients; perturbations to these cycles by human activities; the effects of these changes on ecosystems and global processes; and options for mitigating these effects.

\section{Major Questions}

- What are the major sources and sinks for nitrogen and phosphorus through time and across different geographic scales? How are these cycles interacting with carbon, major cations, and other metals? How are they changing with global changes?

- What are the biological, chemical, and physical factors regulating transformations to, from, and within the global reservoirs of nitrogen and phosphorus?

- How has increased nitrogen from anthropogenic sources affected terrestrial and aquatic ecosystems and the services they deliver?

- How do carbon-nitrogen-phosphorus interactions affect ecosystems, land conditions, and the positive or negative feedbacks to climate change? How might climate 
and land-use change exacerbate or mollify future changes in these major biogeochemical cycles?

- How can human alterations to biogeochemical cycles, through agriculture, energy provision, and other activities, be managed at large scales to control adverse impacts to the greater environment, especially highly vulnerable freshwater and marine resources?

- What is the nature and what are the risks associated with human alterations to other biogeochemical cycles, such as sulfur, iron, and zinc?

\section{Strategic Actions and Products}

Short Term (1-5 Years)

- Publish an overview of the past variations and changes of major biogeochemical cycles and interactions with the carbon cycle.

- Develop a monitoring strategy for tracking and predicting major biogeochemical sources and sinks at local to global scales and collaborate with other national networks to implement this strategy.

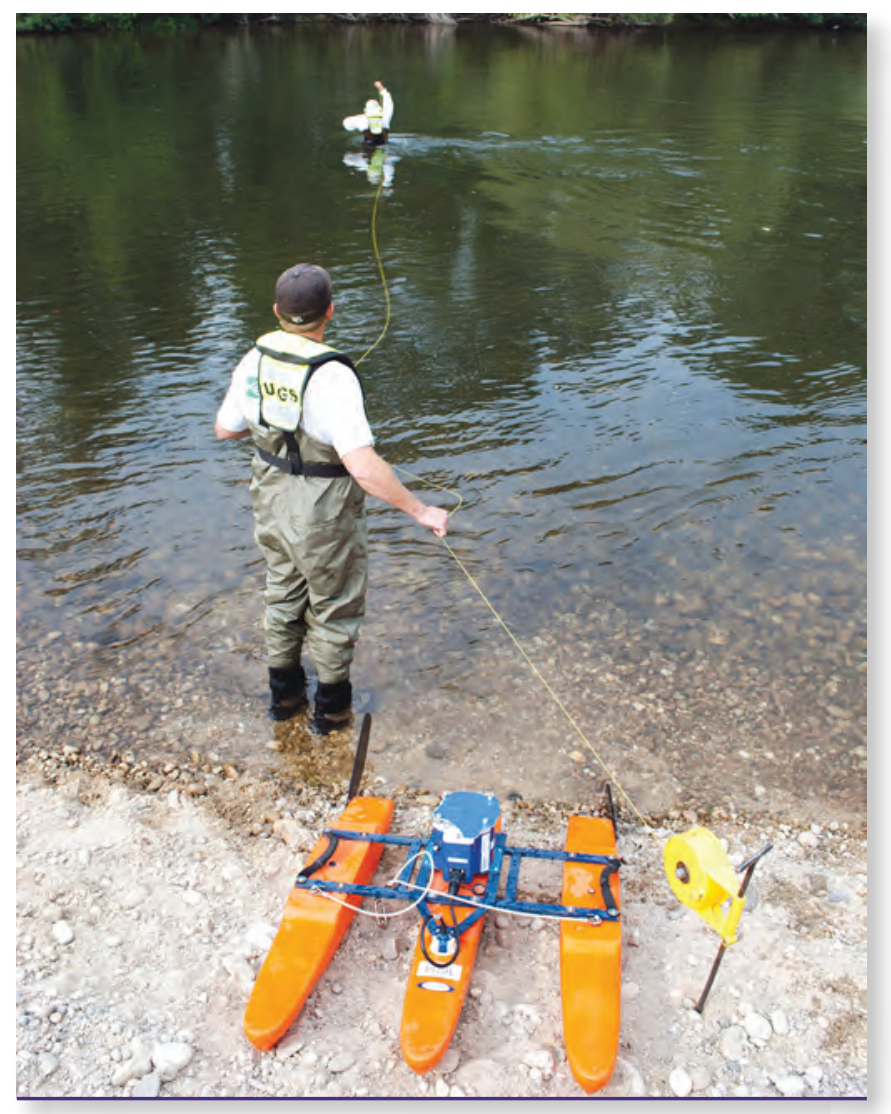

USGS scientists prepare to use an acoustic Doppler current profiler to measure streamflow on the Boise River in Boise, Idaho, as part of a study of phosphorus mass balance. Photograph by Tim Merrick, USGS.
- Augment USGS research and modeling to identify and track vulnerabilities of the global biogeochemical cycles to human-induced change, as well as key direct and indirect effects of changing cycles on ecosystems and other global processes.

- Conduct a detailed national assessment of nitrogen deposition patterns and impacts on ecosystem structure and function, including water quality.

- Document and model transfers of nitrogen and phosphorus between terrestrial and aquatic ecosystems in natural and agricultural settings at local and regional scales.

- Document and model how changes in climate and $\mathrm{CO}_{2}$ will affect biotic and abiotic transformations within the nitrogen and phosphorus cycles in different climatic regions.

- Characterize nitrogen and phosphorus cycles (and their interactions with each other and carbon) in ecosystems known to be sensitive to deposition of these elements and establish minimum loading levels possible before ecosystem structure and function are disrupted.

Longer Term (5-10 Years)

- Publish recurring national summaries of observed variations and changes in nitrogen and phosphorus sources, sinks, reservoirs, and fluxes with attribution of the role of human activities in these variations and changes.

- Develop local, regional, national, and global projections of nitrogen and phosphorus sources, sinks, and fluxes in response to projected economic and agricultural developments and to projections of climate, land-, and water-use change.

- Conduct field, laboratory and modeling research on the potential for large-scale mitigation of human impacts on global biogeochemical cycles.

- Conduct comparative analysis among the Nation's ecosystems to determine the vulnerability and resilience of ecosystems to increased nutrient loading.

- Incorporate biogeochemical cycling in scenario-based predictive modeling of global change impacts.

- Better understand oceanic nitrogen, phosphorus, and iron cycles in relation with ocean temperature, $\mathrm{pH}$ and biotic functioning.

- Investigate how the cycles of other elements interact with nitrogen and phosphorus cycles. 


\section{Water, Energy, and Biogeochemical Budget Studies}

USGS water, energy and biogeochemical budget research focuses on observations of hydrologic and biogeochemical fluxes across contrasting landscapes and analysis of how these fundamentally important cycles respond to climate variability and landscape change; enhanced measurement of organic and inorganic carbon fluxes in aquatic environments, using continuous in-stream sensors coupled with conventional sampling and lab analysis, to foster improved understanding of the role of freshwater carbon fluxes in the global carbon budget; and synthesis of measurements and understanding of water budget components to develop models to predict potential changes in water availability in response to climate change. A "small watershed approach" is used to take advantage of
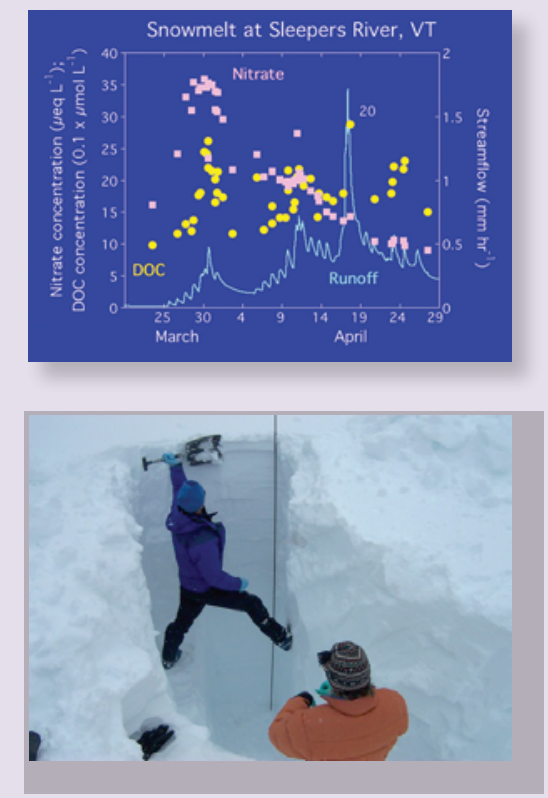
well-defined hydrologic inputs and outputs and well-quantified basin characteristics of small watersheds to develop the critical link between plot-scale studies and large regional surveys and monitoring programs.
Plot showing nitrate $\left(\mathrm{NO}_{3}\right)$ and dissolved organic carbon (DOC) dynamics during the 1993 snowmelt at a Sleepers River site in Vermont. Each snowmelt peak causes a peak in concentration but for nitrate the peaks concentrations diminish as snowmelt progresses.

There is uncertainty about the source areas and emission types that contribute to nitrate $\left(\mathrm{NO}_{3}\right)$ deposition in the Rocky Mountains, which can adversely affect sensitive aquatic habitats of high-elevation watersheds. Surveys of snowpack depth, water content, and chemistry are performed each spring, in early April at a Loch Vale, Colorado, site. Because contaminants accumulate in the snowpack throughout the winter, the springtime samples allow calculation of total contaminant deposition for the winter period.

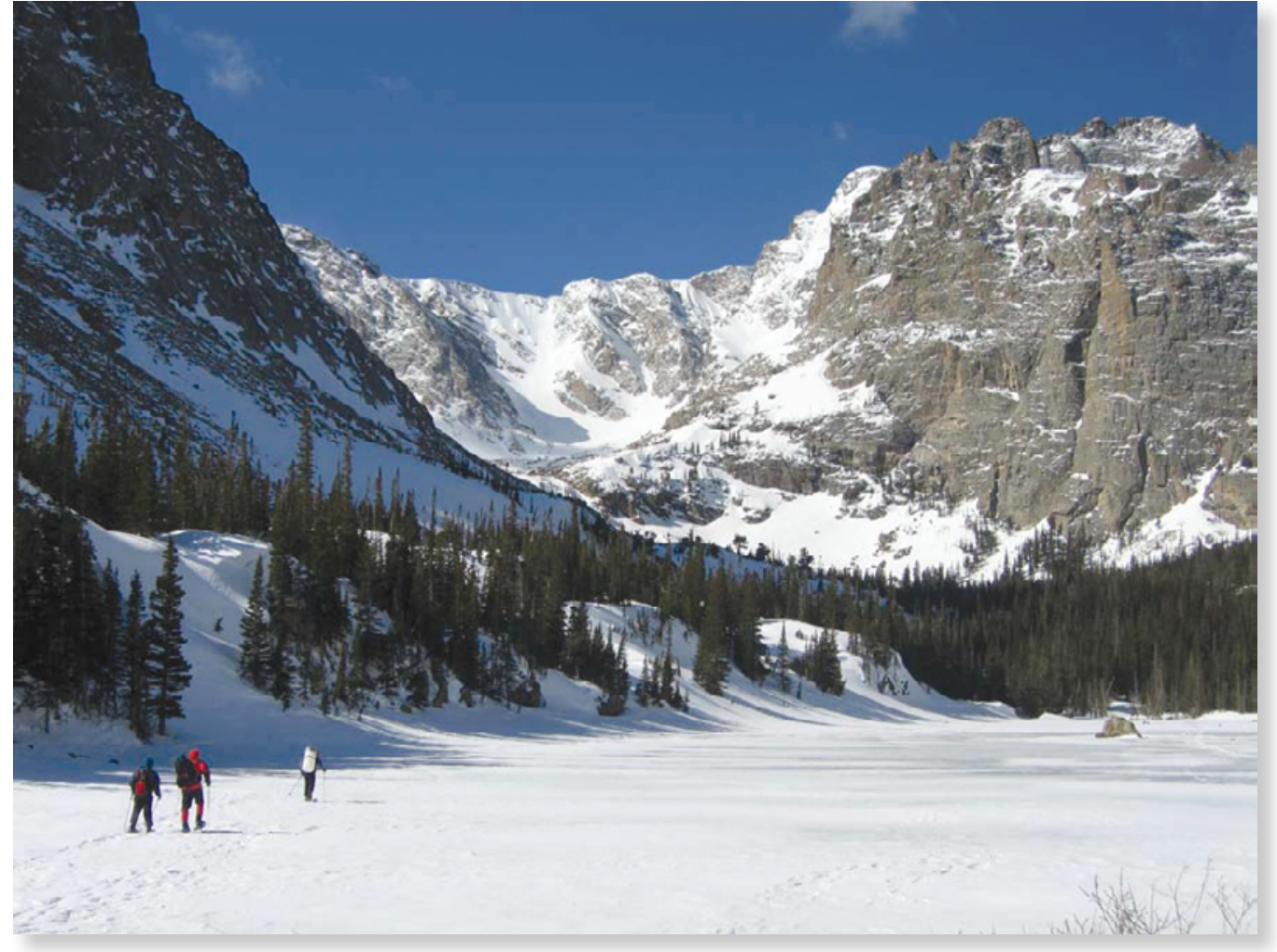




\section{Goal 4: Improve Understanding of Land-Use and Land-Cover Change: Rates, Causes, and Consequences}

Changes in land cover, use and condition affect climate; climate and other global change factors, in turn, affect land cover, use, and condition. These changes at the land surface alter biogeophysical, biogeochemical, and energy exchange processes, which affect weather and climate variability at local, regional, and global scales. At local and regional levels, these changes pose direct challenges for natural resource managers as land change can fragment and degrade habitat, alter water quality and quantity, and reduce options for managing ecosystem resilience to climate change. Changes resulting from natural disturbances (for example, fire, insect outbreaks, and drought), land-use change (for example, conversion of forests to cropland), or land-use intensification (for example, irrigation, multicropping, and urban densification) must be considered due to alteration of hydrologic dynamics and nitrogen cycling, impacts on water-quality degradation, and contributions to weather and climate variability because of alteration of energy and water exchange between the land and atmosphere. Distinguishing natural disturbances and variability from anthropogenic influence relies on understanding how land cover, use, and condition change. Effective land management requires interdisciplinary knowledge of patterns, processes, and consequences of changes in land use and land cover to understand the interaction between human activities and natural systems over multiple spatial and temporal scales.

Because land changes have local origins and regional and global consequences, interdisciplinary land-change science investigations focus on patterns, processes, and consequences at multiple spatial and temporal scales. This USGS global change science goal includes the following critical elements:

- Monitoring patterns of land change, including disturbances, using ground surveys and long-term, highquality geospatial data from calibrated and validated remotely sensed imagery;
- Identifying drivers of change and applying spatially and temporally explicit models to forecast plausible scenarios of land change;

- Assessing consequences of past, present, and future land change on vulnerability and resilience of coupled human-environment systems and the services they provide; and

- Applying land-change science and knowledge to policy and decisionmaking to address consequences of land change and inform critical DOI issues.

Pursuing these elements will require close communication with organizations managing the impacts of change in land use, cover, and condition, such as DOI bureaus and USDA agencies, State resource management agencies, and nongovernmental organizations (NGOs). Scientific partnerships with the NASA, NOAA, the U.S. Forest Service and Natural Resources Conservation Service, the Bureau of Census, and others will be required to accomplish the research associated with this goal.

\section{Vision Statement}

The USGS will explain how changes in land use, cover, condition, and land management alter climate, impact natural systems, and affect human health and well-being.

\section{Major Questions}

- Is our current understanding of land-cover characteristics and dynamics adequate for understanding their impact on climate, natural systems, and human health and well-being?

- What are the major drivers of land change (including population, public policy, economics, and technology), and how do those drivers interact to affect the regional variability of land-use change characteristics? 
- How do climate variability and change (including extreme events) affect land use, cover, and condition?

- How will changes in land use, cover, and condition affect the ability of ecosystems to provide essential goods and services?

- What past, current, and future patterns and attributes of land use, cover, and condition affect carbon and nitrogen cycles, sediment production, atmospheric processes, and ecosystem structure and function?

- What are the impacts of future land use, cover, and condition on sediment movement, air and water quality, water quantity, and nutrient cycles?

- What opportunities exist for managing land-use change to minimize negative impacts and maximize positive outcomes on natural and human systems?

\section{Strategic Actions and Products}

Short Term (1-5 Years)

- Conduct methodological research leading to more accurate land-cover maps and statistics.

- Produce validated maps, statistical analyses, and reports on 5-year rates of regional, national, and global land-use and land-cover change.

- Develop regional and national scenarios and projections of U.S. land change over 5- to 50-year periods, keyed to various economic and policy assumptions, for use in resource planning, climate, and hydrologic modeling investigations.

- Conduct sensitivity studies on how land-use and landcover changes (LULCC) affect surface albedo (reflectance), evaporation and transpiration, snow cover, greenhouse gas fluxes, and particulates; analyze how type and distribution of land cover affects regional weather and climate patterns.

- Evaluate effects of LULCC on carbon dynamics, including analyzing impacts of land use on greenhouse gas mitigation and management.

- Develop an integrated model of how land-use change in different climatic settings affects sediment production, storage, transport, and delivery.

- Assess the impact of cumulative changes in land use, cover, and condition, in combination with climate variability and change, on the ecological integrity of the Nation's conservation lands.

- Develop decision-support tools for communication and use of land information by researchers, resource managers, and others.

Longer Term (5-10 Years)

- Publish validated maps, statistical analyses, and reports on annual rates of regional, national, and global landuse and land-cover change.

- Develop a community land-change model that couples land use, land cover, and disturbance variables with climate, hydrological, biogeochemical, ecosystem, and other process models.

- Report on results of how changes in land use, cover, and condition affect soils, ecosystem processes, water and nitrogen cycles, plants and wildlife changes, and the delivery of ecosystem services.

- Conduct periodic assessments of the impact of land change and land cover on ecosystem services.

- Provide decision-support tools for communication and use of land information by researchers, resource managers, and others.

View of the High Plains, Wyoming and Nebraska. Photograph by Jon Mason, USGS. 


\section{Patterns of U.S. Land-Use and Land-Cover Change}

The USGS has a longstanding history of research and assessments dealing with land-change science-the interdisciplinary knowledge of the patterns, processes, and consequences of changes in land use, land cover, and land condition at multiple spatial and temporal scales that is associated with the interaction of human activities and natural systems. A series of land-cover geospatial datasets is produced using Landsat remotely sensed data, and national and regional land-change studies describing the characteristics and dynamics of contemporary U.S. land cover are conducted. The rates and types of land-use and land-cover change vary from place to place and over time. Understanding the tempo or pulse of change is necessary for identifying and managing the local to regional impacts of change, the cumulative effects of change, and the patterns of future change. USGS land-cover change studies also provide information that enables scientists to determine the role of land change in modifying the exchange of water, energy, and greenhouse gasses with the atmosphere, interacting with the hydrological cycle, and affecting habitat and biodiversity. Land-use and land-cover change studies also provide the historical basis for forecasting future scenarios of land-use and land-cover change.

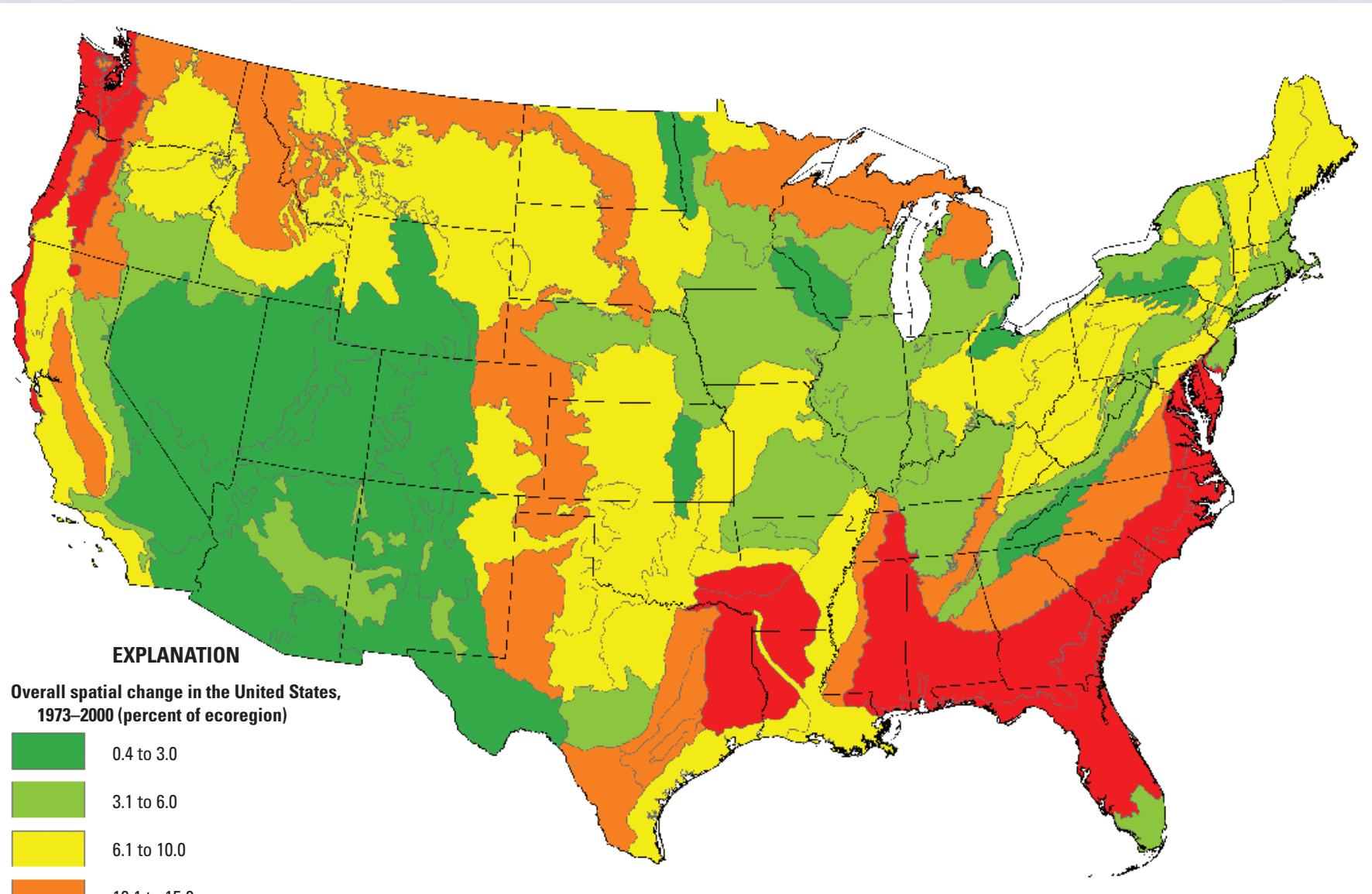

10.1 to 15.0

15.1 to 33.8

Overall change in land cover at the ecoregional level for the last quarter of the 20th Century. Note red and orange areas with the most dramatic percentage change (Sleeter and others, 2012). 
Goal 5: Improve Understanding and Predictions of Changes in Hydrologic Processes, Droughts, Floods, and Water Availability Under Changing Land Use and Climate

Water sustains human societies and ecosystems. Water in snowpack, glaciers, permafrost, soils, bedrock, lakes, rivers, and streams represents a commodity, provides a range of services, and also poses risks to human populations and natural and managed ecosystems. Water affects and is affected by human activities, such as land use, water use, and fire management. Hydrological processes are key controls on humandriven changes in global cycling of carbon, nitrogen, and other elements. The water cycle and climate are inextricably linked.

Natural resource and disaster managers, as well as emergency responders, need information and tools to confront the challenges of planning and management under highly uncertain projections of climate change. In practice and as used here, water "availability" is both a matter of the available quantities of water and the availability of water of acceptable (for the uses envisioned) quality. Quantifying the impacts of altered water availability on ecosystems and human societies and identifying effective management responses require climate-change information and process-based understanding. Commonly, the response of river basins to shifting climatic factors such as precipitation, radiation, and temperature are masked and may be dominated by changes in water use, water management, and land use and by natural variability at annual to multidecadal scales. These masking influences are important stressors in their own right. Projections of future precipitation amount, intensity, and event frequency have been only poorly constrained by climate science, so projections of water availability and water-related hazards are, and will continue to be, highly uncertain. Gaps in understanding of sensitivity of hydrologic processes to climate increase the uncertainties with respect to climate change. Providing managers with meaningful information for long-term planning can be accomplished by a program of research on coupled land-atmosphere processes, alongside a vigorous program of empirical research that aims to document, based on historical and proxy records (with appropriate ties to Goal 1 efforts), the hydrologic changes now underway. Synthesis efforts, wherein model results and empirical water data are explored and compared on an ongoing basis, will be necessary to interpret and plan for these changes.

USGS monitoring, analysis, and modeling activities are key to detecting, understanding, and predicting changes in hydrology. The USGS led the Nation in developing monitoring methods and standards that enhance national monitoring systems to address global change. USGS predictive and diagnostic modeling expertise for surface water, groundwater, water chemistry, soil salination, sediment transport, and geomorphic change also will lead to the next generation of hydrologic models. The USGS has a long history of collaboration with local, State, and national water-resources organizations, including the U.S. Bureau of Reclamation and the U.S. Army Corps of Engineers, water resources departments in all 50 States, and hundreds of local public water agencies and institutions. Building on such collaborations will provide important baselines and many real world opportunities to address water resource challenges with changing water demands, including those for ecological uses and supplies, changing land use, and changing climate.

\section{Vision Statement}

The USGS will provide scientific knowledge and tools for understanding and predicting impacts of land-use and climate change on water resources. This knowledge and these tools will inform integrated resource management and adaptation strategies to ensure water for human activities and to protect human life, property, and ecosystems.

\section{Major Questions}

- How can we improve characterization of natural variability for improved management and mitigation of drought and flood impacts and facilitate attribution of hydrologic changes to natural variability, human activities on the landscape, and decadal-centennial climate change?

- Where, when, and how do anthropogenic climate change and natural climate variability present the most urgent challenges to water, land, and biological resource managers?

- Which land-use and water-use practices enhance or decrease the effects of climate change on the Nation's citizens and lands?

- How do climate change and land use affect water uses, runoff, streamflow, sediment transport, geomorphology, soil chemistry, groundwater recharge, water quality, water temperatures, water use, and freshwater availability?

- How do climate change and land and water use affect the availability of water to terrestrial and aquatic ecosystems and thereby affect ecological patterns and processes?

\section{Strategic Actions and Products}

Short Term (1-5 Years)

- Define USGS national monitoring-network requirements and evaluate existing networks to facilitate timely detection of climate and land-use change impacts on streamflow, groundwater, water budgets, sediment transport, and water quality. 
- Re-establish monitoring at discontinued sites that already have high-quality, long-term hydrologic records needed to characterize ongoing changes.

- Accelerate analysis of long-term USGS hydrologic records with the aim to improve estimates of hydrologic statistics (for example, seasonal and annual means and extremes) and to understand their trends.

- Produce a national summary of observed and projected climate change and land-use impacts on water supply quantities and on flow and temperature regimes in altered and unaltered systems.

- Conduct research and develop models, modeling strategies, and scenarios of impacts of climate, water use, and land use on water quality to develop improved predictive methods.
- Execute initial scoping for a national assessment of historical and projected climate change impacts on water quality, integrated with the National Water Quality Assessment (NAWQA) Program.

- Assess changing sediment and dust mobilization and transport mechanisms, their relation to land-use and climate change, and their geomorphic and hydrologic consequences.

- Produce a national-scale evaluation of changing and projected flood and drought risks under climate change.

- Determine the effects of streamflow alteration on stream ecosystems and the physical and chemical mechanisms by which streamflow alteration causes degradation.

\section{Regional Hydroclimatology in the USGS}

The discharge and quality of U.S. rivers and reservoirs fluctuate on timescales ranging from minutes to centuries in complicated ways that often seem random. By taking a large-scale view of those fluctuations and linking them to global scale climatic processes, researchers at the USGS are beginning to see a great deal more structure and predictability than has been recognized previously. The Nation's water resources are tied together on regional scales by their shared responses to temperature and precipitation variations that, in turn, are highly affected by atmospheric circulation and interactions with the Earth's ocean and land surfaces on global scales.

Recent studies by USGS scientists have linked the Nation's water resources to climatic events like El Niño-Southern Oscillation in the tropical Pacific and decadal climatic variability in the North Pacific and North Atlantic regions. The linkages provide a better scientific basis for predicting and planning for droughts, floods, and water supplies months to years in advance and also are building the scientific basis for projecting possible effects of future climate changes. By learning to recognize the role of climatic variables, other influences on streamflow can be identified, such as land-use change and upstream resource management.
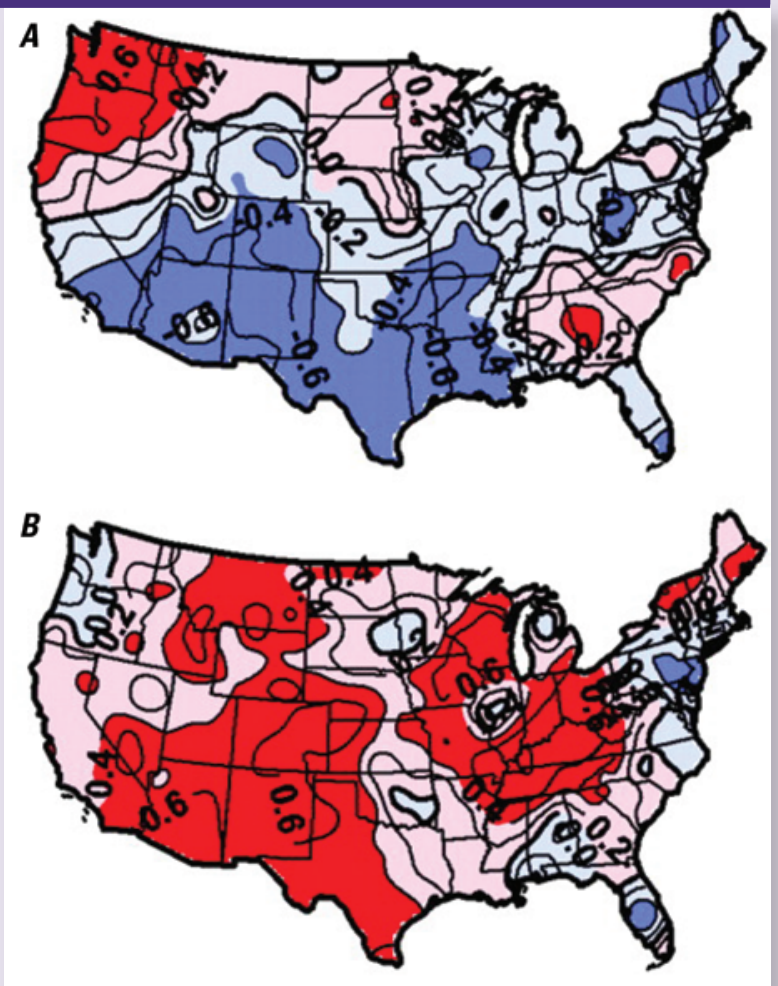

Areas of the conterminous United States where droughts are more frequent (red) or less frequent (blue) under the influences of oceanic changes in $A$, the North Pacific, and $B$, North Atlantic Oceans on decade-to-decade timescales (McCabe and others, 2004). 


\section{Longer Term (5-10 Years)}

- Produce a national summary of observed and potential impacts of the combination of land-use and climate change on water quality and soil salination (in collaboration with land-use and water-quality evaluations by the USGS NAWQA Program).

- Develop decision support strategies, data resources, and tools for water planning and management under land-use, water-use, and climate change, including strategies, tools, hydrologic projections, and information resources for scenario-based assessments, management under uncertainty, and identification of vulnerability thresholds in resource systems.

- Produce water-use forecasts and scenarios under climate change and land-use scenarios for planning and modeling.

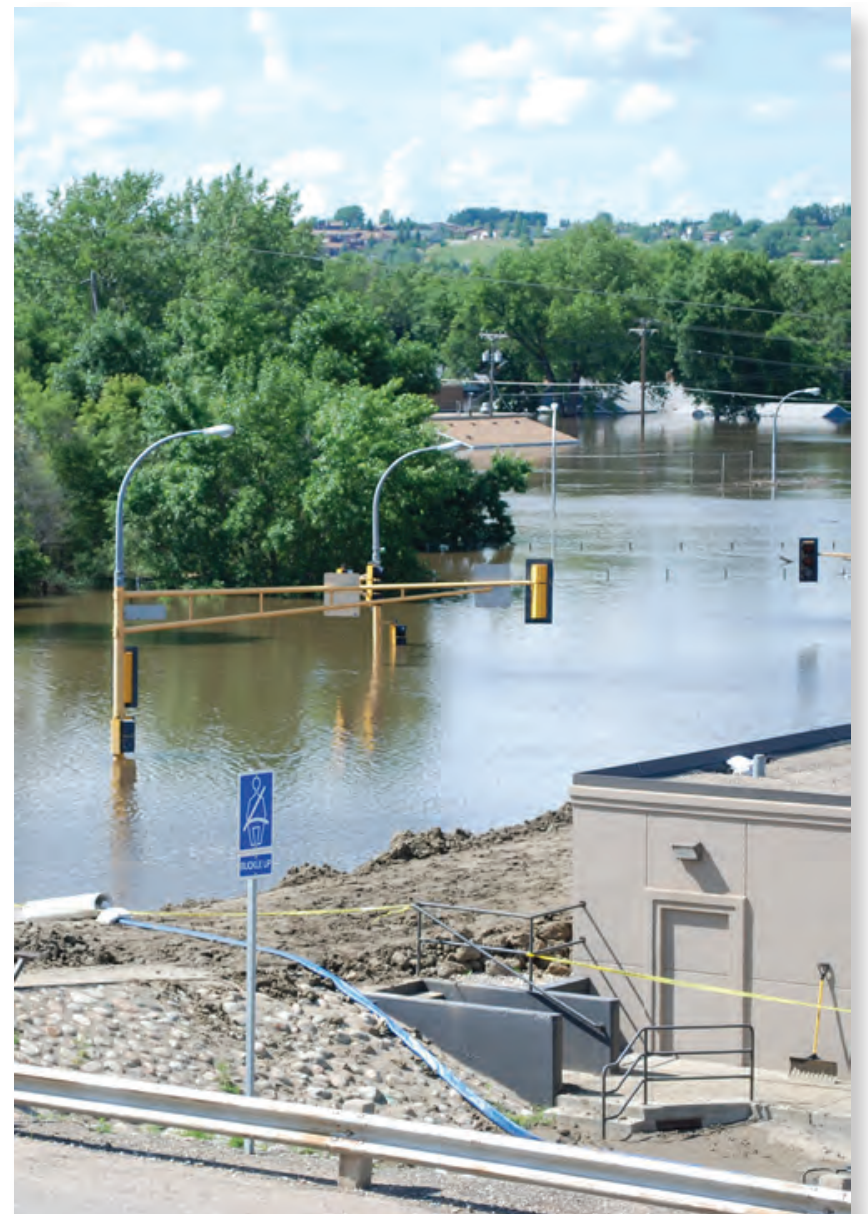

- Produce national evaluation and projections of flood and drought risks under climate and land-use changes with direct ties to within-agency and interagency efforts like the National Integrated Drought Information System, WaterSMART, and flood-risk guidance programs.

- Develop terrestrial system models that synthesize understanding and predictive capabilities for hydrology, biogeochemistry, landscape conditions, biota, and ecological processes.

- Conduct research to model and observe how changes in climate, land use, land cover, and streamflow will affect sediment transport, geomorphology, riparian and aquatic habitats, and riparian and aquatic ecosystem structure and function.

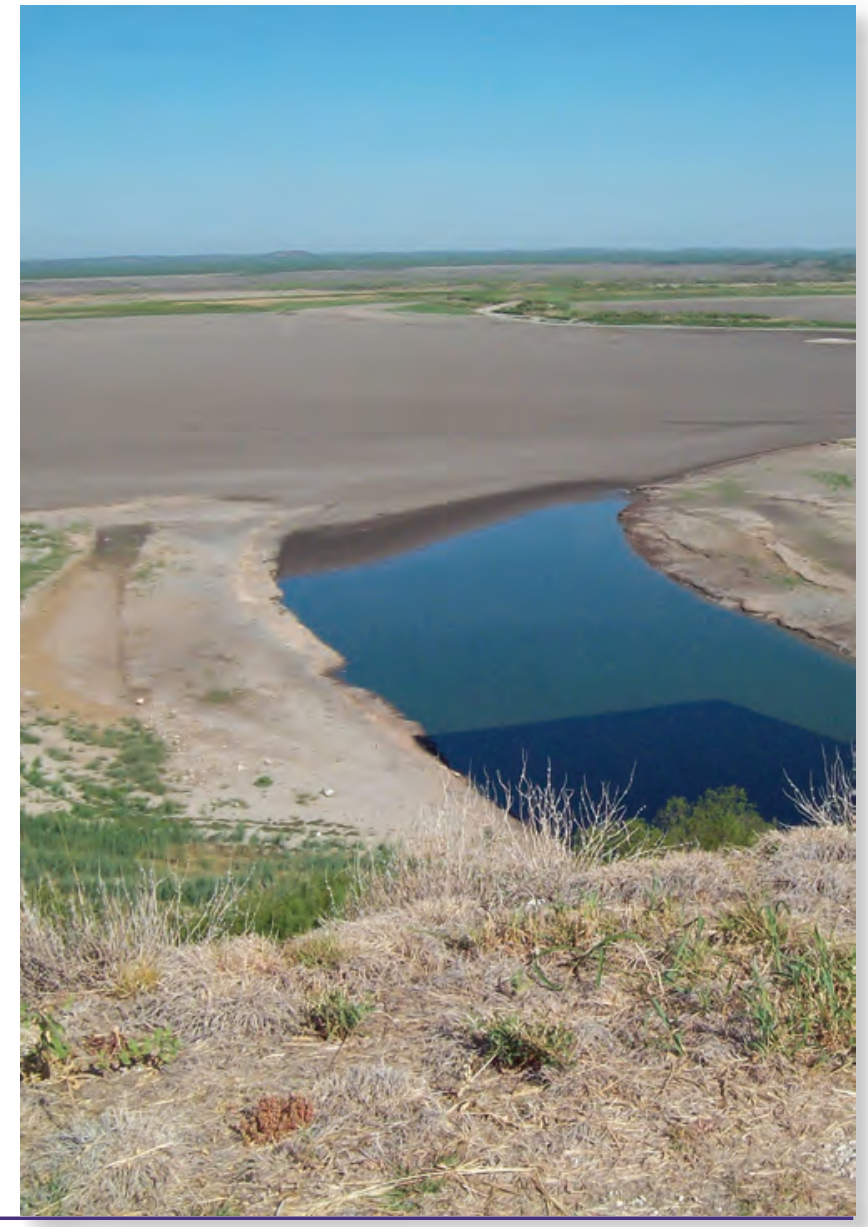

While the Souris River was in the throes of record high flooding in Minot, North Dakota, 0.C. Fisher Lake near San Angelo, Texas has been experiencing the exact opposite for a number of years now-a ground-cracking drought. These locations have more than their extreme water conditions in common. Though about 1,000 miles apart, these places are situated north and south of each other just west of the 100th meridian of longitude. Photograph at left: Flooding at Minot, North Dakota, June 26, 2011. Photograph by Marisa Lubeck, USGS. Photograph at right: 0.C. Fisher Lake outlet tower vicinity near San Angelo, Texas, June 23, 2011. Photograph by Travis Dowell, USGS. 


\section{Goal 6: Improve Understanding and Prediction of Coastal Response to Sea-Level Rise, Climatic Change, and Human Development}

Coastal areas are highly complex systems, vulnerable to abrupt change, and stressed by human development activities. Future sea-level rise, coupled with changes in storm intensity and freshwater runoff, may result in dramatic changes in coastal systems. The relation between coastal processes and climate-related forcings has become an important focus of USGS research in recent years. Understanding onshore and nearshore impacts of global change is crucial to people who live in or are dependent on services of coastal regions. Helping coastal communities, including Native American tribes and indigenous peoples, anticipate and adapt to change within defined ranges of uncertainty is now possible with tools developed and demonstrated by the USGS in its coastal studies programs and projects. These studies (for example, Plant and others, 2008; Pendleton and others, 2010; Hapke and others, 2011) emphasize understanding, monitoring, and modeling of coastal processes, including impacts on threatened mangrove, coral reef, tidal marsh, and estuary and bay coastal systems.

The USGS is part of a research community that evaluates and predicts processes that cause relative sea-level change along the coast. Research on regional and global processes, such as land subsidence due to sediment loading and groundwater extraction, regional glacio-isostatic adjustment, marsh accretion rates, vertical tectonic movements, and cryospheric mass balance and ice dynamics, is needed to assess future rates and impacts of sea-level rise. Understanding the rate of sea-level rise and its spatial and temporal variability along our coasts is critical to forecasting coastal impacts.

Studies of modern processes and investigations of sea-level rise in the recent and distant past will provide the scientific basis to understand and anticipate future changes, including the potential for extreme and abrupt change. Analysis of geologic and environmental records of past sea-level rise and coastal response will provide the observational records to test models, assess the potential for extreme change, and understand how sea-level and other environmental indicators respond to changing climate.

\section{Vision Statement}

As the impacts of climate change, sea-level rise, and human development intensify, predictive tools and solid scientific understanding of climate-change processes and coastal response will enhance the stewardship of coastal resources and lead to safer, more resilient coastal communities.

\section{Major Questions}

- How rapidly has sea level risen in the past? What can we expect for future relative sea-level rise over timescales ranging from years to centuries? What extremes in sea-level rise rates are possible? How does sea-level rise vary regionally?

- How will changes in seasonal storm activity and intensity affect coasts?

- How will continental shelf, slope, and coastal ecosystems, including wetlands, Arctic shorelines, coral reefs, barrier islands, and estuaries, respond to the combined impacts of storms, sea-level rise, increased water temperature, and coastal erosion?

- How will the combination of changing storm conditions, sea-level rise, and changes in wetlands, coral reefs, and barrier shorelines impact the vulnerability and resiliency of coastal communities, fisheries, tourism, and other economic and ecosystem services?

- How will low-lying coastal systems along the U.S. coastline respond to sea-level rise with and without adaptation measures?

- How will sea-level rise and climate change affect small islands and DOI trust territories in the Pacific and Atlantic regions?

- How accurate do digital elevation models need to be to accurately assess the impacts of sea-level rise?

\section{Strategic Actions and Products}

Short Term (1-5 Years)

- Conduct process-oriented studies to quantitatively identify impacts of sea-level rise and other stressors on coastal systems for each U.S. coastal region.

- Provide high-resolution sea-level rise scenarios for U.S. coastlines, in cooperation with partners like NOAA, incorporating coastal, eustatic, and steric processes.

- Develop predictive models of coastal retreat, land-use and habitat change, and land loss under a range of sealevel rise and concomitant coastal adaptation scenarios.

- Synthesize current science regarding likely and maximum rates of sea-level rise, combining cryospheric, geologic, biologic, hydrologic, remote sensing, and modeling assets of the USGS.

- Synthesize information on glacier mass balance in the United States and, in collaboration with outside organizations, synthesize glacier and ice-sheet contributions to sea-level rise. 


\section{Providing Coastal Managers and Communities with Tools to Assess Coastal Change Vulnerability}

Initial USGS regional assessments of the relative vulnerability of different coastal environments to future sea-level rise are based on the relative contributions and interactions of six variables: historical rates of relative sea-level change, tide range, wave height, coastal slope, geomorphology, and historical shoreline change rate. This framework allows scientists to make probabilistic predictions of the future state of coastal environments for outcomes such as shoreline change, wetland survival, and changes in the depth to groundwater. The predictions also have estimates of outcome uncertainty that can be expressed as both numbers (for example, 90 percent) and words (for example, very likely). The ability to communicate potential impacts, including the contribution of sea-level rise through observation of past sea level, in terms of a probabilistic prediction can improve scientists' ability to support decisionmaking and evaluate specific questions about management alternatives.

Probabilities of shoreline change can be calculated with a Bayesian Network informed by information regarding rate of long-term shoreline change, rate of long-term sealevel rise, coastal slope, geomorphic setting, mean tidal range and mean wave height. The resulting probabilities can be expressed as likelihoods and described in terms used by the IPCC for climate-change impacts. This map shows the probability of shoreline ero-

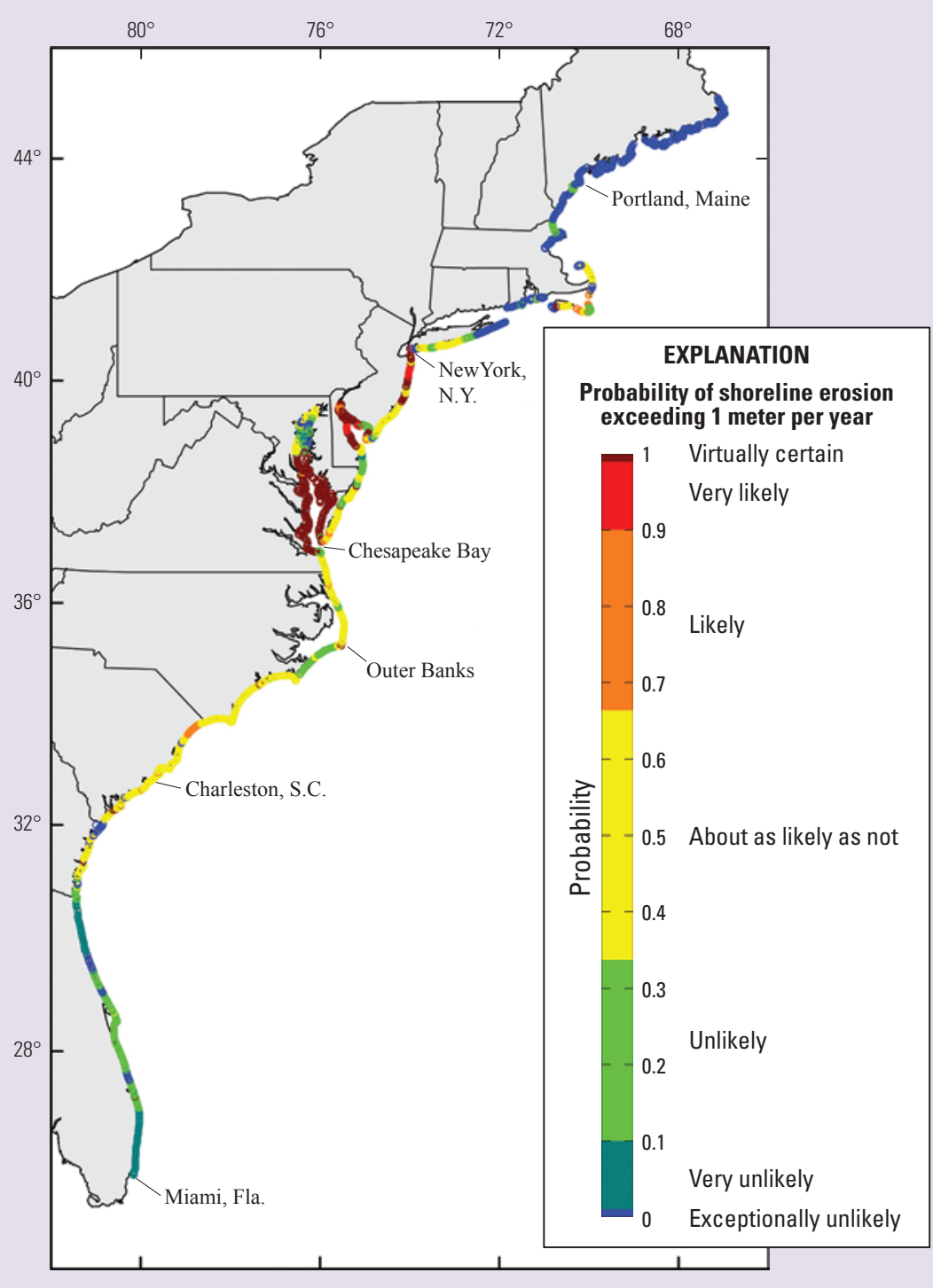
sion exceeding 1 meter per year (modified from Gutierrez and others, 2011).

Longer Term (5-10 Years)

- Conduct integrated watershed and coastal impact studies of changing freshwater discharge, sediment, and nutrient influx on coastal receiving waters.

- Continue and enhance national coastline monitoring and mapping of physical and environmental changes using new geospatial technologies and high-resolution elevation data to produce a national coastline vulnerability assessment.

- Develop and interpret historic and geologic records of sea level to provide reconstructions of baseline conditions for periods of warm climate and elevated greenhouse gas concentrations.

- Develop assessments of sea-level rise and climate change for U.S. islands and insular territories.

- Develop assessments of changing coastal vulnerability as a consequence of climate change-driven alterations of protective natural features (wetlands, coral reefs, barrier beaches, and Arctic sea ice).

- Develop datasets on coastal inundation by storm surge for use in coastal hydrodynamic modeling to assess storm-surge and sea-level rise risk and vulnerability. 


\section{Goal 7: Improve Understanding and Prediction of Biological Responses to Global Change}

Twentieth Century trends and projections for the coming decades point to rapid alterations of climate and physical conditions; land cover, use, and condition; and biogeochemical cycles. Although there may be some positive benefits from the predicted climate changes for some biota, these changes will pose significant challenges to managing biological resources. Loss and fragmentation of habitat, modification of freshwater resources, changes in wildfire frequency and impacts, insect outbreaks, alteration of disturbance regimes, drought, and zoonotic diseases spread by humans are among the drivers that threaten the viability and genetic diversity of populations and communities.

In the short term, increased air and water temperatures may lead to increased productivity in aquatic and terrestrial ecosystems. It is anticipated, however, that biota will generally shift to higher latitudes and altitudes as the climate warms, and there may be unexpected responses as these changes cross tipping points for ecosystems, populations, and species. The scope and rate of biotic responses to rising temperatures will be affected by shifts in precipitation regimes, availability of suitable substrates and habitats, and other environmental factors, including responses to an expected increased frequency of wildfires. Changes in seasonality will affect phenology, potentially disrupting interactions that determine the persistence of species, as well as how ecosystems function and what services they provide. New connections among habitats and unintentional dispersal by humans will provide opportunities for organisms to spread. These conditions can lead to novel problems when climate change, coupled with this enhanced mobility, allows pests, pathogens, and invasive species to colonize habitats from which they previously were excluded. Many such biotic changes are already underway, giving national urgency to addressing these challenges. Of particular concern are tribal cultures that are based on connections to the land and the foods the land and water provide. Treaty agreements have limited the areas in which Native peoples can harvest those foods. Climate change threatens Native peoples' ability to harvest traditional foods by changing the timing of migrations and the locations of vegetation. If the range of certain foods changes in response to climate change (for example, they move to cooler northern areas), they may not be available on the tribes' usual and accustomed harvest lands.

The USGS will provide the science needed to support the management of biological resources in this rapidly changing world. Studies of past climatic and environmental changes provide insights into how life on our planet reacts to largescale changes in climate and atmospheric chemistry. Extensive long-term physical, chemical, and biological monitoring efforts allow the USGS to determine how species and ecosystems are responding to climatic and land-use changes at local to continental scales. Efforts such as the National Phenology
Network, the National Climate Change and Wildlife Science Center (NCCWSC), and the regional Climate Science Centers (CSCs) will enhance USGS capabilities to support resource managers in areas such as the following:

- Forecasting and scenario development of climate impacts to fish, wildlife, and habitats - Climate Science Centers will use predictions from an ensemble of climate scenarios to assess the effect of precipitation and temperature changes on stream hydrology and the occupancy of streams by fish and mussels of interest to resource managers.

- Region-specific climate information-Climate Science Centers and research and development projects within the Climate and Land Use Change Mission Area will provide regional data products, such as derivative products developed using downscaled climate predictions (for example, vegetation dynamics, fish occupancy, and sea-level rise maps) that serve as a common scientific point of reference for resource managers in a region.

- Integrated monitoring design and protocols - Climate Science Centers will coordinate with NAWQA and the National Water Quality Monitoring Council to develop a comprehensive assessment of air, water, and terrestrial monitoring networks, by region, to allow researchers and managers to access information about possible monitoring data collected in geographic areas of interest.

- Development of best practices - the National Climate Change and Wildlife Science Center will provide national and multiregion syntheses and intercomparisons of science products developed by the CSCs, Landscape Conservation Cooperatives, and other collaborators, providing information useful to address large-scale management decisions.

- Thresholds in biotic responses to change - research on the critical rates of change pertaining to species distributions, phenology, genetic adaptation potential (that is, adaptive capacity), and ecosystem-level state changes will be conducted.

- Evaluation of adaptation strategies - the efficacy of decision frameworks (for example, Structured Decisionmaking) for implementing long-term adaptation strategies and management responses will be evaluated.

- Potential future impacts of climate and land-use change on ecosystems and ecosystem services - the relative vulnerability of habitats, ecosystems, and associated ecological services to climate impacts and other stressors will be evaluated. 
Attention will focus on identifying regions and ecosystems especially vulnerable (for example, coastal, alpine, desert regions) to the effects of changes in climate, land use, and other environmental factors. This will be done in concert with appropriate partners, including DOI bureaus, State natural resources and conservation agencies, and nongovernmental organizations.

\section{Vision Statement}

The USGS will provide scientific knowledge needed to manage the Nation's biological endowment affected by rapidly changing climate and land use.

\section{Major Questions}

- How will changes in climate and land use, cover, and condition affect local to regional ecosystem structure and function, and how will these ecosystem changes interact with climate, hydrology, and biogeochemical cycles? How will ecological response be affected by the spatial and temporal scales at which climate and land use varies and changes?

- How will changes in climate and land use affect species, populations, and ecosystems, and how will these changes affect the distribution and extent of current and potential species habitats?

- How will changes in habitat fragmentation or connectivity affect the ability of species and ecosystems to adjust their geographic distributions in response to global change?

- How will other critical ecological stressors (for example, invasive species, pathogens, altered nutrient cycles, insect outbreaks) interact with climate and land-use change to affect ecosystem components and processes?

\section{Strategic Actions and Products}

Short Term (1-5 Years)

- Investigate how biological systems (including soil biota and their activities/processes) have adapted to past changes in climate, land use, and atmospheric chemistry.

- Create dynamic, nationally integrated maps of the distribution of species, their habitats, and other factors that may control their distribution (for example, insects, pathogens, disease).

- Work with other agencies and the broader scientific community to establish standards, priorities, and networks to better monitor ongoing changes in species, ecosystems, and landscapes associated with changing abiotic and biotic factors.

- Develop regional and national science agendas in collaboration with resource managers and scientific experts; use these agendas to identify commonalities and issues.

- Identify thresholds in key processes that occur in response to global change in terrestrial and aquatic ecosystems.

- Identify ecosystems most vulnerable to global change (for example, coast, alpine, desert) and develop research and monitoring strategies for these areas, including documenting their biodiversity, baseline conditions of processes and biota, and the response of these processes and biota to future changes.

- Assess current and likely future habitat fragmentation and connectivity in targeted landscapes and identify the role that wildfires may play in that fragmentation.

Longer Term (5-10 Years)

- Document diversity from genetic to population scales for plants, soil microorganisms, and fish and wildlife species of concern.

- Identify specific ecosystem thresholds, their potential reversibility, and their environmental consequences, as well as associated uncertainties, to the interacting positive and negative effects of climate, land use, and other environmental drivers through evaluation of long-term monitoring, paleo-environmental, and model data.

- Develop integrated process models that combine landscape properties; land use, cover, and condition; and disturbances with climate, hydrological, biogeochemical, ecosystem, and other process models to predict impacts of future changes.

- Examine how changes in external drivers (for example, invasive species, pathogens, altered nutrient cycles, insect outbreaks, wildfires) interact with global changes to affect ecosystem components and processes.

- Investigate the mechanistic relations among soil biota and decomposition rates, nutrient dynamics, and soil organic matter stability and how these relations affect ecosystem structure and function, including carbon cycles. 


\section{Plant and Ecosystem Responses to Climate and Land Use on the Colorado Plateau}

Paleorecords show that drylands in the western United States were once coniferous woodlands. With current warmer and drier conditions, these areas are dominated by grasses and shrubs. Global models predict that future conditions will be even hotter and drier, resulting in a decrease in soil moisture and, thus, lowered growth and survival of desert plants. Three lines of USGS research indicate that grasses will be especially vulnerable to higher temperatures. First, analysis of a 20 -year vegetation monitoring record in protected national parks across the Colorado Plateau indicates that many perennial plants, especially native perennial bunchgrasses, decline in abundance with warmer temperatures (upper graph and both pictures). Second, native bunchgrasses growing under lamps warming the soils $2^{\circ} \mathrm{C}$ have significantly lower photosynthesis and higher mortality rates than those without additional warming. Third, grasses under shelters that exclude 30 percent of incoming moisture (imitating the effect of warming on soil moisture) are also dying, whereas those outside the shelters are not.

Declines in perennial grass cover, coupled with compressional disturbance to biological soil crusts-the community of cyanobacteria, mosses, and lichens that hold the soil together-can push these ecosystems past a tipping point, accelerating land degradation and the loss of biological resources. A decline in perennial grasses and biocrusts accelerate the magnitude of dust storm activity over a range of wind speeds (lower graph), which has negative effects on human and ecosystem health. Dust deposited on the snowpack accelerates melt rates. This increases evaporative loss as soils are exposed longer and results in less water entering streams. Perennial grasses are at the base of the food chain, and their decline can reverberate throughout the system. Loss of perennial grasses also can make the ecosystem more susceptible to invasive species and increase fire frequency, causing reductions in native plant and animal diversity.

The graphs show $A$, perennial grass and all perennial vegetation cover, and $B$, modeled wind-driven sediment flux at five wind speeds in relation to mean annual temperature in the previous years in perennial grasslands. From Munson and others (2011).

Repeat photographs of Chesler Park, Utah in a year with $A$, cool, wet conditions, and $B$, dry, hot conditions.
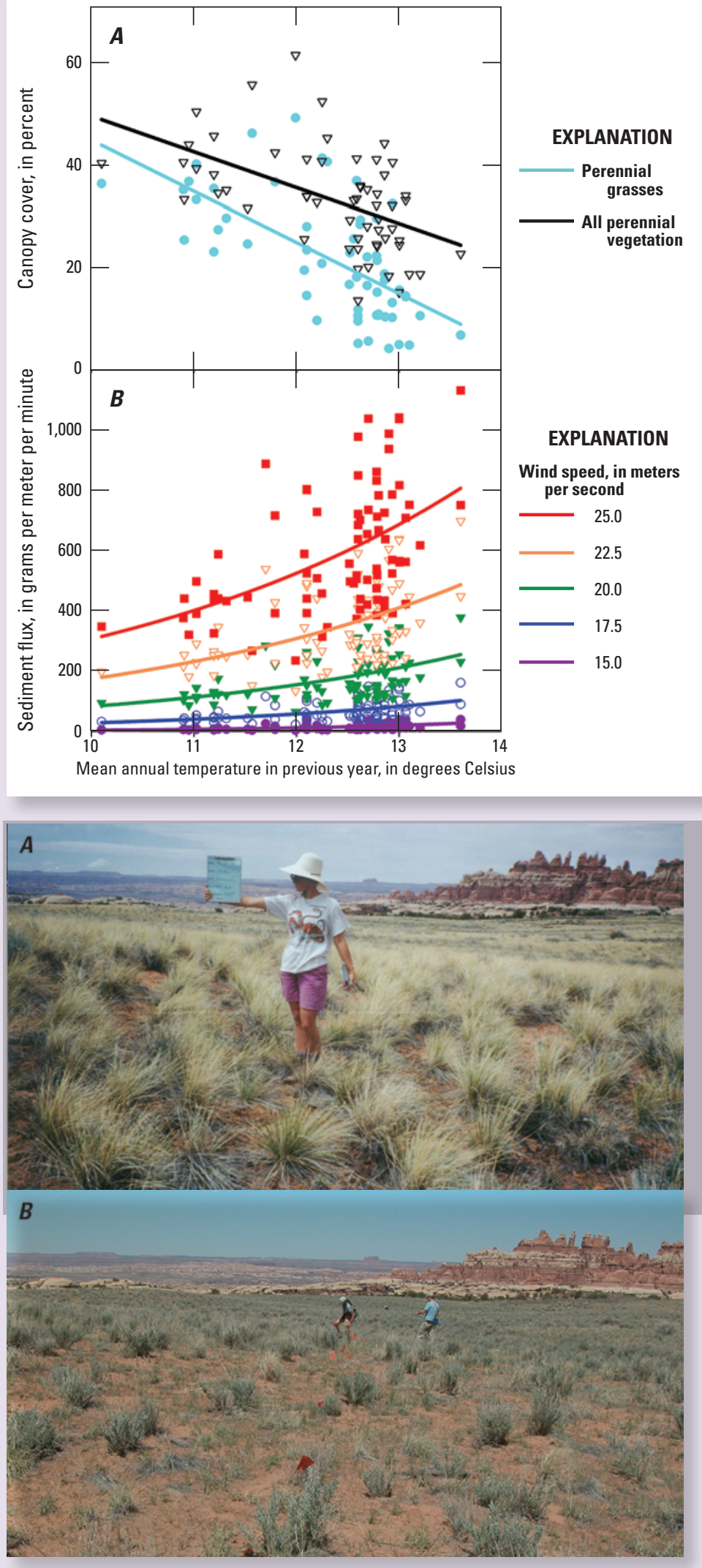


\section{Monitoring: A Critical Component of Global Change Science and Adaptive Resource Management}

A strong, relevant, and integrated monitoring program is a foundation of global change research and the USGS Climate and Land Use Change Mission Area. Tracking factors of environmental change and their effects on natural resources is a high priority for DOI bureaus and other resource-management partners at the State and Federal levels. Meeting current and future challenges in monitoring and detecting an expanded range of environmental variables will require the USGS to upgrade, improve, and in some cases reposition its current networks. Innovative approaches and new perspectives can be used to address an expanded range of environmental variables. Effective partnerships with other institutions monitoring global change and its impacts on natural resources will maximize efficiencies by jointly planning and implementing monitoring strategies.

The USGS Science Strategy (2007) recognized the central role of monitoring, recommending that global change research should rely on existing "....decades of observational data and long-term records to interpret consequences of climate variability and change to the Nation's biological populations, ecosystems, and land and water resources." Some of the monitoring needs to address this plan's science goals and objectives are listed in the following examples:

- Detection of changes and trends in shorelines in response to sea-level rise, subsidence, storms, and human development; trends in accretion rates; and other processes that affect sustainability of coastal systems.

- Timing, amounts, and availability of water; impacts of droughts and floods on terrestrial and aquatic resources.

- Rates and geographic extent of land-use and land-cover change.

- Effects of human activities on landscape properties, nutrient, and carbon cycling.

- Changes in abundance and distribution of plants and animals; trends in variables that indicate ecosystem condition.

The necessity to monitor interdependencies among global change drivers and their effects highlights the need for an integrated, Bureau-level monitoring emphasis and strategy.

Throughout its history, the USGS has been a national and international leader in the conception, design, and implementation of cooperative monitoring networks to track environmental indicators. USGS remote sensing capabilities, for example, provide data for more than 40 years of evidence of global changes in the Earth's land and water, and USGS hydrologic monitoring networks provide historical data, in some locations, to the late 19th Century. USGS monitoring capabilities include nationwide monitoring of hydrology, land cover and land use, migratory birds, species-through-ecosystem conditions, and phenology. USGS monitoring platforms range from detailed plot scales, to widely distributed streamgage networks, and airborne and satellite imaging systems.

Many current monitoring protocols and networks were designed with other data needs in mind and may not be capable of detecting and tracking the changes anticipated in response to climate-driven global-level change trends. Existing monitoring efforts need to be evaluated for the following reasons. First, priorities for monitoring locations may change. USGS streamgages are at many locations that are important for flood prediction and reservoir management and are commonly funded on a cooperative basis but may not be capable of monitoring areas sensitive to global change. The monitoring of plant or animal populations designed to detect the effects of one threat may need to be changed to address new issues. Second, global change effects may require significant increases in monitoring for emerging issues, such as dust, nitrogen deposition, and carbon and sediment transport in rivers. Third, it will be increasingly important to establish multivariable monitoring networks, where hydrologic, biotic, meteorologic, and other factors are measured at the same locations. Placement of sites needs to be planned such that these in-place measurements can be "scaled up" to a larger geographic context to provide comprehensive monitoring of plants, animals, and ecosystem condition and to detect land changes in areas that lack in situ monitoring. Synoptic monitoring of selected geoand biophysical variables using remote sensing is an important tool in scaling up plot data and, therefore, in assessing how human and natural disturbances affect physical landscapes, plants, animals, and ecosystem condition. With its rich historical land remote sensing archive, the USGS can provide the consistent, calibrated terrestrial time-series datasets needed to detect and monitor global change events and processes. However, as with other monitoring activities, land remote sensing systems will need to be managed specifically to detect and understand biotic and abiotic conditions and trends attributable to global change.

The USGS can lead evaluation and design of new multipurpose, multivariable monitoring networks even as it continues quantitative enhancements of existing monitoring systems to assure data for timely, reliable, and authoritative detection and attribution of global change impacts.

Monitoring at multiple spatial and temporal scales with locally to nationally consistent measurements and integrated data products will require coordination among Climate and Land Use Change, other USGS mission areas and programs, and our external partners engaged in monitoring (for example, States, NOAA, NASA, NSF, U.S. Army Corps of Engineers, Bureau of Land Management, National Park Service, and 


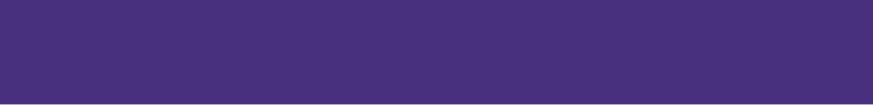

Droughts have had significant effects on landscapes of the United States, particularly in the semiarid Great Plains region, as shown in the adjacent images.

In the Great Plains, large areas of landscape are covered with stabilized (vegetated) sand dunes. During dry periods, when there is too little precipitation to sustain vegetation, sand dunes can become active again. Shown here are two aerial photographs of the same landscape in the Great Plains region, on the New Mexico-Texas border. In recent decades, such as in this 1991 photograph $A$, dunes are largely stabilized by vegetation. During the 1930s drought, however, many of these dunes were fully active, as shown in the 1936 photograph $B$. Reactivation of Great Plains dunes in a future drought would impact thousands of square kilometers of the region and have significant effects on grazing land, cropland, wildlife habitats, and infrastructure.

\section{A. Quay County, New Mexico, 1991}

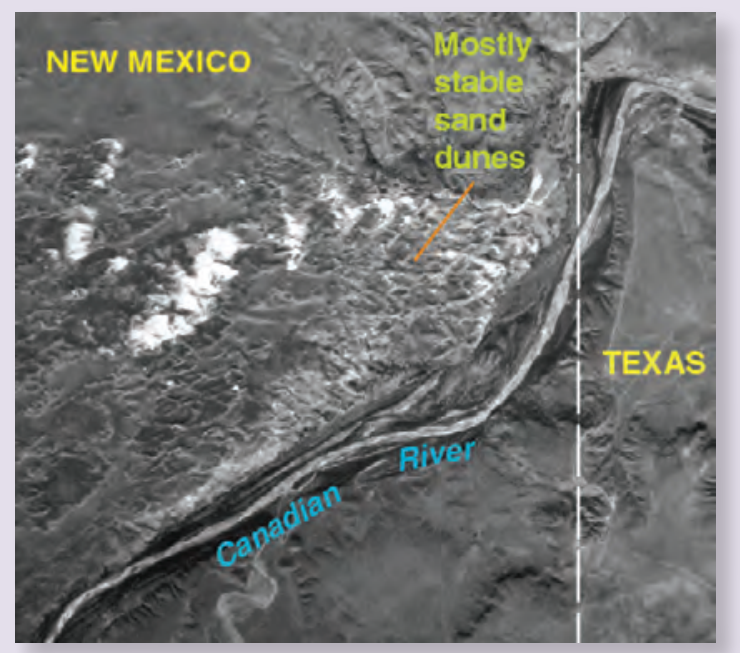

\section{B. Quay County, New Mexico, 1936}

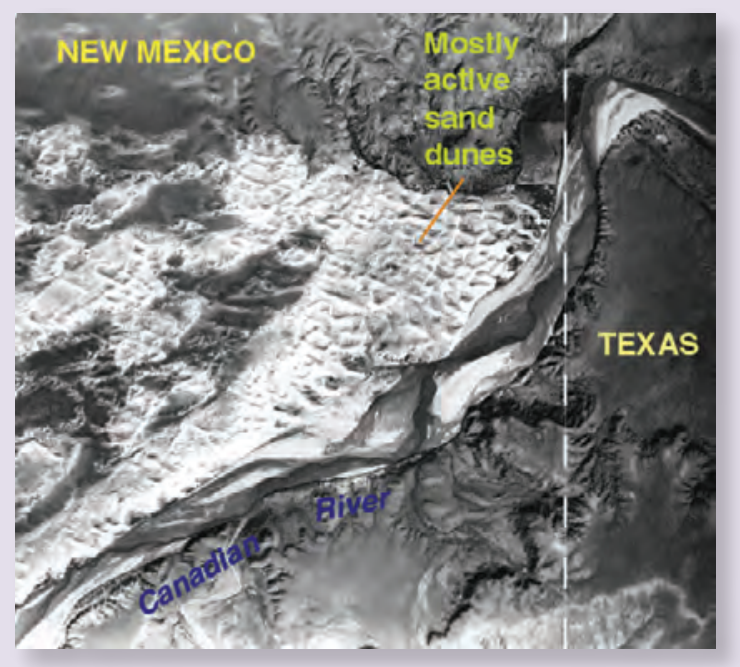

tribal groups). Coordination will strengthen each organization's efforts, help develop common protocols, allow better interoperability among databases, and effectively communicate results to all, including policymakers and the public.

Three specific actions will help guide the USGS in designing and instituting an integrated and strategic monitoring plan:

1. Establish a standing USGS Monitoring Advisory Group, comprised of representatives from USGS science centers and mission area national-level programs, to determine what global change monitoring efforts are best suited for the USGS:

- Identifying core USGS monitoring strengths.

- Expanding and confirming future monitoring needs outlined in this report.

- Identifying gaps where USGS core monitoring capabilities could be applied.

- Identifying and recommending research needed to support monitoring efforts.

- Recommending ways to modify current monitoring efforts to better detect global change and the protocol development needed to enhance detection of global change.

- Recommending ways to fill the voids in monitoring that hamper progress toward the science goals described in Section 3 of this document.

2. Work with partners to establish a standing Interagency Monitoring Advisory Group comprised of representatives from the USGS Monitoring Advisory Group (above) and external partners to develop a clear monitoring strategy spanning site-specific to global scales. This monitoring strategy will minimize duplication of effort and maximize coverage, integration, reliability, and timeliness of global change detection through partnerships. The group is needed to address the following key questions:

- Do our existing monitoring networks and activities support high-quality basic scientific research?

- What data are needed at what scales for accurate detection of long-term change?

- Are current observational and monitoring networks adequate for detecting changes associated with global change in a timely and reliable manner? 
- How can partnerships enhance existing and planned networks; what will be the governance for these partnerships; and who would be responsible for what data?

- What new methods, standards, sites, and observations need to be developed and integrated to provide the monitoring necessary for change detection, attribution of causes of change, and management of consequences?

- How can new data, previously collected information, and data from different observational methods and different agencies be integrated in a manner most useful to scientists, managers, policymakers, and the public?

- How do we monitor opportunistically after extreme climatic events and ecological disturbances, such as in evaluating pathways of succession after episodes of fires, insect outbreaks, and plant die-offs synchronized at the regional to sub-continental scale (for example, the 2002-2003 drought in the American West)?

- How can remotely sensed and in situ data be most effectively integrated to develop consistent time series useful for detecting and monitoring evidence of global change?

- How can data from the geologic record, historical data, and newly collected data best be used to assess the efficacy of models that simulate observed environmental responses to climate change and land use?

- How can information from data-model comparisons best be used to improve our ability to project potential future changes in plants, animals, and water resources?

- How can long-term or spatially extensive datasets best be used for detection of global change? For example, how best can migratory bird information or historical photos and images for change-detection maps of critical and sensitive areas be used to detect global change?

3. Enhance and ensure effective USGS monitoring of global change phenomena through the following actions:

- Manage national land remote sensing assets; implement, in conjunction with NASA, Landsat and other satellite missions; develop calibrated and validated geophysical measurements and integrated data products with the accuracy and precision needed to map, measure, and monitor land changes attributed to climate change, other natural disturbances, and human activity; and identify and evaluate new remote sensing technologies to provide measurements needed to detect and monitor global change.

- Use recommendations from the advisory groups above to establish or enhance monitoring sites in areas highly vulnerable to global change. Multiple variables (hydrologic, climatic, biotic processes and components, socioeconomic, and other factors) will be measured at these sites in ways that allow the advisory groups to answer local- to national-scale questions through the integration of both data and modeling.

- Maintain and enhance more specialized networks (for example, streamgages, dust sources, deposition, and animal populations) where needed to detect global change.

- Ensure that the life cycle of data gathered by monitoring networks includes quality assurance and control, management, and dissemination plans.

\section{The Colorado River runs dry on the United States-Mexico border 2 miles below the Morelos Dam. Photograph taken January 13, 2009, by Pete McBride, USGS.}


The international climate-change community requires consistent global observations and measurements for climate monitoring. To accomplish this goal, "essential climate variables" measuring the atmosphere, oceans, and land have been defined that are technically and economically feasible for systematic observation and are needed to meet the goals of the U.S. National Assessment and a host of international groups conducting climate-change assessments. Several of the 14 land climate variables referred to as Terrestrial Essential Climate Variables (ECV) can only be measured by in situ observation, whereas others are suitable for measurement by remote sensing technologies. USGS has initiated the development of ECVs from data collected by the Landsat missions, which constitute the longest continuous record of satellite observations of the Earth's land surface. The 40-year Landsat record represents the longest and most comprehensive global record of global land change ever assembled. This record is particularly valuable for differentiating between human-caused and natural change. The development, calibration, and validation of terrestrial ECVs from the Landsat record will require the integration of airborne, satellite, and in situ measurements using robust data assimilation and modeling techniques.

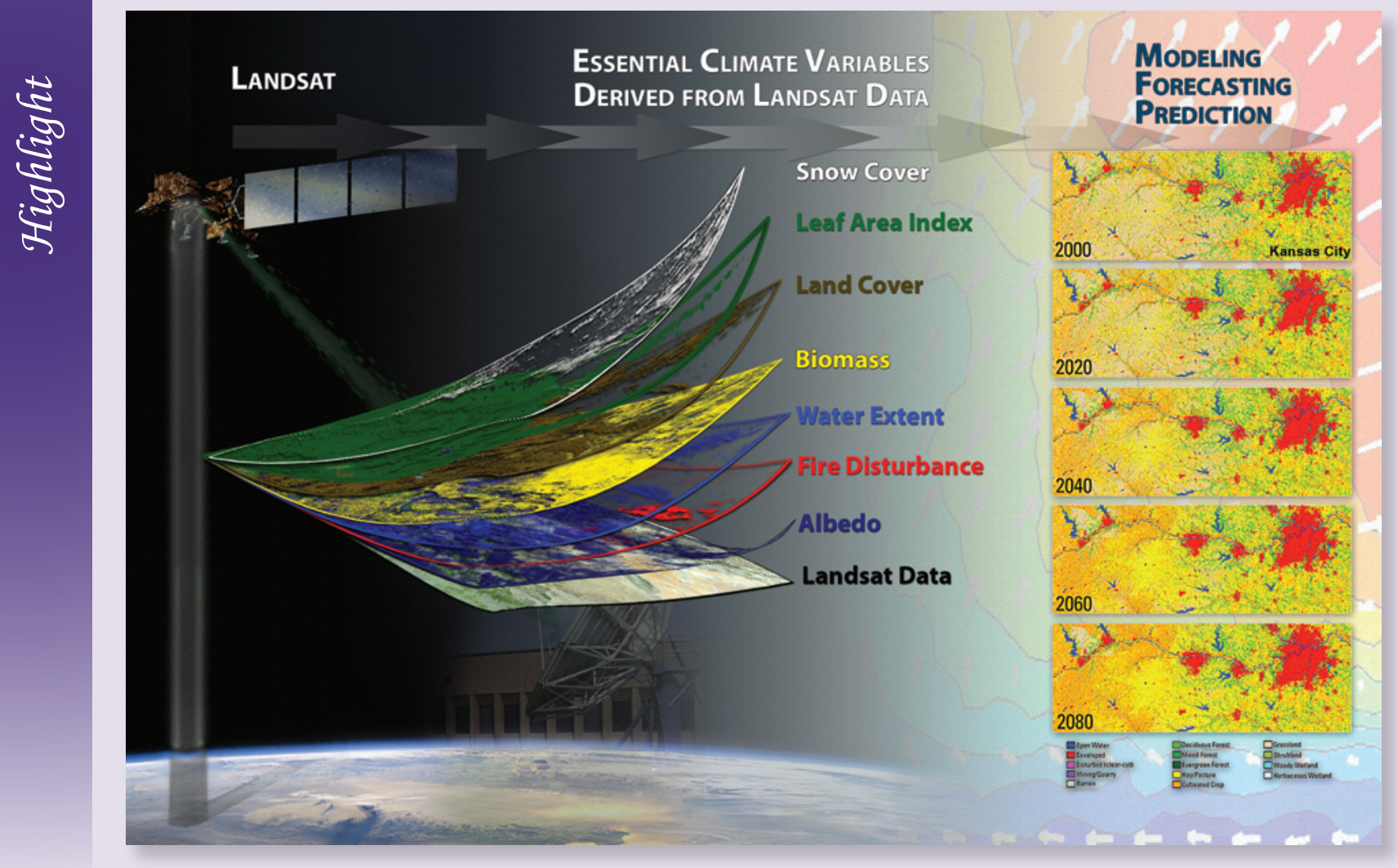

Landsat 4 satellite images showing the development of sediment-established land over time in the Wax Lake Delta region in Louisiana. 


\section{Interrelations of Climate and Land Use Change and Other Mission Areas}

This Climate and Land Use Change Science Strategy emphasizes research and development activities that embrace the broad definition of global change, referenced at the beginning of this circular, that includes alterations in climate, land productivity, oceans or other water resources, atmospheric chemistry, and ecological systems that may change the capacity of the Earth to sustain life. This science strategy applies this concept of global change to define the USGS tradition of conducting science to assist society in understanding and responding to changes in the environment at all spatial scales.

The seven goals for CLU each interact with the other six mission areas to various degrees. Climate and land-use change science will support the activities of the other six science strategies through integrated scientific research, monitoring, and modeling activities on a wide range of topics. The seven USGS science missions will be coordinated (fig. 4) such that research projects, topical expertise, databases, and field activities and laboratory facilities are made available to decisionmakers in a seamless way. The following section summarizes some complementary activities shared among USGS mission areas.

Core Science Systems. - Geographic, geologic, hydrologic, and biologic data on Earth systems are essential information to any investigation and evaluation of the impacts of climate and land-use change. To understand the causes and effects of climate and land-use change, core science information is needed through time and over space. Monitoring networks, including data collection, storage, dissemination, analysis, and observation registries, are key components of Core Science Systems (CSS) that support integrated monitoring. The CSS concept of situational awareness offers a framework that facilitates and enhances integrated science. The focus on change within climate and land use will be strongly supported by the temporal component of the CSS situational awareness framework. Not only will diverse data be managed and discoverable for multiple uses and analyses, the results of analyses will be presented to the user community in an efficient, consistent manner.

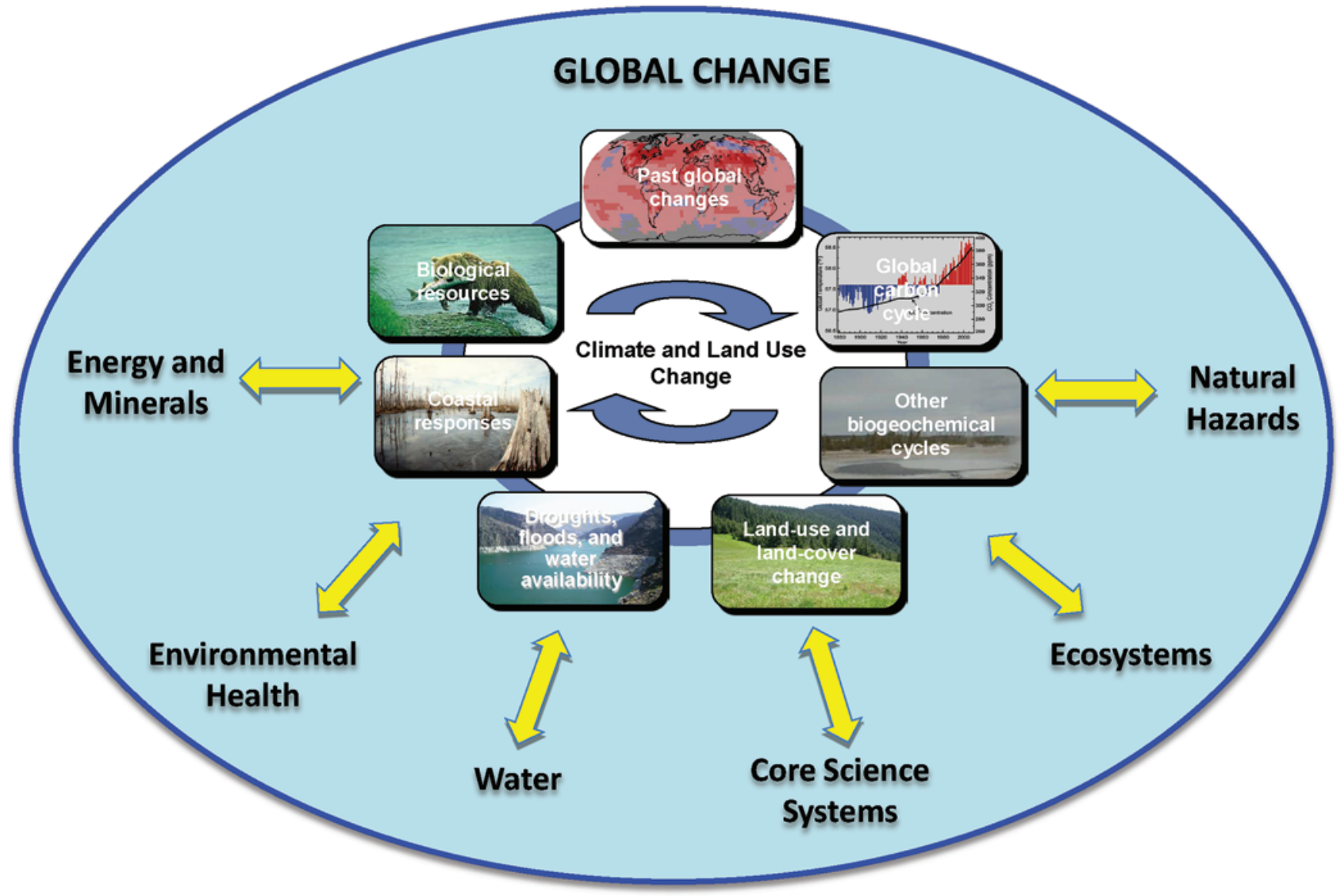

Figure 4. Climate and Land Use Change interacts with the other mission areas to understand global change. 
Ecosystems.-Ecosystems science gathers knowledge essential to climate and land-use change as it seeks to understand fundamental ecosystem processes and functions. Likewise, changes in climate and land use affect ecosystem functioning worldwide. For example, the loss of protective wetlands and coral reefs may have significant impacts on coastal communities given projected effects of global change that include sea-level rise and increased hurricane intensity. Developing integrated process models that combine landscape properties (for example, use, cover, condition) and climate with hydrology, biogeochemistry, ecology, and ecosystem processes to forecast impacts of future change for specific ecosystems across different scales will help identify the vulnerability of key species and ecosystems to changes in climate and land use.

Energy and Mineral Resources.-Energy and mineral resources strategies involve profound uses of, and impacts to, the land surface. To understand and forecast the changes in the landscape that result from energy and mineral resource-related activities require close coordination with climate and land-use change investigations. Forecasting the impacts of deep waste disposal for the geologic sequestration of carbon, investigating the land-use legacy of energy development sites, estimating the $\mathrm{CO}_{2}$ footprint of resource extraction, and anticipating landscape changes due to energy and mineral resource development are areas for collaborative research between these two mission areas.

Environmental Health.-Climate and land-use change affect environmental conditions that determine the distribution of contaminants and pathogens, ecological and human exposures, the severity with which they might cause disease, and their ultimate fate. These environmental factors include changes in distribution of pathogens, their hosts, and vectors caused by changes in habitat; the effects of changes in temperature and seasonality on disease processes in fish, reptiles, and amphibians; increases in contaminant loads and pathogen abundance from changes in the number and severity of extreme weather events; and increases in windborne contaminant and pathogen exposure pathways. The varied impacts of climate and land-use change also affect the susceptibility of aquatic and terrestrial organisms to other environmental stresses, making those impacts an essential consideration in the multiple stressors that could be affecting environmental health. The Environmental Health Science Strategy will be coordinated closely with the Climate and Land Use Change Science Strategy to ensure that global change factors affecting the environment are considered in environmental health assessments as well. The Environmental Health research activities and efforts to establish linkages with the public health community will assist assessments, particularly in regard to the human health implications of climate and land-use change.

Natural Hazards. - Climate change can have a direct effect on natural hazards, such as increased flooding and stronger, more frequent storms. Identifying and predicting how changing climates may affect certain hazards and estimating the impacts is a critical part of any adaptation strategy.
Similarly, land-use change also affects the impact of natural hazards and can be the determining factor in whether a natural hazard leads to a disaster or not. Understanding the impact of climate change on sea-level rise and coastal processes, for example, in conjunction with the vulnerability of coastal communities and infrastructure to environmental processes affected by severe storms and tsunamis, is one area of collaborative research. Hazard events, in turn, also can have an impact on climate and land use, such as volcanic ash in the atmosphere and sea-level rise. Evaluating the potential contribution of climate and land-use change to hazard exposure, vulnerability, and risk will play a central role in linking these mission areas.

Water-A comprehensive understanding of the effects of climate variability and land use on water availability at multiple spatial and temporal scales is important in the design of monitoring strategies for detecting change. Understanding past hydrological responses to climate change can help to distinguish between natural and human influences on water availability. Predicting future changes in the quantity and quality of water resources in response to climate and land-use change requires the development and application of models to predict the potential effects of changes in population, land use, climate, and management practices on future water availability. Scenarios need to be developed to quantify the response of the hydrologic system (for example, infiltration, runoff, and sediment transport) to land uses such as urbanization, agriculture, grazing, forestry practices, and water-retention projects. The new national water census will provide a complete data and interpretive framework for assessing potential impacts of climate and land-use change; linkages among climate and land use and water quality will inform the National Water Quality Assessment Program; linking plausible scenarios of water- and land-use changes with corresponding climate and socioeconomic scenarios will help to understand the effects of land-use and climate changes as they become increasingly significant to the Nation's water resources. Existing and planned monitoring networks that address a variety of water resource management needs should be configured to best capture the impacts of changing climate and land use.

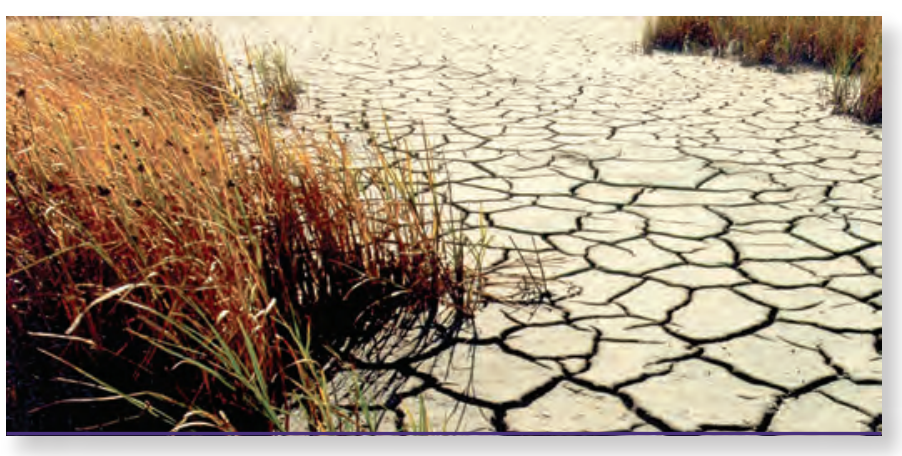

The Vegetation Drought Response Index (VegDRI) incorporates satellite observations of vegetation to monitor at a finer spatial detail than other commonly used drought indicators. Photograph by USGS. 


\section{Communicating Science to Society—Services, Products, and Delivery}

Recognition by policymakers, resource managers, and the public of the increasing pace and unpredictability of global change is generating increased demand for information about the nature of impending changes and how to respond to them effectively. There is also consensus, within the USGS and elsewhere, that the nature of projected future environmental change will require expanded and better integrated scientific and observational activities and that those adaptation strategies will be enhanced by landscape- and regional-level partnerships of science and management.

USGS scientists will meet the needs of our changing world by providing timely, scientifically sound, state-ofthe-science information on global change and its effects in a variety of formats and venues. USGS science is used by a wide range of people and institutions, from highly technical, global-scale scientific collaborations to individuals seeking information on river stages for recreational boating. The USGS delivers science in multiple forms, which include Web-enabled databases, peer-reviewed literature, and technical assistance to resource managers. The portfolio of scientific activities described in this strategic plan will complement the work of a large array of international, Federal, State, tribal, NGO, academic, and private partners.

\section{Services and Products}

\section{Research Results-From Fundamental to Applied}

USGS global change research consists of investigating the fundamental biological, hydrological, geological, chemical, and physical processes that underlie global stressors and environmental response. Results of these scientific investigations will serve as the building blocks for additional scientific progress and can be applied to a variety of outputs and tools.

1. Research findings: USGS scientists, as active members of a global scientific community, will continue to contribute to the growth of scientific knowledge about how the Earth system functions. In addition to providing building blocks for additional scientific progress, many research results are used by managers directly, often with significant assistance, advice, and collaboration from USGS scientists. This direct and hands-on interaction is often crucial to effective transfer and application of research findings.

2. Assessments: Assessments provide scientific synthesis and analysis of patterns, trends, pace, and global, national, regional, and sectoral issues affecting Earth systems. They provide key findings, new understanding, strategies, and new or improved methods that can assist and guide policymakers and resource managers in monitoring, mitigation, and adaptation decisions linked to global change and in providing information to the public. Assessments by the USGS and its partners will use existing and new observations to detect and describe effects of global change on natural resources, environmental conditions, and people.

3. Methods and tools: Standard methods and tested tools provided by the USGS further the standard for scientific and management knowledge. Among these products are dynamic, mechanistic, statistical, conceptual, and other types of models that portray how global systems behave at multiple temporal and spatial scales; the likelihood and consequences of actions, drivers, interrelations, trends, and forecasts; and consequences of adaptation and mitigation techniques. Also included are basic research, field and laboratory techniques, monitoring-program designs, and data-integration methods.

\section{Modeling and Projection}

Understanding how natural systems function and observing their past and present behavior form a powerful intellectual basis for making informed statements about the future. USGS scientists develop and participate in a wide range of modeling efforts, from projections of flows, particularly streams under changed climatic conditions, to tackling crucial elements of global models used by the IPCC.

These models continue to evolve as fundamental knowledge of natural systems grows through expanded research and observation and as modeling techniques are refined. The USGS will work to enhance and evolve USGS modeling to reduce uncertainty through consistent modeling approaches; integration and linking hydrologic, geologic, ecologic, and land-use projections of change; and expanding access to resulting data.

\section{Technical Support}

A goal of USGS global change science is to translate and deliver scientific results of maximum value to other scientists and natural-resource managers. Transferring scientific knowledge for application to real-world problems is facilitated by direct interaction among scientists and resource managers or decisionmakers. The USGS will continue to strengthen this capability by encouraging interaction among individual scientists. USGS programs and stakeholders, including resource managers and the public, will use these interactions to develop decision-support tools to help communicate with stakeholders within an adaptive management framework. This nexus between science and management will ensure that USGS science programs respond to management needs and that resulting science products are accessible, appropriately translated, and effectively applied. 


\section{Enabling Efficient Transformation of Data to Knowledge}

The USGS has a unique legacy as the producer of longterm datasets for multiple uses, many of which are geographically extensive. Complex scientific questions posed by global change and its impact on Earth systems require analysis, integration, synthesis, and modeling of science data and information from multiple disciplines, locations, and timescales. Complex data, models, and other information from a variety of sources, in different formats, spatial scales, and resolutions, will need to be integrated and made available for policymakers, resource managers and partners, and for public use. A comprehensive global change informatics strategy for data and infrastructure will enable scientists, partners, and stakeholders to create, disseminate, find, access, and use new and existing global change data from the USGS and other sources.

\section{Delivering Science-USGS Framework for Collaboration and Communication}

The USGS recognizes that if science is to be responsive to societal needs, we must communicate effectively with those who use the products of our global change science. USGS will take advantage of its national presence to expand communication and collaboration. This plan supports a coordinated multiagency (Federal, State, tribal, and local) national strategy that renews and expands communication and collaboration efforts that will integrate climate and land use and efficient use of resources.

\section{Collaboration}

The USGS has been participating in and collaborating with the international and national scientific community to address global change for 20 years and will continue to do so. One example of the global change science initiatives undertaken within DOI is the establishment of the NCCWSC. DOI Secretarial Order No. 3289 issued on September 14, 2009, lays out a Department-wide plan for "Addressing the Impacts of Climate Change on America's Water, Land, and Other Natural and Cultural Resources" (Salazar, 2009). This order charged the USGS with leading the establishment of eight DOI regional Climate Science Centers as primary components of the DOI climate-change response strategy. DOI's regional Climate Science Centers and the NCCWSC are essential vehicles for implementing this USGS Science Strategy as well as achieving many of the specific goals contained in the DOI Strategic Plan.
The USGS NCCWSC, in collaboration with the Climate Science Centers, DOI Landscape Conservation Cooperatives, and NGOs, is jointly designing and implementing research and monitoring activities and technical support and translation of research results for application in a management context and in a manner that directly supports the management needs of partners and advances societal understanding and adaptation to global change. The NCCWSC is a strategic source for USGS Global Change collaboration and communication efforts, engaging partners at the national, State, regional, and local levels.

1. National: The framework for collaboration among U.S. Federal agencies is the U.S. Global Change Research Program (USGCRP). The USGCRP Office and its interagency working groups (IWGs) each provide vehicles for communicating and promulgating USGCRP science. The USGS maintains its involvement and representation on these IWGs as an effective way to integrate USGS science and science planning with others, to ensure that high-priority issues for the USGS and its partners are reflected in the national agenda for adaptation science, and to increase visibility for USGS science.

2. Regional: The USGS recognizes that increased collaboration at landscape and regional scales is needed to address global change. The USGS has established eight regional Climate Science Centers as part of a larger DOIwide climate partnership initiative that also includes the Landscape Conservation Cooperatives, which function as management science interfaces involving State and Federal partners.

3. State and local: States are partners in the full range of USGS scientific products, and demand for these products is increasing as States expand their efforts to adapt to a variety of land and ecosystem changes. States have major management responsibilities that will be affected by global change, and they devote significant management and science resources to these issues. Local governments, tribes, and private resource managers also are expanding their efforts to address these changes and, in doing so, are looking to the USGS for critical information. Interactions with these partners involve identifying management concerns, jointly designing and implementing research and monitoring activities, and providing technical support and translation of research results for application in a management context. 
The USGS National Climate Change and Wildlife Science Center (NCCWSC), based in Reston, Virginia, has played a leadership role in establishing DOI's eight regional Climate Science Centers (CSCs). The CSCs will leverage USGS and other Federal scientific capabilities and new universitybased capabilities and link directly to DOI Landscape Conservation Cooperatives as well as many other public and private resource managers and scientists. The CSCs will produce partner-driven science that improves understanding of a wide variety of global changes and that assists managers in adapting to these changes. CSCs and NCCWSC will accomplish the following activities:
- Work with management partners to identify and prioritize science needs,

- Develop relevant climate and land-use forecasts,

- Improve understanding of the effects of likely global changes on valued natural and cultural resources, and

- Identify lands, resources, and communities that are most vulnerable to adverse impacts of change.

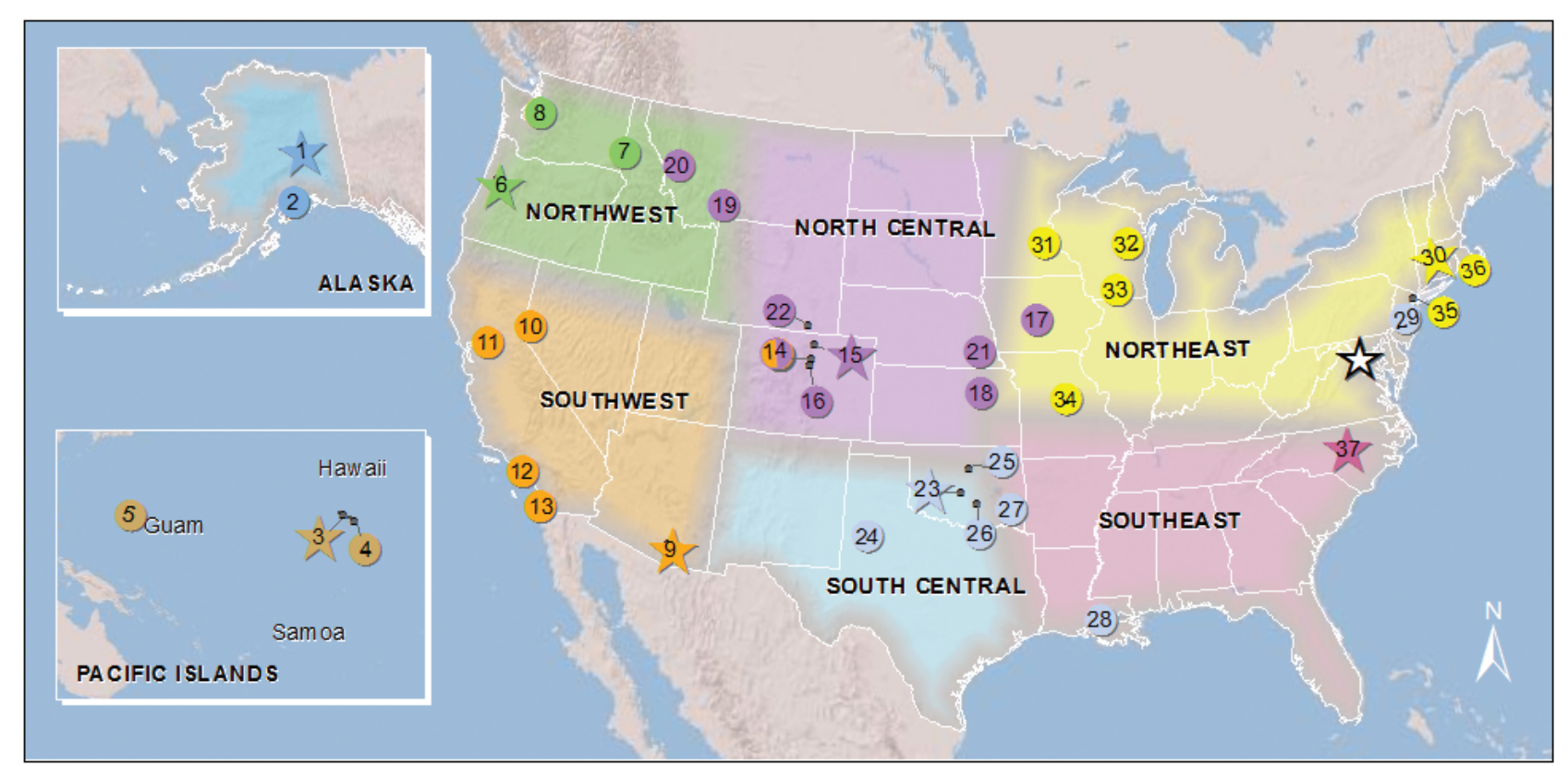

Base from Esri, 2009, Albers Equal-Area Conic projection, North American Datum of 1983

EXPLANATION

National Climate Change and Wildlife Science Center

Climate Science Center (CSC) lead institution

2) CSC institution

Alaska CSC

1. University of Alaska-Fairbanks

2. University of Alaska-Anchorage

Pacific Islands CSC

3. University of Hawai i at Manoa

4. University of Hawai i at Hilo

5. University of Guam

Northwest CSC

6. Oregon State University

7. University of Idaho

8. University of Washington

Southwest CSC
9. University of Arizona
10. Desert Research Institute (Nevada)
11. University of California-Davis
12. University of California-Los Angeles
13. Scripps Institute of Oceanography
14. University of Colorado
North-central CSC
14. University of Colorado
15. Colorado State University
16. Colorado School of Mines
17. Iowa State University
18. Kansas State University
19. Montana State University
20. University of Montana
21. University of Nebraska-Nebraska
22. University of Wyoming

Southwest CSC

University of Arizon

. Desert Research Institute

12. University of California-Los Angele

13. Scripps Institute of Oceanography

rth-central CSC

14. University of Colorado

15. Colorado State University

17. Colorado School of Mines

19. Montana State University

21. University of Nebraska-Nebraska

22. University of Wyoming
South-central CSC

23. University of Oklahoma

24. Texas Tech University

25. Oklahoma State University

26. Chickasaw Nation

27. Choctaw Nation of Oklahoma

28. Louisiana State University

29. National Oceanic and Atmospheric

Administration Geophysical Fluid

Dynamics Laboratory

Northeast CSC

30. University of Massachusetts-Amherst

31. University of Minnesota

32. College of Menominee Nation

33. University of Wisconsin-Madison

34. University of Missouri-Columbia

35. Columbia University

36. Marine Biological Laboratory 


\section{Communication}

Good communication is critical to enhancing productivity, coordination, and effective planning in any shared endeavor. Improved internal communication was cited as a high priority by USGS scientists at 2006 and 2010 USGS Global Change Science Workshops. Providing opportunities for linking our scientists and keeping them apprised of program developments, opportunities, and science planning also were cited as needs by field scientists and by participants from USGS regional offices and other DOI bureau representatives at both workshops. Improving internal communications should be a top priority for global change activities in FY2013 and beyond.

Uncertainty is a fundamental characteristic of the scientific products that USGS scientists produce to describe and understand the world we live in. Communicating the nature and impacts of uncertainty presents substantial challenges for USGS scientists. A misunderstanding about the meaning of scientific uncertainty may inhibit or even distort decisionmaking critical for mitigating or adapting to climateassociated risks. Developing and implementing a strategy to improve understanding and use of climate-related predictions, particularly pertaining to risks, vulnerabilities, and proposed mitigation/adaptation activities, should be a priority for USGS science.

The following actions can be initiated to promote sustained communication of its global change science:

- Regular national USGS global change research workshops to integrate efforts and information flow throughout the Bureau.

- Internal self-subscribed mailing lists and Web sites at the level of major global change programs, for each of the seven science goals (discussed in the Science Goals and Objectives Section), and for each of the USGCRP IWGs, as well as at the broad disciplinary and interdisciplinary collaborative levels.

- An integrated global change information gateway with both internal and external components for collaboration and seamless access to projects, resulting data, models, information, decision-support tools, and derived products that highlight services of global change research and increase its visibility, effectiveness, and transparency. In addition to improving internal communications, this Science Strategy Planning Team recommends improving external communications through the USGS Global Change Web site. As part of the home page, in coordination with other Federal agencies, the USGS could develop a public outreach initiative specifically to translate and communicate complexities of global change research in a clear and consistent manner to the American public to highlight implications of this research to human and ecological landscapes. Success of such an initiative would improve the public's understanding of global change research findings. The USGS Office of Communications and Publishing should continue to support the program through its contacts with the news media, press releases, social media, public presentations, and Congressional hearings and presentations.

- A small committee of USGS scientists and communications experts could be formed to develop an internal and external communications strategy. This group could provide advice concerning the USGS Climate and Land Use Change Web site and consider the initiative concept above. The team also could identify actions that would improve communications about program developments among USGS managers and scientists, such as internal newsletters or Intranet postings, periodic workshops for scientists, and Webinars.

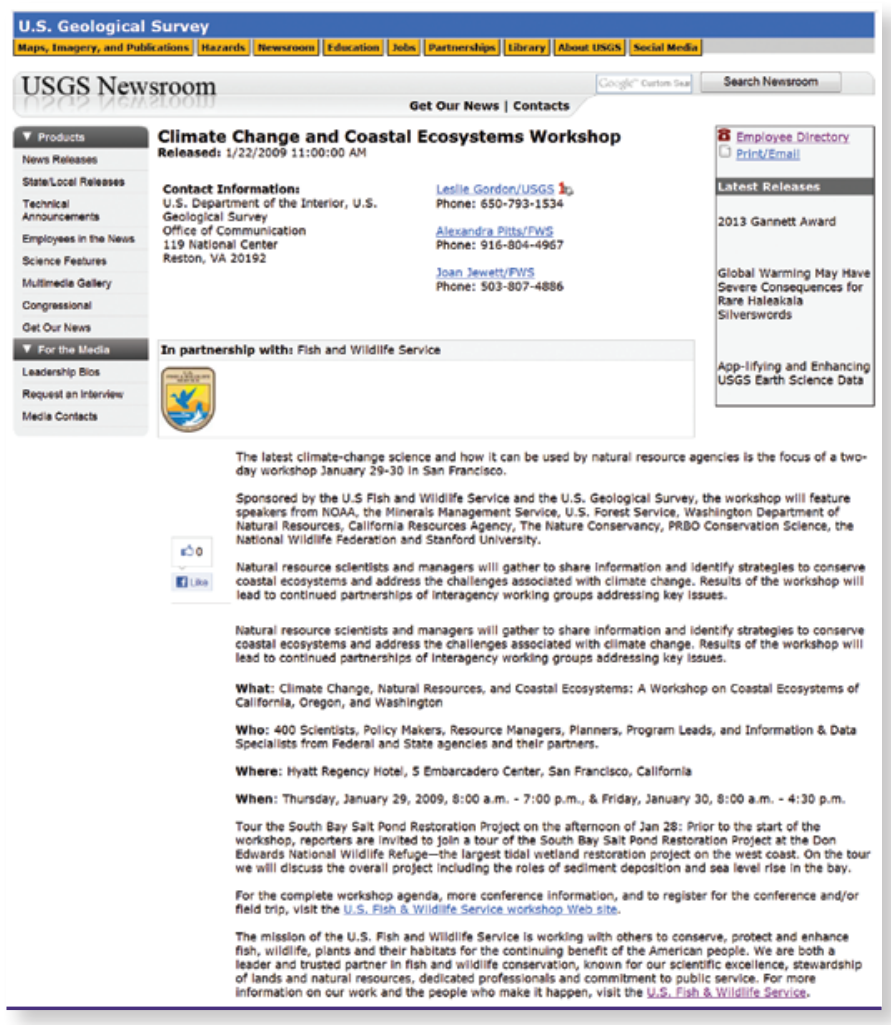

Periodic national USGS global change research workshops will integrate efforts and information flow throughout the Bureau. 


\section{Summary-Understanding and Responding to Climate and Land-Use Change}

Natural processes, in combination with the effects of human actions, can result in global changes with substantial potential consequences for the natural world and society. Uncertainty about these changes and their consequences limits the Nation's ability to respond appropriately, and policymakers, resource managers, and the public are increasingly demanding more and better information to support mitigation and adaptation efforts. As the only integrated natural-resources research organization in the Federal Government, the USGS plays a critical role in providing the global change information that will help the economy, the environment, and human communities remain strong. By achieving the visions and goals presented in this science strategy, the USGS can become the Nation's leader and gateway for accessing information and understanding past, present, and future effects of climate and land-use change on natural resources and human communities. USGS global change research will help policymakers and resource managers make difficult decisions regarding the management and stewardship of lands, resources, and communities. This strategy emphasizes the importance of a coordinated intra- and multiagency (Federal, State, and local) national strategy that renews and expands communication and collaboration efforts with stakeholders and partners.
When implemented, this plan will accomplish the following:

1. Build on USGS leadership in global change investigations.

2. Fill knowledge gaps of how the natural and human-altered world is changing.

3. Extend strategic partnerships.

4. Improve communication and collaboration.

5. Ensure a sustained observational effort.

6. Address topics critical for managing natural resources and the environment, with tangible effects on environmental goods, services, and risks.

7. Use USGS core capacity, disciplinary strengths, integrative capacities, and long-term databases.

8. Invest in comprehensive, integrated observation and monitoring to understand local to global change processes and conditions.
View of calving glacier, Prince William Sound, Alaska, August 22, 2008. Photograph by Don Becker, USGS.

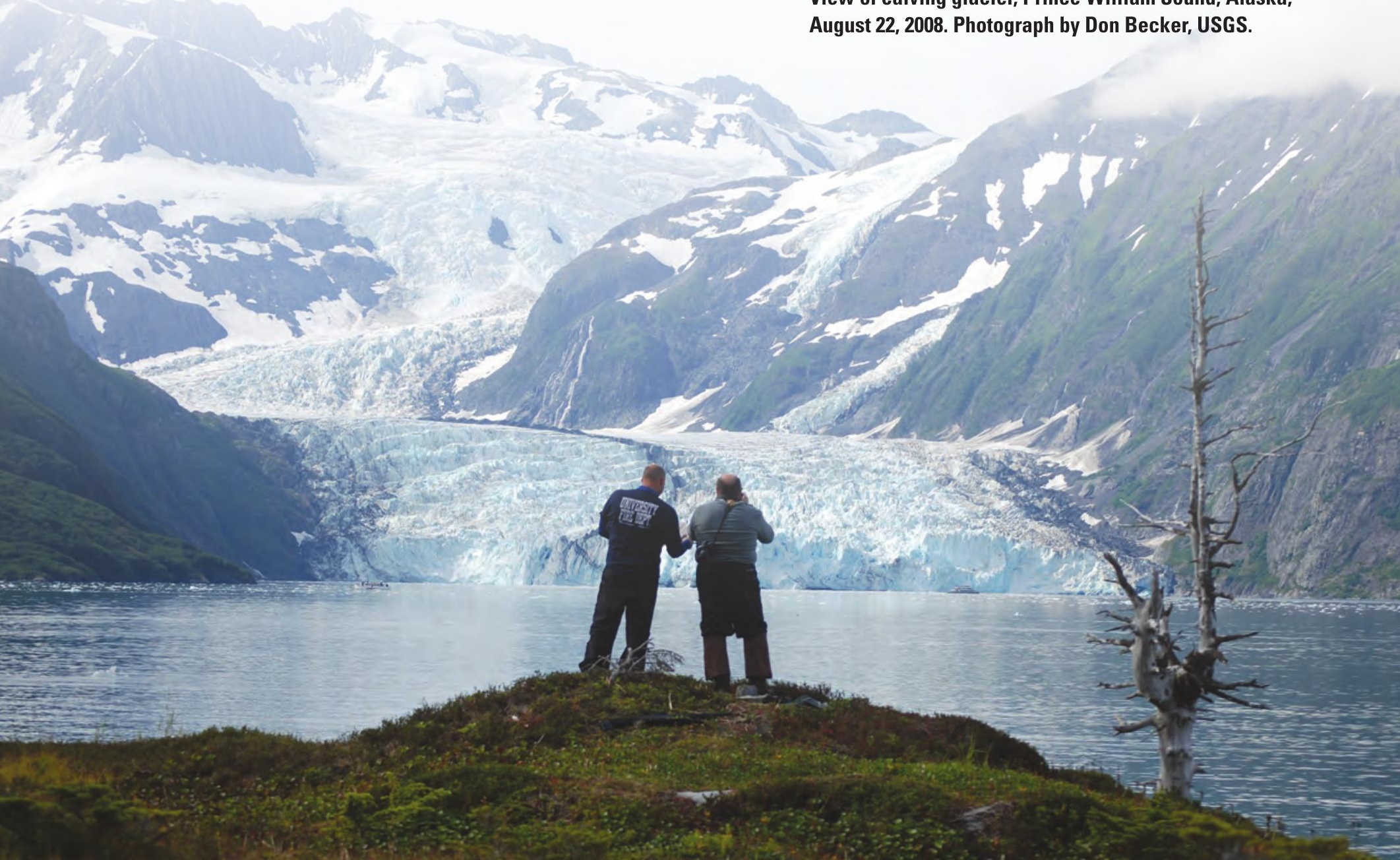




\section{References Cited}

Baron, J.S., Driscoll, C.T., Stoddard, J.L., and Richer, E.E., 2011, Empirical critical loads of atmospheric nitrogen deposition for nutrient enrichment and acidification of sensitive US lakes: BioScience, v. 61, no. 8, p. 602-613.

Baron, J.S., Hall, E.K., Nolan, B.T., Finlay, J.C., Bernhardt, E.S., Harrison, J.A., Chan, F., and Boyer, E.W., in press, The interactive effects of excess reactive nitrogen and climate change on aquatic ecosystems and water resources of the United States: Biogeochemistry.

Brennan, S.T., Burruss, R.C., Merrill, M.D., Freeman, P.A., and Ruppert, L.F., 2010, A probabilistic assessment methodology for the evaluation of geologic carbon dioxide storage: U.S. Geological Survey Open-File Report 2010-1127, 31 p. (Also available at http://pubs.usgs.gov/of/2010/1127/.)

Energy Independence and Security Act of 2007, Public Law 110-140, 110th Congress, 1st Session, U.S. Statues at Large 2007, v. 121, statute 1492, U.S. Government Printing Office. (Also available at http://www.gpo.gov/fdsys/pkg/ STATUTE-121/html/STATUTE-121-Pg1492.htm.)

Gutierrez, B.T., Plant, N.G., and Thieler, E.R., 2011, A Bayesian network to predict coastal vulnerability to sea level rise: Journal of Geophysical Research, v. 116, no. F2, p. F02009.

Hapke, C.J., Himmelstoss, E.A., Kratzmann, M., List, J.H., and Thieler, E.R., 2010, National assessment of shoreline change; historical shoreline change along the New England and Mid-Atlantic coasts: U.S. Geological Survey Open-File Report 2010-1118, 57 p. (Also available at http://pubs.usgs. gov/of/2010/1118/.)

Hönisch, Bärbel, Hemming, N.G., Archer, David, Siddall, Mark, and McManus, J.F., 2009, Atmospheric carbon dioxide concentration across the mid-Pleistocene transition: Science, v. 324, no. 5934, p. 1551-1554, (Also available at http://www.sciencemag.org/content/ suppl/2009/06/18/324.5934.1551.DC1.)

Intergovernmental Panel on Climate Change, 2007, Climatechange impacts, adaptations and vulnerability: Intergovernmental Panel on Climate Change, Working Group 2, Fourth Assessment Report, London, UK, Cambridge University Press, 976 p.

Sleeter, B.M., Wilson, T.S., Acevedo, W. (eds.), 2012, Status and Trends of land change in the western United States - 1973 to 2000: U.S. Geological Survey Professional Paper 1794-A, 336 p. (Also available at http://pubs.usgs. gov/pp/1794/a/.)
Luethi, D., Le Floch, M., Bereiter, B., Blunier, T., Barnola, J.M., Siegenthaler, U., Raynaud, D., Jouzel, J., Fischer, H., Kawamura, K., and Stocker, T.F., 2008, High-resolution carbon dioxide concentration record 650,000-800,000 years before present: Nature, 453, 379-382, accessed January 19, 2013, at http://dx.doi.org/10.1038/nature06949.

McCabe, G.J., Palecki, M.A., and Betancourt, J.L., 2004, Pacific and Atlantic Ocean influences on multidecadal drought frequency in the United States: Proceedings of the National Academy of Sciences, USA, v. 101, no. 12, p. 4136-4141, accessed January 19, 2013, at http://www. pnas.org/content/101/12/4136.long.

Munson, S.M., Belnap, J., and Okin, G.S., 2011, Responses of wind erosion to climate-induced vegetation changes on the Colorado Plateau: Proceedings of the National Academy of Sciences, v. 108, p. 3854-3859.

National Research Council, 1999, Global environmental change-Research pathways for the next decade: Washington, D.C., National Academies Press, 603 p.

National Research Council, 2009, Informing decisions in a changing climate-Panel on strategies and methods for climate-related decision support: Washington, D.C., National Academies Press, 188 p.

Pagani, M., Liu, Z., LaRiviere, J., and Ravelo, A.C., 2010, High Earth-system climate sensitivity determined from Pliocene carbon dioxide concentrations: Nature Geoscience 3:27-30, accessed January 17, 2013, at http://dx.doi. org/10.1038/ngeo 724 .

Pardo, L.H., Fenn, M.E., Goodale, C.L., Geiser, L.H., Driscoll, C.T., Allen, E.B., Baron, Jill, Bobbink, Roland, Bowman, W.D., Clark, Christopher, Emmett, Bridget, Gilliam, F.S., Greaver, Tara, Hall, S.J., Lilleskov, E.A., Liu, Lingli, Lynch, Jason, Nadelhoffer, Knute, Perakis, S.S., Robin-Abbott, M.J., Stoddard, John, Weathers, Kathleen, Dennis, R.L., 2011, Effects of nitrogen deposition and empirical nitrogen critical loads for ecoregions of the United States: Ecological Applications, v. 21, no. 8, p. 3049-3082.

Pendleton, E., Barras, J., Williams, S., and Twichell, D., 2010, Coastal vulnerability assessment of the Northern Gulf of Mexico to sea-level rise and coastal change: U.S. Geological Survey Open-File Report 2010-1146. (Also available at http://pubs.usgs.gov/of/2010/1146/.)

Plant, N.G., Gutierrez, B.T., Thieler, E.R., 2008, Application of a Bayesian statistical approach to predicting geomorphic response to sea level rise: Association of American Geographers Annual Meeting, April 15-19, 2008, Boston, Massachusetts. 
Salazar, Ken, 2009, Department of the Interior, Secretarial Order 3289, Subject-Addressing the impacts of climate change on America's water, land and other natural and cultural resources.

Sarmiento, J.L., and Wofsy, S.C., 1999, A U.S. carbon cycle science plan-Report of the Carbon and Climate Working Group: Washington, D.C., U.S. Global Change Research Program.

U.S. Congress, 1879, Organic Act: 43 U.S.C. 31.

U.S. Global Change Research Act of 1990, Public Law 101-606 (11/16/90) 104 Statute 3096-3104. (Also available at http://www.gcrio.org/gcact1990.html.)

U.S. Department of the Interior, 2011, Strategic Plan for Fiscal Years 2011-2016: Washington, D.C., U.S. Department of the Interior, Office of Planning and Performance Management, $44 \mathrm{p}$.

U.S. Global Change Research Program, 2009, Global climatechange impacts in the United States: Washington, D.C., U.S. Global Change Research Program, 189 p.

U.S. Global Change Research Program, 2010, Our changing planet-The U.S. Climate Change Science Program for fiscal year 2010: Washington, D.C., U.S. Global Change Research Program, 172 .

U.S. Global Change Research Program, 2011, Our changing planet-The U.S. Climate Change Science Program for fiscal year 2011: Washington, D.C., U.S. Global Change Research Program, 96 p.

U.S. Geological Survey, 2007, Facing tomorrow's challenges-U.S. Geological Survey science in the decade 2007-2017: U.S. Geological Survey Circular 1309, 69 p. (Also available at $h t t p: / / p u b s . u s g s . g o v / c i r c / 2007 / 1309 /$.

U.S. Geological Survey, 2009, National Climate Change and Wildlife Science Center-Proposed 5-year strategy (20092014): U.S. Geological Survey, Reston, Va., 21 p.

U.S. Geological Survey, 2010, USGS Science planning, funding, and implementation model: USGS internal document prepared by the Regional Executives and Chief Scientists Team, U.S. Geological Survey, Reston, Va.

U.S. Geological Survey, 2010, Aligning USGS senior leadership structure with the USGS Science Strategy: U.S. Geological Survey Fact Sheet 2010-3066, 4 p. (Also available at $h t t p: / / p u b s . u s g s . g o v / f s / 2010 / 3066$.)

U.S. Geological Survey, 2011, Budget justifications and performance information fiscal year 2011: U.S. Geological Survey, Reston, Va.
Vitousek, P.M., Naylor, R., Crews, T., David, M.B., Drinkwater, L.E., Holland, E., Johnes, P.J., Katzenberger, J., Martinelli, L.A., Matson, P.A., Nziguheba, G., Ojima, D., Palm, C. A., Robertson, G.P., Sanchez, P.A., Townsend, A.R., Zhang, F.S., 2009, Nutrient imbalances in agricultural development: Science, v. 324, no. 5934, p. 1519-1520.

Zhu, Zhiliang, ed., Bergamaschi, Brian, Bernknopf, Richard, Clow, David, Dye, Dennis, Faulkner, Stephen, Forney, William, Gleason, Robert, Hawbaker, Todd, Liu, Jinxun, Liu, Shuguang, Prisley, Stephen, Reed, Bradley, Reeves, Matthew, Rollins, Matthew, Sleeter, Benjamin, Sohl, Terry, Stackpoole, Sarah, Stehman, Stephen, Striegl, Robert, Wein, Anne, and Zhu, Zhiliang, 2010, A method for assessing carbon stocks, carbon sequestration, and greenhouse-gas fluxes in ecosystems of the United States under present conditions and future scenarios: U.S. Geological Survey Scientific Investigations Report 2010-5233, 190 p. (Also available at http://pubs.usgs.gov/sir/2010/5233/.)

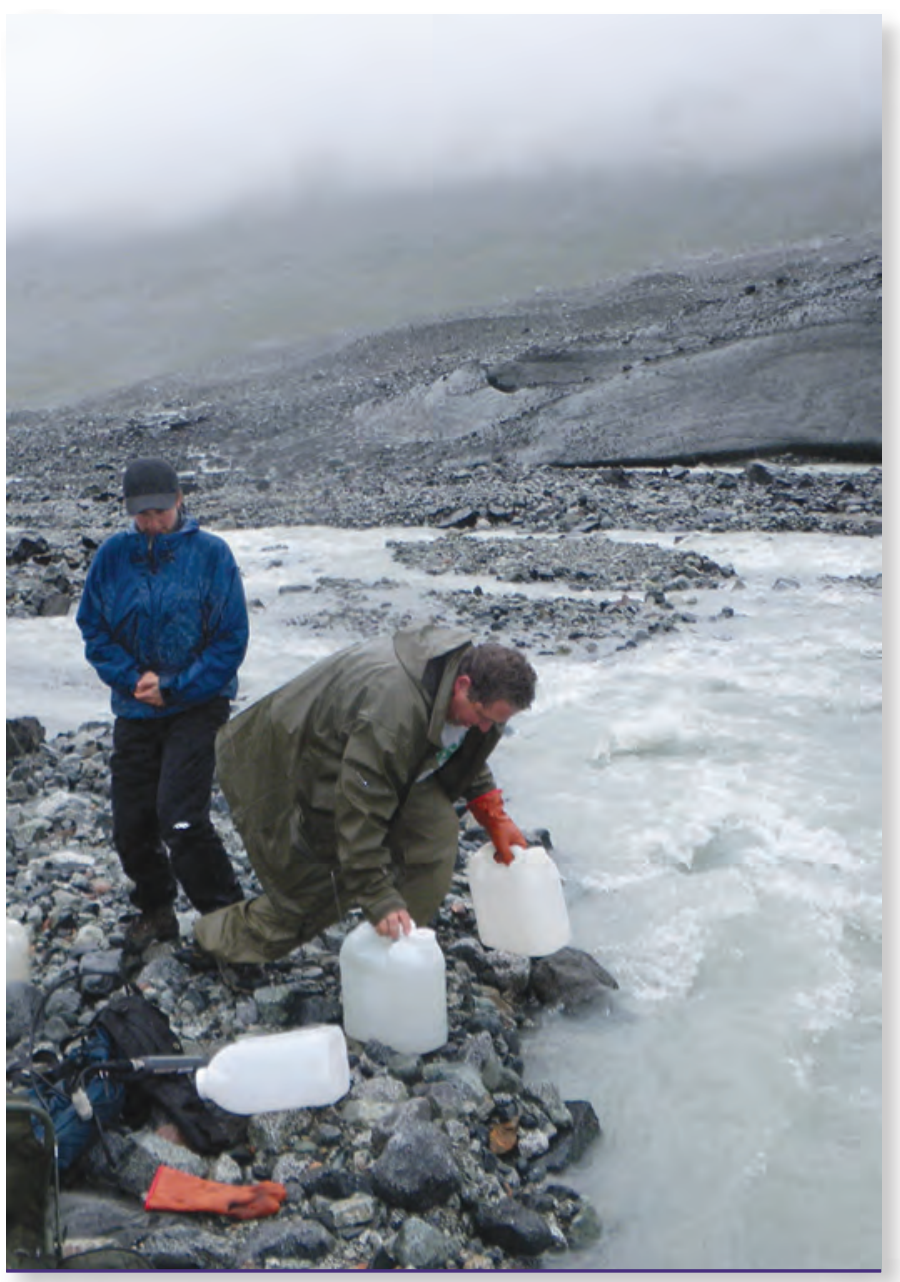

USGS scientists collecting melt water samples from Gulkana Glacier, Alaska. USGS research of the Yukon River has had a long term goal of determining the source and fate of organic carbon transported by the river to the Bering Sea and ultimately the Arctic Ocean. Photograph by Rob Striegl, USGS. 


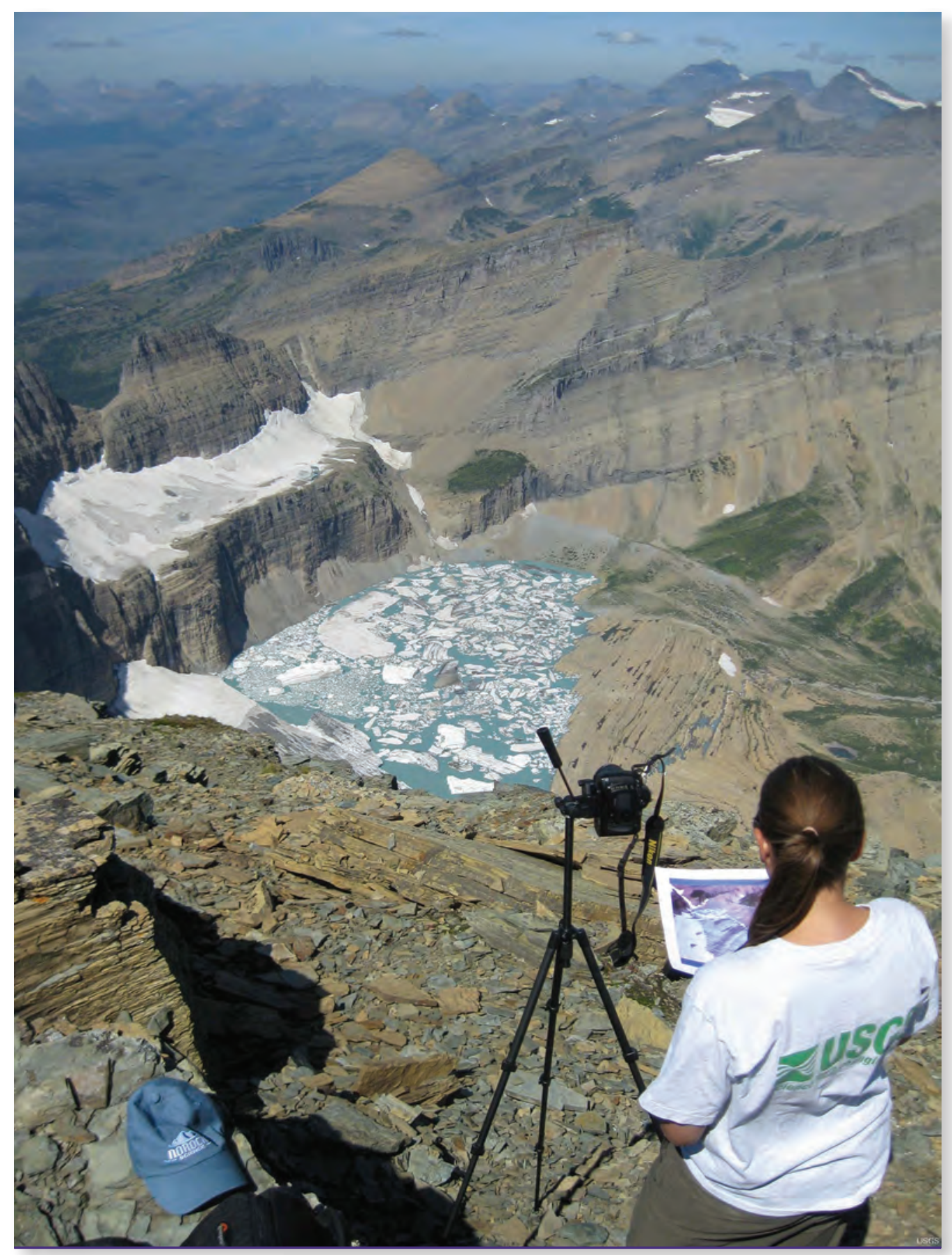

USGS scientist sets up a repeat photograph of Grinnell Glacier in Glacier National Park, Montana, to illustrate glacial recession because of impacts of climate change, January 1, 2010. Photograph by Lisa McKeon, USGS. 


\section{Glossary of Terms}

adaptation in climate-change discussions, refers to adjustments in natural or human systems in response to actual or expected climatic stimuli or their effects, which moderates harmful effects or exploits potential benefits.

albedo the fraction of incoming solar radiation that is reflected by a surface or an object.

carbon cycle a term used to describe the flow of carbon (in various forms, for example, carbon dioxide) through the atmosphere, ocean, terrestrial biosphere, and lithosphere.

cation an ion or group of ions with a positive charge.

climate change any change in climate over time, whether due to natural variability or as a result of human activity.

climate-change impacts effects of climate changes such as temperature change, precipitation change, changes in severe weather patterns, and sea-level rise on human and natural systems.

climate variability variations in the mean state and other statistics (such as standard deviation) of a climate variable on a temporal or spatial scale.

climate model numerical representation of the climate system that is based on the physical, chemical, and biological properties of its components and their interactions.

detection and attribution in the context of climate change, this refers to the detection of change in a system and the attribution of that change to natural causes or anthropogenic climate change.

eustatic denoting or referring to a worldwide change in sea level.

global change large-scale changes in the environment that may alter the Earth's capacity to sustain life and human endeavor.

greenhouse gas gaseous constituents of the atmosphere that absorb and reflect thermal infrared radiation emitted by the Earth's surface, clouds, and the atmosphere itself.

mitigation actions taken to reduce the anthropogenic forcing of the climate system, generally in the form of reducing emissions of greenhouse gases or enhancing greenhouse gas sinks.

paleoclimate climatic conditions in the geologic past. These conditions are reconstructed based on evidence found in the geologic record, generally in the form of glacial deposits, fossils, sediments, and rock and ice cores.

phenology refers to recurring plant and animal life-cycle stages, such as leafing and flowering, maturation of agricultural plants, emergence of insects, and migration of birds.

proxy an indicator that is interpreted to represent conditions back in time. Examples of proxies are pollen records and tree rings that are analyzed to determine temperature in the absence of an instrumental record.

scenario a plausible description, story line or image of how the future may develop.

sea-level rise an increase in the mean level of the ocean. Relative sea-level rise occurs where there is a local increase in the level of the ocean relative to the land, which might be due to ocean rise and land-level subsidence.

sensitivity the degree to which a system is affected by a change in a condition that alters the structure or function of the system.

stakeholders individuals, groups, and institutions with a stake in the outcome of a decisionmaking process.

steric relating to the spatial arrangement of atoms in a molecule; when referring to sealevel rise, the term refers to the increase in sea level associated with the thermal expansion of seawater.

volatization The vaporization or conversion of a chemical substance from a liquid or solid state to a gaseous or vapor state by the application of heat, by reducing pressure, or by a combination of these processes.

vulnerability the degree to which a system is susceptible to, or unable to cope with, adverse effects of climate change, including climate variability and extremes. Vulnerability is a function of the character, magnitude, and rate of climate variation to which a system is exposed, its sensitivity, and its adaptive capacity.

zoonotic pertaining to a zoonosis, which is a disease caused by infectious agents that can be transmitted between (or are shared by) animals and humans. 



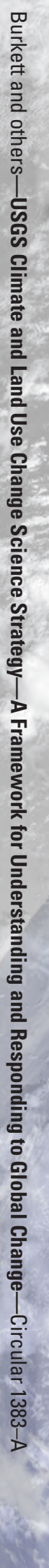

